\title{
4 Untersuchungsmethode: Diskurs(macht) - Wissen - Definition
}

\subsection{Theoretische und methodische Vorüberlegungen zum Zusammenhang von Praktiken bzw. Praxis und Wissen}

\subsubsection{Das Verhältnis von Praxis und Wissen}

Um den diskursiven Prozess der Wissenskonstituierung im Wechselspiel inner-und außerdiskursiver Elemente, reflexiver und vorreflexiver Verfahrensweisen sowie sozialer, konventioneller und individueller Momente $\mathrm{zu}$ beschreiben, ist das sozial- und kulturtheoretische Konzept der >Praxis` bzw. >Praktiken` aufschlussreich (vgl. Schäfer/Wrana 2014: 310). Denn Begriffe wie >Praxis` und >Praktiken ${ }^{111}$ stehen für analytische Kategorien an der Schnittstelle von Wissen, dem Sozialen als Struktur, Sprache und Kommunikation sowie Verhalten und Handeln innerhalb eines bestimmten (fach-)kulturellen Bereichs (vgl. Konerding 2009: 96ff., vgl. Schmidt 2012: 11). Sie verdeutlichen die enge Verbindung zwischen „[K]ollektive[n] Lebenspraxen als Gesamtheit von bedürfnisgesteuerten menschlichen Aktions- und Interaktionstypen“ und „Wissen, das ausschließlich durch ein symbolisch vermitteltes Repräsentationsformat bestimmt ist“ (Konerding 2009: 84f.), sprich zwischen prozeduralem und deklarativem Wissens:

\footnotetext{
Prozedurales Wissen erwirbt man durch die schrittweise Einübung in eine entsprechende Praxis begleitet durch sprachliche Hinweise und Erklärungen zu Funktionsweisen und zu beachtenden Zusammenhängen, durch praktischen Versuch und zugehörigen Irrtum. Dies wird ergänzt durch begleitende Anweisungen und konstruktive Kritik, die der metakognitiven Simulation, Steuerung, Regulation, Optimierung des Verhaltens bei der Selbstkontrolle und Habitualisierung dienen.

(Konerding 2009: 84)
}

Die Aneignung von Fähigkeiten und Alltagswissen ist also „eingebettet in in weiten Teilen nicht reflektierte kollektive Lebenspraxen, d. h. in konkrete Lebenssituationen und zugehörige problemlösungsbestimmte Verfahrensweisen, Verhaltensformen, -routinen und -traditionen“ (Konerding 2009: 85). Das deklarative Wissen entsteht aus „symbolische[n] Modellierungen von prozeduralem Wissen,

111 Diese Arbeit unterscheidet im Anschluss an Konerding (2009: 83) zwischen „,Praxis‘ zur Bezeichnung der Gesamtheit aller,Praktiken', letzteres im Sinne von Verhaltens- und Handlungsweisen einer Kultur oder eines bestimmten kulturellen Bereichs.“ Als Plural von Praxis schlägt Konerding „Praxen“ vor.

D Open Access. (c) 2021 Theresa Schnedermann, publiziert von De Gruyter. (@)BY-NC-ND Dieses Werk ist lizenziert unter einer Creative Commons Namensnennung-Nicht-kommerziell-Keine Bearbeitung 4.0 International Lizenz. https://doi.org/10.1515/9783110727838-004 
von praktischem Tun, insbesondere in dessen Regelhaftigkeiten“, wobei es diese repräsentiert, „strukturiert, elaboriert, ergänzt und sichert“(Konerding 2009: 86).

Am Thema „Entspannung“, das im Burnout-Diskurs große Bedeutung besitzt, lässt sich das „intrikate Verhältnis von deklarativem zu prozeduralem Wissen“ (Konerding 2009: 86) folgendermaßen skizzieren: Menschen kommen von klein auf mit Praktiken der Beruhigung mit dem Ziel der Entspannung in Berührung. Sie werden beispielsweise in den Schlaf gewiegt und bedienen sich später als Eltern selbst dieser Beruhigungspraktik. Reflektiert man gemeinsame Merkmale von Beruhigungspraktiken, so findet sich beinahe immer das Attribut des 'Gleichmäßigen’ darin (gleichmäßige Bewegungen, Geräusche). Die Reflexion dieser kollektiven Erfahrung mündet in symbolische Repräsentationsformen zu Entspannungstechniken.

Die These dieser Arbeit ist, dass man eine ähnliche Verschränkung zwischen vorreflexiven und reflexiven Handlungs- und Verhaltensweisen auch bei Definitionshandlungen in für Menschen essentiellen Bereichen wie Gesundheit und Krankheit annehmen und diskursiv nachzeichnen kann. Für eine nachvollziehbare Beschreibung dieses intrikaten Verhältnisses in diskursiven Definitionsprozessen bietet sich das Begriffspaar der >Praxis/Praktikı an. Aus diesem Grund werden in den folgenden Kapiteln zunächst Bestimmungsstücke eines linguistischen Praktikbegriffs und die Foucaultsche Theorie diskursiver Praxis entfaltet, um im Anschluss daran diese Ansätze miteinander zu verbinden und drei Untersuchungsebenen diskursiver Praxis daraus abzuleiten.

\subsubsection{Der Begriff der >Praktikı in der aktuellen linguistischen Diskussion}

Verschiedene Disziplinen der Sozial- und Kulturwissenschaften haben sich mit dem Begriff der >Praktik«/>Praxis` in den vergangenen Jahren aus kulturwissenschaftlicher (z. B. Hörning/Reuter 2004), soziologischer (im Überblick Schmidt 2012, Hillebrandt 2014), kommunikativ-linguistischer (im Überblick Deppermann/Feilke/Linke 2016) oder diskurs-, wissensanalytischer/-soziologischer und diskurslinguistischer Perspektive (u. a. Fairclough 22001: 18ff.; 2008: 4-10; Keller 2011: 255ff.; Jäger, Siegfried 2011: 92, 118ff.; Konerding 2009, Müller 2015: 19ff.) auseinandergesetzt. Deppermann, Feilke und Linke (2016), die in ihrem Beitrag zu „Sprachliche[n] und kommunikative[n] Praktiken: Eine Annäherung aus linguistischer Sicht“ prominente Positionen und Bestimmungsstücke beschreibend gegenüberstellen, konstatieren: „Obwohl es zwar zahlreiche Vertreter der Praxistheorie gibt [...], in deren Arbeiten gewisse Aspekte von Praktiken im Zentrum 
stehen, gibt es kein festes praxistheoretisches Theoriegebäude“ (Deppermann/ Feilke/Linke 2016: 2f.). ${ }^{112}$

Im Folgenden werden Kernpunkte der linguistischen Diskussion und im Anschluss daran Bestimmungsstücke, die für das Praktikverständnis dieser Arbeit zentral sind, dargestellt. Im Anschluss werde ich diese mit dem Konzept (nicht-)diskursiver Praktik bei Foucault verbinden.

Viele der linguistischen, aber auch soziologischen Ansätze eint, dass sie unter Praktiken soziale Phänomene verstehen, die interaktiv (bzw. diskursiv) als kollektive Verfahren zur Befriedigung gesellschaftlicher Bedürfnisse entstehen und durch Rekurrenz zur Routine werden. ${ }^{113}$ Sie unterscheiden sich allerdings vor allem darin, wie stark sie den „Modus des Selbstverständlichen“ (Schmidt 2012: 10) oder die „Unbewusstheit und Körperlichkeit sozialer Praxen“114 in den Mittelpunkt des Forschungsinteresses rücken oder neben diesen unbewussten Anteilen auch ein souveränes Subjekt bzw. die Bewusstheit und „kognitive Kontrollierbarkeit“ (vgl. Müller 2015: 22) insbesondere bei der Aneignung ${ }^{115}$, Wahl und Realisierung der Praktiken zulassen (vgl. Linke 2010) ${ }^{116}$. Deppermann/Feilke/ Linke (2016: 13) stellen in diesem Zusammenhang fest, dass „bei vielen soziologischen Praktikentheoretikern (s. Reckwitz 2003; Hillebrandt 2014)“ Praktik als „Gegenbegriff $\mathrm{zu}$,Handlung““ gefasst werde ${ }^{117}$ und damit „Akteurseigenschaften wie Intentionalität, Verantwortlichkeit, Intersubjektivität oder Verstehen, die in Handlungstheorien für die Sphäre des Sozialen als konstitutiv erachtet werden“ (ebd.: 4), vernachlässigt würden. „Ein strikter Antimentalismus“ führe „Zu Aporien und Erklärungslücken, da er nicht plausibel machen könne, welche

112 Das Leibniz-Institut für Deutsche Sprache widmete seine Jahrestagung 2015 dem Thema „Sprachliche und kommunikative Praktiken“ mit dem Ziel, „Reichweite, Ertrag und Anwendungsbereiche des Praktiken-Konzepts für die Linguistik auszuloten und zu einer begrifflichen Schärfung und Systematisierung der für dieses Konzept relevanten Aspekte beizutragen“ (Deppermann/Feilke/Linke 2016: 11).

113 In der Zusammenfassung soziologischer Ansätze vgl. Schmidt (2012: 10f.), in Bezug auf linguistische Theorieansätze vgl. Deppermann/Feilke/Linke (2016: 3ff.).

114 Vgl. Müller (2015: 22) in Bezug auf P. Bourdieus Konzept des `Habitus` (Bourdieu 1987).

115 Zur Aneignung literaler und kommunikativer Praktiken unter anderem im didaktischschulischen Umfeld vgl. Feilke (2016: 262ff.); Fiehler/Barden/Elstermann et al. (2004: 103).

116 Linke (2010: 262) begreift „kommunikative Praktiken“ beispielsweise nicht als etwas, dem die Sprachteilnehmenden unterliegen, d. h. ohne kognitive Kontrollmöglichkeiten, sondern trotz oder auch wegen der „Vorgeprägtheit kommunikativer Praktiken“ hätten die „Interaktanten die Möglichkeit, die vorgegebenen Muster mit weiteren kommunikativen Funktionen aufzuladen“. 117 In der soziologischen Forschung wird diese Gegenüberstellung jedoch im Rahmen des Vergleichs klassischer soziologischer Handlungs- und Strukturtheorien mit neueren praxistheoretischen Ansätzen intensiv diskutiert, insbesondere auch im Hinblick auf die Frage, ob das Ansetzen eines ‘practice turn' gerechtfertigt sei. Vgl. Bongaerts (2007). 
Voraussetzungen Akteure mitbringen und welche interpretativen Leistungen sie erbringen müssen, um an Praktiken teilnehmen zu können.“ (ebd.: 18).

Warum, so könnte man sich fragen, gibt es dann diese aktuell zu beobachtende starke Hinwendung in linguistischen Arbeiten zur Analyse von >Praktiken neben Grundbegriffen handlungstheoretischer Ansätze?

Habscheid sieht in einer praxeologischen Herangehensweise (Habscheid 2016: 127) die Chance, die „Probleme und Grenzen handlungslogisch fundierter pragmatischer Analysen“ (Habscheid 2016: 132ff.) zu erkennen und zu überwinden, ohne auf die Möglichkeiten letzterer verzichten zu müssen. Praxeologische Ansätze führen nach Habscheid beispielsweise dazu, den Begriff der >Regel und die „empirische Frage“ neu zu reflektieren, „inwieweit individuelles Handeln als Befolgen von Regeln ${ }^{118}$ - auf der kognitiven Verarbeitung von Regelrepräsentation beruht (vgl. Sharrock 2012, S. 62.f.)“ (Habescheid 2016: 132). Ein weiteres Problem stellt für Habscheid die „(Nicht-)Berücksichtigung der komplexen Kulturalität jeder sozialen Praxis“ in der „handlungslogischen Pragmatik“ dar (ebd.: 133) ${ }^{119}$, und er fordert die Aufmerksamkeit auf die dynamische Verbindung von musterhafter Routine und subjektiver performativer Gestaltung im Begriff der Praxis zu lenken (ebd.: 134), sich intensiv mit einem „Set alltäglicher Rationalitäten [...] und alltägliche[n] Kompetenzen“ zu beschäftigen (ebd.: 136) und den „methodologischen Individualismus“ von Handlungstheorien um die ,interaktionalen, kulturellen Grundlagen“ zur Erreichung sozialer Handlungsziele zu ergänzen (ebd.).

Die Verwendung der Begriffe der >Praxis und >Praktik in dieser Arbeit ergibt sich aus ähnlichen Ansatzpunkten, wie sie gerade referiert wurden. Der PraktikBegriff formiert dabei nicht als Gegenbegriff $\mathrm{zu}>$ Handlung`. Sprachliche und diskursive Praktiken werden als „Spuren ${ }^{120}$ sozialer Interaktion“ (Müller 2015: 21) gedeutet, wobei folgende Aspekte des Begriffspaars als zentral erachtet werden:

118 Habscheid (2016: 131) bezieht sich auf die Ausführungen von Keller 1974 zum linguistischen Regelbegriff (Keller 1974: 10-24), „im Kontext komplexer Spiele“, die er von „Sprachspielen im Sinne soziokultureller Praxis“ der „(praxistheoretischen) Wittgenstein-Rezeption“ (vgl. Hillebrandt 2014: $37 \mathrm{ff}$.) eingerahmt sieht.

119 Aktuelle linguistische Arbeiten der letzten Jahre weisen ebenfalls auf die Bedeutung sozio-kultureller Einbettungsbedingungen für die Analyse des sprachlichen Zeichengebrauchs hin (vgl. insbesondere Günthner/Linke 2006; Linke 2009; Linke/Feilke 2009: 5; Günthner/König 2016). Eine ähnliche Programmatik beschreiben Felder/Gardt (2015: 15) für die „Handbücher Sprachwissen“: „Kommunikation“ wird in dieser Reihe „als eine in Kulturen konventionalisierte Praxis“verstanden.

120 Vgl. zum Spur-Begriff insbesondere die Sammelbände von Fehrmann/Linz/Eppinger-Jäger 2005 und Krämer/Kogge/Grube 2007. Ich beziehe mich mit L. Jäger (2001; 2010b) auf die Tradition des Spurbegriffs, die den „Semiotizitätsaspekt von Spuren“ betont, wie Müller (2015: 54f.) 
Die Arbeit schließt sich erstens einer Analysehaltung an, die das ,intrikate Verhältnis von prozeduralem und deklarativem Wissen“ (Konerding 2009: 86) und die Einbettung jeder (Sprach)-handlung in (fach-)kulturelle, soziale Bedingungsgefüge (vgl. Deppermann/Feilke/Linke 2016: 9ff. vgl., Konerding 2015b; Felder 2009a) für zentral erachtet. Sie geht mit Müller davon aus, „dass Intentionalität immer umspielt ist von im Sozialen gelagerten kognitiven, volitiven, emotionalen und physischen Verhaltensroutinen“ (Müller 2015: 18). Letztere, die meist als „bewährte Routinen für situierte Handlungsaufgaben“ (Deppermann/Feilke/Linke 2016: 8) entstehen, führen zu Sprachverwendungsregularitäten, ohne dass diese Regularitäten den Sprechenden/Schreibenden bewusst sein müssen ${ }^{121}$.

So geraten aus einer phänomenorientierten Analyseperspektive (vgl. Felder/ Gardt 2015: 19), wie sie in dieser Arbeit eingenommen wird, analytisch feststellbare diskursive Relationen in den Blick, die mitunter nicht intendiert oder bewusst hergestellt wurden. ${ }^{122}$ Busse spricht in diesem Zusammenhang von ,nichtintendierten“, (nicht) bewussten, teilweise „nur analytisch feststellbaren Kontextualisierungen“ (Busse 2007: 82), die „mit anerkannten Methoden einer tiefensemantischen Analyse“ (ebd. 83) herausgearbeitet werden können. So erhält das >Verhalten//২Erleben` einer Person im Burnout-Diskurs beispielsweise erst durch das implizierte 'gesunde' ,Verhalten $</>$ Erleben $`$ und vor dem Hintergrund präsupponierter Bedingungen und Normgrenzen Symptomstatus (vgl. Kap. 3.3).

es in seinem Überblick prägnant formuliert. Spuren, d. h. materielle Abdrücke (in Laut- oder Graphemreihen, etc.) für etwas Vorgängiges, spielen für Jäger eine erkenntnisstiftende Rolle im Rahmen seines Transkriptionsmodells: „Erst in der Spurenlese, der Relektüre, in der der Geist der medialen Spur der eigenen mentalen Akte begegnet, in der Transkription des Mentalen in die semiologischen Register des Medialen, kann sich begriffliche Distinktivität einstellen [...]“ (Jäger 2010b: 307). Eine weitere Dimension der `Spur`, die für die vorliegende Analyse bedeutsam ist, ist die der 'Kontextualität' (vgl. Müller 2015: 54). Spuren verweisen erstens ,auf diejenigen [sozialen Praktiken, T.S.], derer es bedarf, um die Spur als Spur zu erkennen“ und zweitens im Rahmen kommunikativer Handlungen auf soziale Praktiken, die das Ereignis, auf das die Spur hindeutet, verursacht haben (ebd.). In der vorliegenden Arbeit werden Spuren sozialer, definitorischer Praktiken im Bereich von Gesundheit und Krankheit insbesondere durch die Analyse polyphoner Strukturen und verstehensrelevanter Normen und Wissensbereiche aufgezeigt werden (siehe Kap. 6.2).

121 Müller spricht in diesem Zusammenhang vom „Unwillkürlichkeitsgedanken“ als einem „Begriffsaspekt von ,sprachlichem Verhalten““ (Müller 2015: 18/19). Diesen Gedanken führt er einige Seiten später im Zusammenhang des Lernens von Handlungsabläufen weiter aus: „Lernen bedeutet Verunwillkürlichung von Handlungsabläufen“ (ebd.: 23).

122 Dieser Umstand wird zudem durch Gardts Hinweis gestützt, dass ein Textproduzent insbesondere bei komplexer schriftlicher Textproduktion unmöglich „das Bedeutungspotential seines Textes vollständig bewusst [zu] kontrollieren“ kann (Gardt 2013: 40). 
Zweitens übernimmt diese Arbeit von den praxeologischen Ansätzen die Überzeugung, dass Praktiken nicht nur im medial mündlichen, sondern auch im medial schriftlichen Bereich auf interaktionalen, kulturellen Grundlagen basieren (vgl. Habscheid 2016: 136; Linke 2010: 262; Fiehler/Barden/Elstermann et al. 2004: 100) und dass sich dieses Moment der Interaktion diskursdynamisch in intertextuellen und polyphonen Strukturen (Angermüller/Scholz 2013: 306f.), „transkriptive[n] Bezugnahmeformen“ (Jäger 2012b: 16; vgl. auch Feilke 2016 ${ }^{123}$ ) innerhalb von „Diskursgemeinschaften“ (Spitzmüller/Warnke 2011: 181) und fachkulturellen Praktiken der Wissenskonstitution (vgl. Konerding 2015b: 72; Felder 2009a) ausdrückt.

Drittens bezieht die Arbeit die Dimensionen der Medialität (Jäger 2015; Spitzmüller/Warnke 2011: 183f.) und Materialität (Deppermann/Feilke/Linke 2016: 5f.; Spitzmüller/Warnke 2011: $166 \mathrm{ff}$.) in ihre Analyse mit ein. Das bedeutet, dass die Analyse an der Textoberfläche ansetzt, und einerseits prüft, inwiefern von den materiellen Strukturen und modalen Ressourcen (z. B. Typo- und Topografie $^{124}$ oder Bildern) „praktische Effekte“ (Deppermann/Feilke/Linke 2016: 4) ausgehen und andererseits, welche „Medialitätserwartungen“ (vgl. Spitzmüller/ Warnke 2011: 184) bestimmte Medien (z. B. die Massenmedien) evozieren. Fragen, die sich daraus ergeben, sind zum Beispiel: Ist die Kategorie der Textdisposition entscheidend dafür, ob ein Textabschnitt als definierend verstanden wird? Inwiefern bedingen die Strukturen des zitierten Materials die Wiederholung und Kommentierung desselben? Können häufige Wiederholungen bestimmter Aussagen oder Textpassagen das Spektrum der möglichen Äußerungsvarianten so einschränken, dass „eine bestimmte Aussage“ eher erscheint als eine „andere an ihrer Stelle“ (vgl. Foucault [1969] 1981: 42)?

Die letzte Frage schließt unmittelbar an die Kernfrage der Foucault'schen Diskursanalyse an: „[W]ie kommt es, daß eine bestimmte Aussage erschienen ist und keine andere an ihrer Stelle?“ (ebd.). Foucault nähert sich der Beantwortung dieser Frage durch die Analyse der „Beziehungen zwischen Aussagen“ (ebd.: 48) sprich diskursiven Formationsregeln und Praktiken an. Diese werden im folgenden Kapitel beschrieben, um im Anschluss daran die Merkmale der diskursiven Praktiken nach Foucault und die Bestimmungsstücke der linguistischen Praktiken-Diskussion miteinander zu vergleichen und daraus den Praktik-Begriff für die folgende Analyse zu entwickeln.

123 Feilke beschreibt bezugnehmend auf das Gießener Forschungsprojekt „Eristische Literalität“" (einsehbar unter: http://www.uni-giessen.de/fbz/zmi/projekte/eristischeliteralitaet, zuletzt eingesehen am 11.11.2019) anschaulich „Praktiken des Referierens“, die im Textmodus des Zitierens Gestalt annehmen, als Teil wissenschaftlicher literaler Praktiken (Feilke 2016: 268ff.).

124 Zur Bedeutung typografischer Elemente vgl. Spitzmüller 2010. 


\title{
4.1.3 Praxis und (nicht-)diskursive Praktiken, Wissen und Diskursmacht bei Michel Foucault
}

Foucaults Begriffe von `Praxis` und `(nicht-)diskursiven Praktiken sind nur vor dem Hintergrund seines Gesamtverständnisses der diskursiven Konstituierung von `Wissen` und dessen Transformation zu erklären. Daher sollen im Folgenden seine Vorstellungen dieser Zusammenhänge dargestellt und Anknüpfungspunkte für die spätere diskurslinguistische Analyse diskursiver Definitionspraxis deutlich gemacht werden. Wissen ist für Foucault:

\begin{abstract}
„[...] keine Summe von Erkenntnissen - denn von diesen muss man stets sagen, ob sie wahr oder falsch, exakt oder ungenau, präzise oder bloße Annäherungen, widersprüchlich oder kohärent sind; keine dieser Unterscheidungen ist für die Beschreibung des Wissens gültig, das aus einer Gesamtheit von Elementen (Gegenständen, Formulierungstypen, Begriffen und theoretischen Entscheidungen) besteht, die aus ein und derselben Positivität heraus im Feld einer einheitlichen diskursiven Formation gebildet sind.“
\end{abstract}

(Foucault [1968] 2001, Über die Archäologie der Wissenschaften. Antwort auf den Cercle d'épistémologie, S. 921, Unterstreichungen T.S.)

Eine solche „einheitliche diskursive Formation“, oder wie Foucault auch sagt, ein solches „Formationssystem“ zu definieren, „heißt [...], einen Diskurs oder eine Gruppe von Aussagen durch die Regelmäßigkeit einer Praxis zu charakterisieren“ (Foucault [1969] 1981: 108).

Es sind diese Formationsregeln oder „Praktiken“, die in ihrer Gesamtheit einen Diskurs ausmachen und „die systematisch die Gegenstände bilden, von denen sie sprechen“ (Foucault [1969] 1981: 74).

Am Beispiel der Transformation „des Diskurses der Psychopathologie seit dem 19. Jahrhundert“ erläutert Foucault sein Erkenntnisinteresse im Hinblick auf die Formation der Gegenstände eines Diskurses (Foucault ([1969] 1981: 62, Unterstreichungen T.S.):

Die Gegenstände, mit denen die Psychologie seit dieser Zäsur zu tun gehabt hat, sind nun aber sehr zahlreich, zu einem großen Teil sehr neu, jedoch ebenso zerbrechlich, in Veränderungen begriffen und teilweise zu einem schnellen Verschwinden bestimmt: neben motorischer Unruhe, Halluzination und abwegigen Reden [...], konnte man Erscheinungen beobachten, die sich in bis dahin benützten Registern nicht fanden: leichte Verhaltensstörungen, sexuelle Störungen und Verirrungen, [...], Kriminalität. Und in jedem jener Register sind vielfältige Gegenstände genannt, umschrieben, analysiert, gelöscht worden. Kann man die Regel feststellen, der ihr Erscheinen unterworfen war? Kann man in Erfahrung bringen, gemäß welchem nicht-deduktiven System diese Gegenstände sich haben nebeneinander stellen und einander folgen können, um das zerstückelte Feld der Psychopathologie zu bilden [...]? 
Foucaults methodische Antwort auf diese Frage in der Archäologie des Wissens lautet, man müsste zunächst die „Oberflächen, wo sie [die Gegenstände] erscheinen $^{125}$, sich abgrenzen ${ }^{126}$, analysiert werden und sich spezifizieren“"127 ausfindig machen (vgl. Foucault [1969] 1981: 71). Daraufhin - das ist für ihn der entscheidende Punkt - sollte die „Gesamtheit von [...] Beziehungen“ (Foucault [1969] 1981: 67) zwischen diesen Oberflächen in ihrer Regelmäßigkeit und Wiederkehr (Foucault [1969] 1981: 44; vgl. Kelm 2015: 226) aufgezeigt werden, um auf diese Weise die „diskursive Formation“ beschreiben zu können. (Foucault [1969] 1981: 67)..$^{128}$

An den verstreuten Beispielen, die Foucault selbst gibt, lässt sich dieses Programm etwa folgendermaßen skizzieren: Dass SExuALItät und etwaige ABwEICHUNGEN zum ersten Mal im 19. Jahrhundert im Kontext psychopathologischer Analyse und Diskussion auftreten, könnte damit zusammenhängen,

daß sie durch die Familie, die umgebende soziale Gruppe, das Arbeitsmilieu, die Glaubensgemeinschaft bestimmt wurden (die alle normativ, gegenüber der Abweichung empfindlich sind, die alle eine Toleranzgrenze und Schwelle haben, [...], die alle eine Bezeichnung und Ablehnung des Wahnsinns haben, die alle, wenn nicht die Verantwortung für die Heilung und die Behandlung, so doch wenigstens die Aufgabe der Erklärung der Medizin übertragen); [...] gerade in dieser Zeit [beginnen] neue Oberflächen des Auftretens wirksam zu werden: die Kunst mit ihrer eigenen Normativität, die Sexualität (ihre Abweichungen werden im Vergleich zu den üblichen Verboten zum ersten Mal für den psychiatrischen Diskurs zum Gegenstand der Orientierung, [...]). In diesen Feldern der ersten Differenzierung, in den Entfernungen, den Diskontinuitäten, den Schwellen, die sich darin manifestieren, findet der psychiatrische Diskurs die Möglichkeit, seinen Bereich abzugrenzen, das zu definieren, worüber er spricht, ihm den Objektstatus zu geben - es also erscheinen zu lassen, es nennbar und beschreibbar zu machen.

(Foucault [1969] 1981: 63) (Unterstreichung T.S.)

125 Foucault bezieht sich hierbei zum Beispiel auf die sozial-historischen Kontexte (vgl. Foucault [1969] 1981: 63; vgl. Kelm 2015: 232) sowie „Toleranzgrenzen und Schwellen, die in bestimmten gesellschaftlichen Konstellationen eine Rolle spielen (Familien, Gruppen, Milieus, Glaubensgemeinschaften)“ (Ruoff 2007: 120).

126 Foucault spricht in diesem Zusammenhang auch von „Instanzen der Abgrenzung“ und bezieht sich auf Instanzen und Disziplinen, die den „Gegenstand diskursiv eingrenzen und ausarbeiten“ (Koller/Lüders 2004: 60; Foucault [1969] 1981: 63/64). Vgl. in diesem Kapitel auf S. 83f. die „Prozeduren der Verknappung“.

127 Foucault schreibt dazu erläuternd, man müsse die „Spezifikationsraster analysieren“, die innerhalb des Diskursbereichs zur Klassifizierung und Neugruppierung der Gegenstände verwendet werden (Foucault [1969] 1981: 64).

128 In ähnlicher Weise beschreibt und fordert Foucault die beziehungssensitive Analyse der diskursiven Formation bzw. Formierung von „Begriffen“, „Äußerungsmodalitäten“ und „Strategien“ (siehe Foucault [1969] 1981: 75-103, im Überblick auch bei Koller/Lüders 2004: 61ff.). 
Es geht Foucault also um das Auffinden von Schwellen oder auch Diskontinuitäten durch Kontextanalysen in Aussagen ${ }^{129}$ des Diskurses, die ein „diskursives Ereignis“ konstituieren können und die „Summe der Relationen, in denen Aussagen“ und Ereignisse zueinander stehen (Spitzmüller/Warnke 2011: 70), d. h. um eine „serielle Vernetzung“130 (Spitzmüller/Warnke 2011: 126/127) bzw. „ein Bündel von Beziehungen“, das „auf konstante Weise an[ge]wendet [wird]“ (Foucault [1969] 1981: 80). Diese Relationen zwischen Elementen des Diskurses, die in Aussagen erscheinen, manifestieren sich für Foucault zum Beispiel in typischen „Formen der Abfolge“ und verschiedenen „Anordnungen der $\ddot{\text { Auße- }}$ rungsfolgen“" (Foucault [1969] 1981: 83f.), z. B. chronologisch, argumentativ oder rhetorisch (vgl. Koller/Lüders 2004: 60). Es geht um den Bezug einer Aussage zu ,alle(n) bereits woanders formulierten Aussagen [...], die in einem Diskurs als anerkannte Wahrheit, als exakte Beschreibung, als begründete Überlegung oder notwendige Maßnahme wiederaufgenommen werden“ (Foucault [1969] 1981: 85).

Ein Jahr später in seiner Antrittsvorlesung am Collège de France 1970, die 1972 unter dem Titel „Die Ordnung des Diskurses“ auf deutsch erschienen ist, beschreibt Foucault diese Arten diskursiver Relationen als „Prozeduren ${ }^{131}$, die als Klassifikations-, Anordnungs-, Verteilungsprinzipien wirken“, die den Diskurs dadurch verknappen und in Grenzen halten sollen (Foucault [1970] 1993: $17 \mathrm{ff}$.). Wichtige Prinzipien der Verknappung dieser Ereignishaftigkeit und Zufälligkeit des Diskurses sind nach Foucault:

1.) der Kommentar, der zwar erlaube „etwas anderes als den Text selbst zu sagen“ (Foucault 1970/1993: 20), aber den Text dennoch reproduziere als „Spiel der Identität in der Form der Wiederholung und des Selben“ (Foucault [1970] 1993: 22, Kursiv. im Orig.),

129 Foucault gibt in der Archäologie des Wissens eine „Art Minimaldefinition“ für seinen Begriff der Aussage. „Eine Aussage liegt demnach vor, wenn ,irgendeine Folge von Zeichen, von Figuren, von Graphismen oder Spuren“ eine Ordnung erkennen lässt. (Foucault [1969] 1981: 123)“ (Ruoff 2007: 73). Spitzmüller/Warnke (2011: 70) weisen darauf hin, dass Foucault mit Aussage (énoncé) „nicht konkret produzierte Äußerungen (tokens), sondern alle prinzipiell in einem Diskurs möglichen Aussagen (types) und deren Position im diskursiven System (vgl. dazu Busse 1987: 227-232)“ meine. Die konkrete Äußerung sei bei Foucault die énonciation (Foucault [1969] 1981: 148-149).

130 Zum Begriff der `Serie` bei Foucault vgl. Foucault [1970] 1993: 35ff sowie Spitzmüller/Warnke 2011: 71; 126/127.

131 Die Foucault'sche Verwendungsweise des Ausdrucks Prozeduren in „Die Ordnung des Diskurses“ lese ich als 'Realisierungsformen von Praktiken'. Im Begriff der >Praktikı sind wiederum Aussagen über den Zweck oder die Zwecke der jeweiligen Praktik enthalten. Kontrollpraktiken bedienen sich z. B. verschiedener Prozeduren der Ausschließung oder Verknappung. Bisweilen scheint Foucault Praktiken und Prozeduren allerdings synonym zu verwenden. 
2.) „der Autor als Prinzip der Gruppierung von Diskursen, als Einheit und Ursprung ihrer Bedeutungen, als Mittelpunkt ihres Zusammenhalts“ (Foucault [1970] 1993: 20), der jedoch im Vergleich zu früheren Zeiten - im Mittelalter „war die Zuschreibung an einen Autor im Bereich des wissenschaftlichen Diskurses [...] Index der Wahrheit“ (ebd.) - an Glaubwürdigkeit verloren habe, denn die „Funktion der Verknappung“ marginalisiere den Autor „im äußersten Fall auf einen Index des Textes“ (Ruoff 2007: 78) oder Namensgeber für ein Syndrom,

3.) die Disziplinen ${ }^{132}$, die sich „durch einen Bereich von Gegenständen, ein Bündel von Methoden, ein Korpus von als wahr angesehenen Sätzen, ein Spiel von Regeln und Definitionen, von Techniken und Instrumenten“ definieren (Foucault [1970] 1993: 22f.) und auf die „Konstruktion neuer Aussagen“ auswirken:

Vom 19. Jahrhundert an war ein Satz nicht mehr medizinisch, [...] und galt als individuelle Einbildung oder volkstümlicher Aberglaube, wenn er zugleich metaphorische, qualitative und substantielle Begriffe enthielt (z. B. die Begriffe der Verstopfung, der erhitzen Flüssigkeiten oder der ausgetrockneten Festkörper); er konnte aber, ja er mußte Begriffe verwenden, die ebenso metaphorisch sind, aber auf anderen Modellen aufbauen, einem funktionellen und physiologischen Modell (so die Begriffe der Reizung, der Entzündung oder der Degeneration der Gewebe).

(Foucault [1970] 1993: 23)

In seiner Antrittsvorlesung am Collège de France stellt Foucault diesen gerade referierten sogenannten diskursinternen Prozeduren weitere an die Seite, die „gewissermaßen von außen“ auf den Diskurs einwirken sollen (Foucault [1970] 1993: 17; 11ff.) und zusammen mit den ersteren den Diskurs kontrollieren, selektieren, organisieren und kanalisieren (ebd: 11).

Foucault beschreibt die Macht äußerer Kräfte auf den Diskurs, z. B. politische, juridische, wissenschaftliche oder pädagogische Institutionen und deren Praktiken. Als ihre „Prozeduren der Ausschließung“ führt er an:

1. das „Verbot, [...] daß man nicht das Recht hat, alles zu sagen, daß man nicht bei jeder Gelegenheit von allem sprechen kann, und schließlich daß nicht jeder beliebige über alles beliebige sprechen kann“ (Foucault [1970] 1993: 11),

132 Nach Ruoff bezieht sich Foucault mit dem Begriff der >Disziplin auf „Fachrichtungen“ (Ruoff 2007: 222). In diskurslinguistischen Forschungsarbeiten wird seit einiger Zeit der Begriff der $>$ Fachkultur` (Konerding 2009) verwendet. Der Begriff der >Fachkultur ist komplexer als $>$ Fachrichtungく, da er betont, dass `Fachkulturen komplexe(n) kulturelle(n) Systeme menschlicher Gesellschaften“ (Konerding 2015b: 72). 
2. die „Entgegensetzung zwischen Vernunft und Wahnsinn“ und damit die Grenzziehung als Form der Ausschließung. Der Wahnsinnige werde beispielsweise vor Gericht nicht gehört und seine Worte würden nicht gesammelt (ebd.: 12)

3. sowie der „Gegensatz zwischen dem Wahren und dem Falschen“ (ebd.: 13) als „wechselseitiges Prinzip der Ausschließung“ (Ruoff 2007: 77); Foucault beschreibt einen „Wille[n] zum Wissen“ und zur „Wahrheit“, der „eine eigene Geschichte“ habe und den zu erkennenden Gegenständen vorgreife, z. B. durch „Ebenen von möglichen beobachtbaren, meßbaren, klassifizierbaren Gegenständen“ oder Ansprüche an „das technische Niveau [...], auf dem allein die Erkenntnisse verifizierbar und nützlich“ erscheinen (Foucault [1970] 1993: 15).

Zuletzt beschreibt er neben den Verknappungsprozeduren des Diskurses und den Ausschließungsprozeduren noch Prozeduren „Der Verknappung der sprechenden Subjekte“ durch Rituale (ebd.: 26f.), Diskursgesellschaften (ebd.: 27f.), Doktrinen (ebd.: 28f.) und Erziehungssysteme (ebd.: 29f.), d. h. Prozeduren, die den Subjekten den Zugang zum Diskurs erleichtern oder erschweren.

Dass Foucault in seiner Antrittsvorlesung ausführlich auf diese externen Mechanismen zu sprechen kommt, wird in der Foucault-Rezeption mehrheitlich als methodische und theoretische Schwerpunktverschiebung in seinem Werk gedeutet:

In den frühen Schriften, vor allem in der Archäologie des Wissens, hatte Foucault versucht,
Diskurse als geordnete Systeme aus sich selbst heraus, also nur mit Blick auf die Aussagen
bzw. diskursiven Ereignisse zu beschreiben. Ab Anfang der 1970er Jahre wendet er sich der
Frage zu, wodurch der ,begrenzte(n) Kommunikationsraum` (Foucault [1969] 1981: 183),
der ein Diskurs ist, begrenzt wird und wie er die Diskursakteure in ihren sprachlichen und
nichtsprachlichen Handlungen begrenzt. Damit wendet er sich erstmals neben den >diskur-
siven Praktiken`, den Regeln, die dem Diskurs inhärent`sind, auch den >nicht-diskursiven
Praktiken` zu, also den gesellschaftlichen, institutionellen und politischen Regularitäten,
die mit dem Diskurs in Wechselwirkung stehen.
(Spitzmüller/Warnke 2011: 72)

Die Entwicklung von der „Archäologie des Wissens“ als Werk Foucaults, in dem er diskursive Formationen ,,aus sich selbst heraus, also nur mit Blick auf die Aussagen zu beschreiben“ (ebd.) versucht habe, hin zur Methode der „Kritik“ und „Genealogie“ (Foucault [1970] 1993: 38ff.; vgl. Koller/Lüders 2004: 63ff.) sowie der „Verschränkung des Diskursiven mit dem Institutionellen“ (Schäfer/Wrana 2014: 309) bzw. der Wissens- mit der Machtanalyse in der Dispositivanalyse (Foucault 1978: 120) wird von den Foucault-Interpreten Dreyfus und Rabinow als Eingeständnis der „Illusion des autonomen Diskurses“ (Dreyfus/Rabinow 1994: 12) gedeutet. Wenn Foucault zu Beginn seiner Antrittsvorlesung „Die Ordnung des Diskurses“ 
allerdings fragt, was „so gefährlich sei an der Tatsache, daß die Leute sprechen und daß ihre Diskurse endlos weiterwuchern“ (Foucault [1970] 1993: 10), dann scheint er dem Diskurs nach wie vor selbstregulierende Kräfte zuzusprechen. Nach der Wende hin zur Genealogie kommen zu den Wirkungen ,anonymer und neutraler Formationsregeln“ jedoch deutlicher als zuvor die „interessiert-strategische[n] Kontrollmechanismen hinzu, die den wuchernden Diskurs in bestimmte Formen bringen“ (Koller/Lüders 2004: 63-64).

Das Verhältnis von Diskurs, Wissen und Macht, das in der „Verschränkung des Diskursiven mit dem Institutionellen“ (Schäfer/Wrana 2014: 309) einen Ausdruck findet, wird in den diskursanalytischen Ansätzen nach Foucault unterschiedlich ausgelegt und diskursanalytisch operationalisiert. S. Jäger setzt auf eine analytische Trennung und stellt in einem zweiten Schritt das „Zusammenspiel diskursiver Praxen (= Sprechen und Denken auf der Grundlage von Wissen), nichtdiskursiver Praxen (= Handeln auf der Grundlage von Wissen) und ,Sichtbarkeiten` bzw. ,Vergegenständlichungen“ (von Wissen durch Handeln/Tätigkeit)“ ins Zentrum seiner Dispositivanalyse (vgl. Jäger 2011: 92). Wrana/Langer hingegen lehnen die binäre Trennung zwischen diskursiven und nicht-diskursiven Praktiken (Wrana/ Langer $2007^{133}$ ) ab und begründen dies damit, dass Foucault diese Unterscheidung selbst relativiert habe (Foucault [1977b]/2003: 396 134 ). Denn diese Unterscheidung

$133 \mathrm{http} / / /$ dx.doi.org/10.17169/fqs-8.2.253, zuletzt eingesehen am 11.11.2019. Der Beitrag enthält keine Seitenzahlen.

134 Im Gespräch „Das Spiel des Michel Foucault“ sprechen im Jahr 1977 unter anderem G. Le Gaufey und J.-A. Miller mit Foucault kurz nach dem Erscheinen von „Der Wille zum Wissen“ über den möglichen Unterschied der Begriffe `Episteme Elemente daran diskursiv und nicht-diskursiv seien. G. Le Gaufey fragt, was es „außerhalb der Aussagen in einem Dispositiv anderes als die Institutionen“ gebe (vgl. Foucault ([1977b]/2003), Schriften, Bd. 3: 396). Foucault antwortet darauf zunächst, die „Institution“ sei „,jedes mehr oder weniger erzwungene, erworbene Verhalten. Alles, was in einer Gesellschaft als Zwangssystem funktioniert, ohne dass es eine Aussage ist, zusammengefasst, das gesamte nicht diskursive Soziale, ist die Institution.“ (ebd.) Auf den Einwand von J.-A. Miller, ob die Institution jedoch nicht „offensichtlich etwas Diskursives“ sei, antwortet Foucault: „[...] für meine Sache mit dem Dispositiv ist es nicht so sehr wichtig, ob es heißt: Dies da ist diskursiv, dies da ist es nicht.“ Foucault führt weiter aus, er glaube nicht, „dass es von großer Wichtigkeit ist, genau diese Trennung vorzunehmen“ und begründet dies damit, dass sein Problem kein „sprachliches“ sei. Die letzte Äußerung ist wohl dahingehend zu verstehen, dass es Foucault stets vorrangig um die Relationalität zwischen Aussagen/Aussagesystemen und Ereignissen (vgl. Foucault [1969] 1981: 44/45; Kelm 2015: 227), sprich um „die Natur der Verbindung [...] zwischen heterogenen Elementen“ als „Gesamtheit bestehend aus Diskursen, Institutionen, architektonischen Einrichtungen, reglementierten Entscheidungen etc.“ geht (vgl. ebd. 392 in seiner Definition des Begriffs ,Dispositiv`). Die hier vorgenommene Abgrenzung von Sprache geht bei ihm auf einen verkürzten Sprachbegriff als geschlossenes, kontextunabhängiges Zeichensystem zurück (vgl. Busse 1987: 243; Schäfer/Wrana 2007; Spitzmüller/Warnke 2011: 76). 
basiere auf einer so bei Foucault nicht eindeutig zu findenden Gleichsetzung der Differenzen diskursiv/nicht-diskursiv und sprachlich/nicht-sprachlich (vgl. Jacob 2017: 155). Dadurch entstehe ein um die Dimension des Handelns verkürzter Begriff sprachlich-diskursiver Formationen bzw. Praktiken:

FOUCAULT [bestimmt, T.S.] die diskursiven Formationen keineswegs als eine Menge von Texten, Textfragmenten oder Äußerungen, er bezeichnet sie vielmehr als „Bündel von Beziehungen“. Der Diskurs ist nicht als eine isolierbare Einheit zu begreifen, sondern als die Funktion der „Herstellung von Beziehungen, die die diskursive Praxis selbst charakterisiert“ (FOUCAULT 1981, S. 70, 126). Unter den homogenen diskursiven Formationen versteht FOUCAULT also weder sprachliche Produkte (Texte) noch sprachliche Elemente (Wörter, Seme, Bedeutungspartikel, rhetorische Figuren oder Ähnliches), sondern die Ähnlichkeit einer diskursiven Praxis der Herstellung von Wahrheit und Bedeutung. Im Zentrum der Diskurstheorie stehen also nicht die Sprache und sprachliche Objekte, sondern sprachliches Handeln. [...] Die Diskursanalyse befasst sich nicht mit der Sprache verstanden als „Sprachsystem“ (SAUSSURE 1967), als immanente Struktur, sondern mit dem Sprechen als sozialem Tun, als konkreter gesellschaftlicher Tätigkeit. [5]

(Wrana/Langer 2007 (Onlinedokument), Unterstreichung T.S.)

Im Zitat von Wrana/Langer zeigt sich, dass für die Bestimmung des Verhältnisses von Sprache, Diskurs und außersprachlicher Wirklichkeit und Praxis entscheidend ist, welcher Sprachbegriff zugrunde gelegt wird. Wrana/Langer deuten dies mit der Gegenüberstellung von `Sprachsystem` und `sprachlichem Handeln` an und betrachten damit zurecht die Foucault'sche Diskursanalyse als eine Analyse, die die „Perspektive der Performanz“ (Linke/Feilke 2009: 5) dominant setzt. Die Kontrastierung von 'Sprachsystem` und ssprachlichem Handeln`sollte jedoch noch differenziert werden. Denn wenn Foucault innerhalb seiner diskursiven Methode fordert, Aussagen, die sich an der diskursiven Oberfläche häufig in sprachlichen Zeichen manifestieren, $\mathrm{zu}$,alle(n) bereits woanders formulierten Aussagen [...]“ (Foucault [1969] 1981: 83) in Bezug zu setzen, dann erhält diese Aussage ihre Bedeutung insbesondere durch ihren Stellenwert im (sprachlichen) Diskursgeflecht. Foucault grenzte sich jedoch deshalb von der sprachsystematischen Analyse ab, weil er Sprache und (sprachliche) Bedeutung (vgl. Spitzmüller/Warnke 2011: 76) - beeinflusst vom Strukturalismus Saussure'scher Prägung und der Generativen Grammatik Chomskys - auf ihre Bezeichnungsfunktion im Rahmen eines vom Kontext losgelösten strukturiert geschlossenen Zeichensystems reduziert sah (vgl. Busse 1987: 242). Nach Wranas und Langers Interpretation ist das Aufbrechen dieser Verkürzung des Sprachbegriffs in der Diskursanalyse in Richtung eines practice turn bei Foucault angelegt (vgl. Wrana/Langer 2007) ${ }^{135}$.

135 http://dx.doi.org/10.17169/fqs-8.2.253, zuletzt eingesehen am 11.11.2019. Der Beitrag enthält keine Seitenzahlen. 
Der folgende Abschnitt aus der „Archäologie des Wissens“ spricht für diese Auslegung. Foucault schreibt darin, man solle Diskurse nicht mehr:

als Gesamtheit von Zeichen (von bedeutungstragenden Elementen, die auf Inhalte und Repräsentationen verweisen), sondern als Praktiken behandeln, die systematisch die Gegenstände bilden, von denen sie sprechen. Zwar bestehen diese Diskurse aus Zeichen; aber sie benutzen diese Zeichen für mehr als nur zur Bezeichnung der Sachen. [...] Dieses mehr muß man ans Licht bringen und beschreiben.

(Foucault [1969] 1981: 74) (Kursivierung im Original, Unterstreichung T.S.)

Foucaults Analyse geht von der Zeichenebene aus, er möchte Zeichen aber nicht auf ihre Repräsentationsfunktion und Bedeutung in einem synchron als statisch gedachten System beschränkt sehen, sondern mit der Diskursanalyse beschreiben, welche praktischen Effekte von ihnen ausgehen und wie sich die Beziehungen zwischen den Diskurselementen im Wechselspiel von Diskurs und Gesellschaft dynamisch entwickeln.

Ich plädiere mit Wrana/Langer (2007) vor diesem Hintergrund für die Aufhebung einer streng binären Unterscheidung zwischen diskursiven und nicht-diskursiven Praktiken und verwende im Folgenden einen umfassenden Begriff `diskursiver Praxis und Praktiken ‘. Diesem Ansatz liegt die Überzeugung zugrunde, dass die diskursexternen Machtprinzipien zwar von außen auf den Diskurs einwirken und sich natürlich auch in nicht-sprachlichen Handlungen ausdrücken, in der überwiegenden Zahl der Fälle aber Spuren im Diskurs hinterlassen ${ }^{136}$, dadurch indexikalisch-diskursiv vermittelt sind und zu diskursiven Praktiken werden. Erst durch die Materialität der (in dieser Arbeit fokussierten sprachlichen) Zeichen erhält man schließlich die „phänomenalen Grundlagen“ zur Analyse von „Kontextualisierungsprozessen in Verständigungshandlungen“ (Müller 2015: 26). Ich beziehe mich dabei zudem auf Feilke, der den Textbezug als „das Definiens für die Unterscheidung literaler von anderen Praktiken“ bestimmt (Feilke 2016: 261) und sehe analog dazu den Bezug auf den Diskurs als „Definiens für die Unterscheidung“ diskursiver von anderen Praktiken, wobei damit nicht bestritten werden soll, dass die diskursiven Praktiken mit kulturellen und sozialen Praktiken im Wechselverhältnis stehen. Gerade diese Verflechtungen, d. h.

136 Insbesondere der Einsatz sprachlicher Mittel zur Stärkung oder Abschwächung des Geltungsanspruchs verweist auf Prozeduren der versuchten Ausschließung (vgl. Deppermann 1997: 11ff.; Busch 2006: 65f., Schnedermann 2016: 238ff.) und Sprachthematisierungen können auf den Umgang von Institutionen mit bestimmten Gegenständen verweisen (vgl. Domasch 2006). Dennoch sind diese,diskurseigenen' Manifestationen sozialer und gesellschaftlicher Faktoren, wie S. Jäger (2011: 122) zurecht anmerkt, nicht als ,objektiver‘ Nachweis realer gesellschaftlicher Praxis zu deuten, sondern als Zuschreibungen von bestimmten Diskurspositionen aus. 
den Diskurs beeinflussende Normen, (Berufs-)rollenvorstellungen, fachkulturelle Methoden und Paradigmen, etc. sollen durch kontextsensitive, tiefensemantische (vgl. Busse 2007, Spieß 2012) Analysen herausgearbeitet werden. Spieß entwirft ein ähnliches Verfahren einer um den Begriff des >Dispositivs « erweiterten Diskursanalyse. Sie integriert außersprachliche, den Diskurs beschränkende und beeinflussende Faktoren in ihre Analyse, indem sie die sprachlichen Phänomene „in Bezug zu und als Ausprägungen von Objektivationen (wie Normen, Institutionen, Architekturen, Gesetzen etc.) und Subjektivationen (wie Subjektrollen, Rollenverhalten)“ untersucht (Spieß 2012: 85). Diesem Analyseprogramm schließt sich diese Arbeit in der Analyse diskursiver Definitionspraxis grundsätzlich an.

Im Folgenden werde ich die Bestimmungsstücke und Verflechtungen sozialkultureller und sprachlich-diskursiver Praktiken zusammenfassen und daraus prospektiv drei Ebenen für die Analyse diskursiver Definierenspraxis im Rahmen diskurspraktischer Wissenskonstituierung ableiten.

\subsubsection{Zusammenfassung und Ausblick: Die Analyse diskursiver Praktiken des Definierens als diskurspraktische Wissenskonstituierung}

Vergleicht man die Bestimmungsstücke der linguistisch-soziologischen PraktikenDiskussion mit Foucaults Konzeption diskursiver Praxis, so scheinen die Theorien folgende Kernmerkmale gemeinsam zu haben:

1.) Sowohl praxeologische Ansätze als auch Foucault schreiben (sprachlichen) Zeichen und Strukturen in ihrer spezifischen Materialität „Formungskapazität“ zu und nehmen eine „phänomenorientierte“ Analyseperspektive ein (vgl. Felder/Gardt 2015: 19; Deppermann/Feilke/Linke 2016: 4; Foucault [1969] 1981: 44).

2.) Geregelte Praxis drückt sich für viele Vertreterinnen und Vertreter praxeologischer Theoriebildung und Foucault in der Regelmäßigkeit bzw. Routiniertheit sozialer oder diskursiver Mechanismen aus. Die praxeologisch-linguistische Analyse beschreibt die sprachlich-semiotischen „Modellierungen [...] von praktischem Tun, insbesondere in dessen Regelhaftigkeiten“ (Konerding 2009: 89), wobei die daraus entstehenden Verhaltens- und diskursiven Formationsregeln den (sprach-)handelnden Personen nicht vollständig kognitiv präsent sein müssen oder können (vgl. Foucault [1969] 1981: 83; Busse 1987: 232f.; Habscheid 2016: 132; Müller 2015: 18f.). Die Einzelautorinnen/-autoren und das Moment der Intentionalität und Variationsmöglichkeit (vgl. Linke 2010: 259, 262) werden dadurch nicht aufgehoben, aber relativiert (vgl. Gardt 2013: 41).

3.) Aus beiden Theorien ergibt sich eine Analyserichtung, die sich ,auf den sprachlichen Zeichengebrauch und seine sozio-kulturellen Einbettungsbedin- 
gungen“ (Felder/Gardt 2015: 15) konzentriert und damit die „Sprachverwendungskonstellationen [...] unter (fach-)kultureller, sprachsystematischer und pragmatisch kommunikativer“ (Felder/Gardt 2015: 18) Perspektive beschreibt. Die Untersuchung setzt bei sprachlichen Zeichen an und sucht „in deren Umgebung im engeren Sinne Anzeichen für ihre Umgebung im weiteren Sinne“ (siehe Müllers Ausführungen zum Analysezugang der „Indexikalität“, Müller 2015: 49 und vgl. Kap. 2.2.2 und 2.3). Sie fokussiert damit sowohl das semantisch-perspektivierende Potenzial der Zeichenressourcen „unter Bezugnahme auf ihren „Stellenwert im Textgeflecht“ (Felder 2012: 128) als auch ihre pragmatische Funktion und kontextuelle Einbettung (ebd.: 129) und dies vor dem Hintergrund (fach-)kultureller Routinen bzw. der Partizipation der Autoren/Autorinnen an einer Diskursgemeinschaft (Spitzmüller/Warnke 2011: 181; vgl. Müller 2015: 25f.) und damit verbundenen Erwartungen an typische Textemittenten, Adressaten, Textsorten und textstilistische Komponenten etc. Der „ganze Gebrauchszusammenhang“ (Feilke 2016: 254) ist relevant.

Praktiken sind vor diesem Hintergrund gewohnheitsmäßige Verhaltens- und Handlungsweisen des „Umgangs mit bestimmten Problemen und Gegenständen“ (Feilke 2016.: 265; vgl. Konerding 2009) und semiotischen Ressourcen.

Bezieht man dieses Praktiken-Konzept nun prospektiv auf den Untersuchungsgegenstand der vorliegenden Arbeit, einer diskursiven Praxis des Definierens, so erscheinen die folgenden Analysezugänge vielversprechend zu sein:

- Die Arbeit sondiert erstens Praktiken, die sich im Diskurs im Medium Sprache ${ }^{137}$ manifestieren und definitorische Funktionen erfüllen ${ }^{138}$, d. h. routinierte Sprachverwendungskonstellationen, die zur diskursiven Entstehung einer Definition beitragen. Im Fokus stehen zum einen Praktiken der Sachverhaltsklassifizierung, -verknüpfung und -bewertung (vgl. Felder 2012: 118),

137 Die vorliegende Arbeit legt einen Fokus auf die Analyse von Spuren definitorischer Praxis im Medium vertexteter Sprache. Dies geschieht zum einen vor dem Hintergrund, dass die interaktive wissenschaftliche Wissensgenerierung in heutigen Gesellschaften zu großen Teilen auf schriftlichen Bezugnahmeformen basiert. Bei Texten des öffentlichen Diskurses, sofern diese multimodal, z. B. mit Bildern erscheinen, werden diese Zeichenbeziehungen jedoch in die Analyse teilweise mit einbezogen. Zum anderen konzentriert sich die Arbeit auf das Medium Sprache und damit einhergehende intramediale Relationen vor der Analyse intermedialer Verhältnisse. Damit schließe ich mich L. Jäger an, der empfiehlt, zunächst die „Medialität des Mediums Sprache selbst stärker in den Fokus der Aufmerksamkeit zu rücken“ [...], ,,weil sich vielleicht erst von hier aus Aufklärung darüber gewinnen läßt, was die Medialität von Medien ausmacht` (Jäger 2000: 10)“ (Jäger 2010b: 302).

138 Eine Heuristik definitionskonstitutiver Komponenten und Funktionen erfolgt im nächsten Kapitel (Kap. 4.2). 
Begriffs- und Themenentfaltung (vgl. Brinker/Cölfen/Pappert ${ }^{8} 2014$ : 60ff.; Müller 2007: 77ff.; Schmidt-Brücken 2015: 88ff.) und zum anderen intertextuelle Praktiken der Bezugnahme, Transkription ${ }^{139}$ (vgl. Berndt/Tonger-Erk 2013; Foucault [1969] 1981: 85; Feilke 2016; Jäger 2010b; 2012b) sowie Verknappung, Geltungsauszeichnung und Legitimation (vgl. Konerding 2009: 85, Felder 2006a), wobei diese sprachlichen Praktiken ihrerseits in Wechselwirkung mit fachkulturellen (Konerding 2015b), wissensvermittelnden bzw. -transformierenden (Liebert 2002, Konerding 2015b: 72ff.) und (massen-) medialen Praktiken (u. a. Fraas/Klemm 2005; Spieß 2012) stehen.

- Zweiter Ansatzpunkt der Analyse sind Repräsentationen an der hauptsächlich sprachlichen Diskursoberfläche von gewohnheitsmäßigen Verhaltensund Handlungsweisen des Umgangs mit Phänomenen aus dem Bereich zwischen 〉Gesundheit` und >Krankheit` in fachlichen und fachexternen Diskursgemeinschaften. Mit anderen Worten geht es hier um die Frage, welche semiotischen sprachlichen Ressourcen wiederholt in spezifischer Weise eingesetzt werden, um Phänomene zwischen den Polen `gesund ‘ und `krankı und >normal $/$ /normentsprechend $८$ bzw. sanormal $</$ abnorm $\iota^{140} \mathrm{zu}$ verorten, voneinander abzugrenzen und damit auch zu definieren.

- Auf der dritten Ebene werden komplexe Typen diskursiver Definierenspraxis zum Phänomen bzw. Begriff >BURNOUT< analysiert, in denen Praktiken der ersten und zweiten Analyseebene zusammenwirken. Hieran schließt sich die Frage an, in welchen Gebrauchskontexten welche Typen in dominanter Weise verwendet werden, mit welchen Funktionen sie einhergehen und welche Aspekte des Phänomens durch die unterschiedlichen Definitionsarten besonders akzentuiert werden.

\footnotetext{
139 Hier beziehe ich mich auf das „Verfahren transkriptiver Bezugnahme“ von Ludwig Jäger (Jäger 2010b: 301). Jäger beschreibt es als „grundlegendes Verfahren der kulturellen Semiosis“ (ebd.) und verbindet es in Rückgriff auf Wilhelm von Humboldt, für den die „unzertrennliche Verbindung des Gedankens, der Stimmwerkzeuge und des Gehörs zur Sprache“ in der menschlichen Natur angelegt ist (Humboldt 1907: Gesammelte Schriften, Bd 7.1: 53), mit dem Begriff der ,Spur', d.h. ohne eine „mediale Vermittlung des Mentalen [...] könne,das Denken [...] nicht zur Deutlichkeit gelangen, die Vorstellung nicht zum Begriff werden'. [...] Das Vorgängige, das zu Bezeichnende, wird erst in der Nachträglichkeit der Bezeichnung, gleichsam in einer transkriptiven Umschrift, konstituiert“ (Jäger 2010b: 307). Unter transkriptiven Prozeduren versteht Jäger zum Beispiel, ,vorgefundene Artefakte zu zitieren, zu paraphrasieren, zu explizieren, zu erläutern oder zu interpretieren [.... “ (vgl. Jäger 2010b: 310ff.).

140 Zur Bedeutung der „Anomalie“ bzw. des erklärungsbedürftigen nicht ,Normalen“ im Rahmen medizinischer Semiotik siehe Kap. 3.1 dieser Arbeit.
} 
Im Anschluss an diese ersten Vorüberlegungen werden im folgenden Kapitel die einzelnen heuristischen Perspektiven, mit denen sich diese Arbeit dem Untersuchungsgegenstand einer diskursiven Definierenspraxis nähert, Schritt für Schritt beschrieben.

\subsection{Definieren als diskursive Praxis der Wissenskonstituierung - eine Heuristik}

\subsubsection{Vorbemerkung}

In Kapitel 4.2 und seinen Unterkapiteln wird im Detail entwickelt, wie sich diese Arbeit dem Untersuchungsgegenstand der sich im Diskurs manifestierenden Definierenspraxis eines Phänomens ${ }^{141}$, Wortes, Begriffs/Konzepts ${ }^{142}$ im Bereich von Gesundheit und Krankheit von sprachwissenschaftlicher Seite aus annähert. Das Kapitel knüpft dabei an das im vorangegangenen Kapitel entfaltete Konzept wissensgenerierender Praktiken und die in Kap. 2 und 3 referierten Modelle zur diskursiven Konstituierung von Bedeutung und Wissen an. Die Annäherung an

141 Unter einem >Phänomen ‘ wird - ausgehend von der Grundannahme Kants, dass uns nicht die „Dinge an sich“, sondern nur deren Erscheinungen zugänglich sind (vgl. Kant 1787/1966: 28ff. (=B XVI ff); vgl. auch Felder 2009b: 16) mit Rückgriff auf das Zeichenmodell von Peirce und in Anlehnung an Köllers Interpretation desselben ein „Zeichenobjekt“ verstanden. Köller beschreibt das „Zeichenobjekt“ nach Peirce wie folgt: „Das Zeichenobjekt ist für Peirce eine Sachgröße, die mit Hilfe des jeweiligen Zeichens als Teilgröße aus dem Kontinuum der physischen oder der geistigen Welt herausdifferenziert wird und die deshalb als pragmatische Ursache der ganzen Zeichenbildung anzusehen ist“ (Köller 2004: 243). Phänomene werden durch Kapitälchen (z. B. BURNOUT) notiert. Zur Notation im Überblick siehe S. XIII-IX.

142 Die Unterscheidung zwischen Wort bzw. Ausdruck und Begriff/Konzept begründet sich aus der linguistischen Unterscheidung zwischen Form- und Inhaltsseite bzw. „zwischen Gestalt und Wert“ (Bär 2015: 176). Unter >Begriff`/>Konzept` wird in dieser Arbeit vor dem Hintergrund erkenntnistheoretischer Überlegungen zur Perspektivität (sprachlicher) Zeichen (Köller 2004) eine durch (sprachliche) Zeichen vermittelte Interpretationsperspektive auf ein Phänomen (vgl. das Zeichenmodell von Peirce, Kap. 2.2.2) bzw. einen Phänomenbereich verstanden, die besondere Aspekte an diesem Phänomen hervortreten lässt und das Phänomen auf besondere Weise in bestehendes Wissen/Denkhorizonte einordnet. Die Arbeit verwendet die Ausdrücke Begriff und Konzept weitgehend synonym. Der Begriffsbegriff betont jedoch stärker die Abhängigkeit der Interpretationsperspektive von sprachlichen, ausdrucksseitigen Objektivierungsformen und reflektiert das Vorgehen der interpretierenden Person dahingehend, dass verschiedene objektsprachliche Ausprägungen einer Interpretationsperspektive beschreibungssprachlich möglichst prägnant gefasst, sprich „auf den Begriff“ gebracht werden müssen (vgl. Bär 2015: 178; 183). 
das Untersuchungsphänomen Definierenspraxis geschieht induktiv-deduktiv in mehreren aufeinander aufbauenden heuristischen Schritten:

1) Erklärungen und Lesarten der Wörter definieren und Definition im allgemeinen einsprachigen Wörterbuch (siehe Kap. 4.2.1);

2) aus der Sicht von Erwartungen an die Tätigkeit des Definierens, die im fachlichen und öffentlichen Burnout-Diskurs geäußert werden (= Metadiskurs zum Definieren, siehe Kap. 4.2.2);

3) aus der Sicht von wissenschaftsgeschichtlichen und -theoretischen Zusammenhängen (siehe Kap. 4.2.3);

4) aus der Sicht (fach)linguistischer und terminologischer Forschung (siehe Kap. 4.2.4);

5) aus einer sprachhandlungsorientierten Perspektive (siehe Kap. 4.3.2) und

6) aus einer praxeologisch-phänomenorientierten Perspektive (siehe Kap. 4.3.3).

Ein besonderes Augenmerk wird auf die Frage gelegt, welches Verständnis von >Definieren</>Definition ‘ Akteure und Stimmen im Diskurs selbst transportieren und welche Zwecke sie Definitionshandlungen oder -prozessen zuschreiben. Die induktiv herausgearbeiteten diskursiven Erwartungen an das Definieren eines Phänomens oder Begriffs im Bereich von Gesundheit und Krankheit werden schlaglichtartig mit wichtigen Aspekten der wissenschaftstheoretischen und (fach-)linguistisch-terminologischen Diskussion zum Definieren verbundenen und leiten über in den praktischen Analyseteil dieser Arbeit. In diesem wird gefragt, welche sprachlichen Mittel, Teilakte und Praktiken zum Tragen kommen oder eingesetzt werden, um die herausgearbeiteten definitorischen Funktionen $\mathrm{zu}$ erfüllen (funktionale Herangehensweise). Stärker phänomenorientiert wird ferner untersucht, welche Sprachgebrauchsformen verschiedener sprachlicher Ebenen und Praktiken definitorische Funktionen in diesem Diskurs übernehmen (semiotische/phänomenorientierte Herangehensweise). ${ }^{143}$

143 Felder (o. Jahresangabe) beschreibt in einem online veröffentlichten Beitrag zum „FormFunktions-Perspektivenwechsel in der Grammatik“ zwei Analyse-Perspektiven in Anlehnung an Zifonun/Hoffmann/Strecker (1997: 2). Es sei denkbar, „einerseits von Funktionen“ auszugehen und „nach den sprachlichen Mitteln im Text Ausschau“ zu halten, „mittels derer die Funktionen erfüllt werden können“ (= „sprachhandlungsorientierte und funktionale Zugangsweise“). Andererseits könnten auch die „grammatische[n] Formen im Hinblick auf ihre Funktionalität untersucht werden“ (= „Phänomen-orientierte Herangehensweise“). Felder: http://www.gs.unihd.de/md/neuphil/gs/sprache02/projekte/felder_form-funktion-perspektivenwechsel.pdf, S. 4. (zuletzt eingesehen am 11.11.2019). 


\subsubsection{Erklärungen und Lesarten der Wörter definieren und Definition im allgemeinen einsprachigen Wörterbuch}

Herbert Freudenberger, der in vielen Texten als Erstbeschreiber des \BURNOUTSYNDROMS « bezeichnet wird, definiert >BURNOUT` zunächst, indem er einen Wörterbucheintrag des Verbs to burnout zitiert (Freudenberger 1974: 159 im QV unter 8.1.5, für eine weitere Analyse siehe Kap. 6.2.2.2 dieser Arbeit). Er nähert sich dem Phänomen oder Begriff, den er mit dem Wort Burnout bezeichnet, damit zunächst über eine lexikografische Definition ${ }^{144}$ an. Damit zeigt Freudenberger, dass er sich als Fachmann auch alltagssemantischer Wissensbestände und Ausdrücke bedient. Diese enge Verbindung von Fach- und Alltagswortschatz entspricht Beobachtungen der neueren Fachsprachenforschung, die eine weniger scharfe Trennung zwischen sprachlichen Praktiken der Fach- und Alltagssprache annimmt als beispielsweise die klassische Terminologielehre der Wiener Schule (vgl. Müller/Behr/Steffek 2019: 106; vgl. Reinart/Pöckl 2015: 73; vgl. Temmerman 2000: 32 mit Bezug auf Boulanger 1995: 197, vgl. Müller/Mell 2020: 198 und 201f.; siehe auch Kap. 4.2.4). Aus diesem Grund und nach dem Rat Ludwig Wittgensteins, dass man, wenn man den Gebrauch eines Wortes und mit diesem seine Bedeutung verstehen will, die Erklärung derselben nachsehen soll ${ }^{145}$, werden zum Einstieg in diese Heuristik Bedeutungserklärungen für das Verb definieren aus dem DUDEN-Universalwörterbuch herangezogen:

de/fi/nie/ren (sw. V.; hat) [lat. definire, eigtl. = ab-, begrenzen]:

a) den Inhalt [eines Begriffes] auseinanderlegen, erklären: ein Wort exakt, ungenau d.; den Begriffsinhalt d.; „Schimmel“ wird im Allgemeinen als „weißes Pferd“ definiert;

b) bestimmen, festlegen; angeben od. beschreiben, worum es sich handelt: das Drehmoment präzise d.; die Farbe des Kleides ist schwer zu d.; ein zeitlich definierter Impuls;

c) $\langle$ d. + sich $\rangle$ seine Stellung bestimmen; sein Selbstverständnis haben: die Ehefrau definierte sich im 19. Jh. häufig durch den Status des Mannes. ${ }^{146}$

144 Eine kritische Auseinandersetzung zu Verfahren der „lexikographischen Definition im allgemeinen einsprachigen Wörterbuch“ findet man bei Wiegand 1989 und in Kapitel 4.2.4.

145 Ich beziehe mich hier auf die Ausführungen Herbert Ernst Wiegands zu „Wortbedeutung und Wortbedeutungserklärungen“ (Wiegand 1999: 424ff.), in denen er von Wittgensteins Werk(interpretation) ausgeht. Die obige Aussage bezieht sich auf die Aussage Wittgensteins: „,Die Bedeutung des Wortes ist das, was die Erklärung der Bedeutung erklärt‘. D. h.: willst du den Gebrauch des Wortes ,Bedeutung verstehen, so sieh nach, was man ,Erklärung der Bedeutung، nennt.“ (Philosophische Untersuchungen (PU), Bemerkung 560, Wittgenstein 1977). Zum Bedeutungsbegriff dieser Arbeit siehe auch Kap. 2.2.1.

146 Abgerufen über die Online-Ressource (über Universitätsbibliothek Heidelberg), https:// woerterbuch.langenscheidt.de.ubproxy.ub.uni-heidelberg.de/ssc/search.html, Oktober 2015 (Unterstreichungen mit Ausnahme des Betonungsunterstrichs von T.S.). Seit 2015 wurde der Ein- 
Die Bedeutungsangaben des Verbs definieren im DUDEN verdeutlichen, dass es verschiedene Teil-Praktiken gibt, etwas zu definieren: durch Auseinanderlegen, Beschreiben (z. B. einzelner Merkmale, wahrgenommener Eindrücke, erhobener Daten) oder Erklären, beispielsweise wie etwas funktioniert oder entstanden ist. ${ }^{147}$ In jedem Fall können verschiedene Praktiken eingesetzt werden, um dem zu definierenden Ausdruck oder Begriff (dem Definiendum) meist intramedial ${ }^{148}$ sprachlich gefasste bekannte Einheiten als Definiens durch Gleichsetzung bzw. in der Beziehung der Äquivalenz zuzuordnen. ${ }^{149}$ Eine Definition antwortet, wie die zweite Lesart des DUDEN-Eintrags nahelegt, auf Fragen der folgenden Art „Worum handelt es sich bei $\mathrm{x} / \mathrm{y}$ ?“ „Was ist/bedeutet $\mathrm{x} / \mathrm{y}$ ?“ und fokussiert dabei bestimmte Merkmale durch Abstraktion und Abgrenzung von anderen Merkmalen. Der auch durch die Etymologie des Verbs definieren ${ }^{150}$ akzentuierte Bedeutungsaspekt des 'Ab- oder Begrenzens' verdeutlicht, dass Begriffe und Begriffsdefinitionen „Perspektivierungsinstrumente“ sind (vgl. Köller 2004: 323/324).

Die dritte Lesart des DUDEN-Eintrags, in der definieren reflexiv als seine Stellung bestimmen; sein Selbstverständnis haben erläutert wird, unterstreicht die Verschränkung von Subjekt- und Objektsphäre, die bei jeder Begriffsbildung zu der Frage führt, ,inwieweit man die jeweiligen Begriffsbildungen in der Ord-

trag zum Lemma Definition überarbeitet. Die Lesarten a) und b) wurden zusammengezogen, die Lesart c) ist gekürzt erhalten geblieben und eine weitere Lesart ist hinzugekommen: ,als unfehlbar geltende Entscheidung des Papstes oder eines Konzils über ein Dogma“, abgerufen über die Universitätsbibliothek Heidelberg unter: https://owb.langenscheidt.com/ (zuletzt eingesehen am 12.11.2019).

147 Vgl. die verschiedenen Arten des Definierens, z. B. in fachlexikografischen Artikeln zum Stichwort Definition. Prechtl unterscheidet im „Metzler Lexikon Sprache“: „a) die deskriptive (feststellende) D.“ [...] (b) die stipulative (festsetzende) D. [...] (c) die ostensive (hinweisende) D. [...] durch Aufzählen geeigneter Beispiele [...] (d) die operationale D. durch Bezug auf ein bestimmtes Meß- oder Untersuchungsverfahren“ (Prechtl ${ }^{5}$ 2016: 131). Ähnliche Unterscheidungen findet man auch bei Metschl (1999: 97).

148 Vgl. Pawłowski (1980: 14f.) zum Äquivalenzcharakter von Definitionen. Natürlich kann eine solche Zuordnung auch intermedial z. B. über Zeigegesten oder ikonische Gesten realisiert werden. Insbesondere für Objektreferenzen und die Vorbereitung von Zweiwortäußerungen im Erstspracherwerb spielen beispielsweise deiktischen Gesten und Kombinationen aus Geste und Wort eine wichtige Rolle (vgl. Iverson/Goldin-Meadow 2005: 367f.; Tomasello 2011: 123ff; Weidinger 2011: $10 \mathrm{ff} . ;$ Rau 2007: 179).

149 Köller beschreibt den Vorgang der Begriffsbildung bzw. -definition mit den Worten Friedrich Nietzsches: „Jeder Begriff entsteht durch Gleichsetzen des Nichtgleichen“ (zitiert nach Köller 2004: 321). Bußmann beschreibt Definition als „Festlegung des Inhalts eines Ausdrucks. Formal gesehen ist jede wissenschaftliche Definition eine Äquivalenz, die dem zu Definierenden (= Definiendum) das definierende Bekannte (= Definiens) zuordnet“ (Bußmann 2002: 148).

150 „Das Wort «definitio〉 ist die lateinische Übersetzung des griechischen horismós/òpı (Umgrenzung)“ (Nobis 1972: 31). 
nungsstruktur der gegebenen Objekte verankern kann oder muss und wie weit in den Differenzierungsbedürfnissen der denkenden [und fühlenden, T.S.] Subjekte“ (Köller 2004: 321). Bei psychischen Krankheiten bzw. Phänomenen ist die Bestimmung dieses Verhältnisses besonders schwierig und relevant. Schwierig, da man zur Objektivierung psychischer Krankheiten innere und äußere Faktoren und die Ähnlichkeit ihres Auftretens bei verschiedenen Personen berücksichtigen muss. Relevant, da die subjektive Dimension bei psychischen Krankheiten immer in Überlegungen der Diagnosestellung und Behandlung eingebunden sein sollte. ${ }^{151}$ Zudem ist ein enges Wechselverhältnis zwischen subjektiven und medial-diskursiven Gesundheits- und Krankheitstheorien anzunehmen.

Wenn im Diskurs eine einheitliche Definition gefordert wird, geht es allerdings weniger um diese Selbstdefinitionen ${ }^{152}$, sondern um Objektivierungsmuster, die intersubjektiv nachvollziehbar gebildet oder durch Konvention gefestigt wurden und dadurch Geltung beanspruchen können (vgl. Köller 2004: 320f.). Dieses verallgemeinernde Moment beim Definieren scheint auch im DUDENEintrag durch, wenn die Verfasser/innen schreiben: ein ,Schimmel' sei im Allgemeinen ein weißes Pferd.

Diese Lesarten des Verbs definieren werden im folgenden Kapitel mit induktiv erschlossenen „Erwartungen an die Tätigkeit des Definierens im Burnout-Diskurs“ verbunden. Erkenntnistheoretische Prämissen und Gütekriterien fachsprachlichterminologischer Definition werden im folgenden Kapitel, wenn sie sich mit den „Erwartungen an die Tätigkeit des Definierens“ überschneiden, direkt in diesen Kontexten dargelegt und diskutiert. In Kapitel 4.2.3 werden weitere wichtige theoretische Linien zur Tätigkeit des Definierens und zu Definitionen aus wissenschaftsgeschichtlicher und -theoretischer Literatur und in Kap. 4.2.4 aus linguistischer und terminologischer Forschung und Praxis referiert. Diese deduktive Herangehensweise wird mit den induktiv erarbeiteten Erwartungen der Diskursgemeinschaft an die Tätigkeit des Definierens in Texten des Burnout-Diskurses in der Arbeitsdefinition einer diskursiven Praxis des Definierens in Kap. 4.3.4 verbunden. Beide Perspektiven gehen damit in das Analysemodell einer diskursiven Praxis des Definierens (Kap. 7.2) ein.

151 Vgl. zu subjektiven Krankheits- und Gesundheitstheorien und ihrer Bedeutung für die Behandlungspraxis Birkner 2006; Birkner/Vlassenko (2015: 140ff) und Kapitel 3.2.

152 Die Geltung von Selbstdefinitionen wird in Texten des Burnout-Diskurses sogar explizit in Frage gestellt, wenn vor „der Selbstdiagnose Burn-out“ gewarnt wird (FAZ 2013b und vgl. Berger (2012, in FAZ) im QV unter 8.1.6). 


\subsubsection{Erwartungen an die Tätigkeiten des Definierens im Burnout-Diskurs (Anspruch A-F)}

Schon früh findet man in Texten des Fachdiskurses zum Thema „Burnout“ wiederholt Formulierungen, welche eine fehlende bzw. defizitäre Definition des Begriffes bzw. Phänomens >BURNOUT< konstatieren, diese aber für eine zukünftige, erfolgsversprechende Forschungstätigkeit für notwendig erachten (z. B. Meier 1984: 211f.; Enzmann/Kleiber 1989: 58, Schaufeli/Enzmann 1998: 19ff.; Rösing 2003: 64ff.; alle im QV unter 8.1.5). Der Ausdruck bzw. Begriff Burnout und mit ihm das in Frage stehende Phänomen werden dadurch zum „Definiendum“, dessen „(fachliche) Bedeutung festgelegt werden soll“ (Roelcke ${ }^{3} 2010$ : 62; vgl. auch Roelcke ${ }^{4} 2020$ : 74). Des Weiteren zeigt die Beurteilung einer Definition als defizitär, dass die jeweilige Diskursgemeinschaft Erwartungen an den Akt des Definierens, an seine Durchführung und Leistung stellt, was auf ein gemeinsames Wissen über Regeln oder die Kompetenz des Definierens schließen lässt, auch wenn jemand beim Vollzug der Definitionshandlung nicht alle „Regeln(n) vor Augen hat“ (vgl. Keller 1974: 15).

Noch 2011 konstatieren Kaschka/Korczak/Broich in einem Übersichtsbeitrag zum Thema „Burnout“ im Deutschen Ärzteblatt: „Eine allgemeingültige, international konsentierte Definition von Burn-out gibt es derzeit nicht“ (Kaschka/ Korczak/Broich 2011: 782, im QV unter 8.1.4).

Neben der Feststellung einer defizitären Definition verdeutlicht das Zitat, was die Autoren von einer Definition des Phänomens und Begriffs >BURNOUT< erwarten würden. Sie soll allgemeingültig und international konsentiert sein. In Analogie $\mathrm{zu}$ anderen klassifizierten Störungen der ICD-10, die von der WHO als allgemeingültige Krankheitsdaten ${ }^{153}$ anerkannt wurden, hieße das, einen internationalen Konsens über Kernsymptome für einen Diagnoseschlüssel zu erzielen. ${ }^{154}$ Von Interesse für die vorliegende diskurslinguistische Untersuchung ist, welche sprachlichen Mittel und Praktiken im Diskurs verwendet werden, um

153 Zum Begriff der >Daten im Vergleich zu >Fakten vgl. Felder (2013: 14) und siehe die Erläuterungen in Kapitel 2.2.1 in Fußnote 57 dieser Arbeit. Dass diese Unterscheidung auch im Bereich von `Gesundheit und `Krankheit Relevanz besitzt, sieht man an der Praxis der Gesundheitsreporte, die auf der Basis von Krankheitsdaten der Bevölkerung erstellt werden.

154 Am 27.5.2019 meldet SPIEGEL ONLINE (= hle/dpa/afp 2019, im QV unter 8.1.6): „WHO definiert Burn-out erstmals als Syndrom“. In der ICD-11, die in Deutschland voraussichtlich ab Januar 2022 gelten soll, wird „Burn-out“ wie in der ICD-10 in die Kategorie „Factors influencing health status or contact with health services“ eingegliedert (siehe https://www.who.int/mental_health/ evidence/burn-out/en/, eingesehen am 12.11.2019, im QV unter 8.1.3, WHO 5/2019), aber es wird detaillierter als dreifaktorielles Syndrom definiert (siehe auch WHO 2019b, im QV unter 8.1.3). Auf diese Definition wird in Kap. 6.2.2.2 weiter eingegangen. 
Konsens bzw. eine Reduzierung der verschiedenen Formen der Sachverhalts- und Bedeutungsfestsetzungen anzudeuten oder zu erzielen.

Im Folgenden werden Äußerungen im zunächst fachlichen, aber auch öffentlich-medialen Burnout-Diskurs analysiert, die Kritik an der Güte der jeweiligen Definition des >Burnout-Syndroms der Vermittlungs- und Medientexte in Kap. 6.2.3.1). Anhand dieser Aussagen wird induktiv herausgearbeitet, welche Kriterien definitorischer Praxis im fachlichen, aber auch öffentlichen Diskurs reflektiert und welche Erwartungen an eine (gute) Definition und damit an den Akt des Definierens als regelgeleiteten sozialen Prozess gestellt werden. Des Weiteren lassen sich daraus Hypothesen aufstellen, welche Zwecke dem Akt des Definierens von Diskursakteuren und -stimmen zuerkannt werden und welche sprachlichen Praktiken und Methoden zur diskursiven Entstehung einer Begriffsdefinition im psycho-somatischen Bereich beitragen können. Die Analyse der im Diskurs geäußerten Kriterien für erfolgreiches Definieren wird begleitet von der Frage, welche erkenntnistheoretischen Traditionen in diesen Diskurs hineinwirken und dadurch die Reflexion über die Praxis des Definierens beeinflussen.

Folgende Ansprüche an eine gute Definition bzw. begriffliche Fassung zeichnen sich in definitionskritischen Äußerungen im Burnout-Diskurs ab:

\section{A) Anspruch auf exakte und eindeutige Bestimmung oder Zuordnung}

Beispiel 1 aus dem fachinternen Diskursstrang aus dem Handwörterbuch Pädagogische Psychologie:

Der Begriff ,Burnout‘ wird also sehr unterschiedlich verwendet: Einmal als ein Syndrom, das mehrere sehr heterogene Symptome umfassen kann, zum anderen als eine mentale Störung, als der Endzustand eines Burnout-Prozesses und schließlich als Prozess selbst.

(Barth 2001: 71, Unterstreichung T.S., im QV unter 8.1.2)

Beispiel 2 aus dem fachinternen Diskursstrang aus einer Monografie zum Forschungsstand:

Ein erklärtes Ziel innerhalb des kritisch-rationalistischen Wissenschaftsparadigmas besteht darin, die Bedeutung der zentralen Begriffe eines Forschungsthemas eindeutig und durch explizite Definitionen allgemeinverbindlich - und verständlich festzulegen. Diese allgemeinverbindliche und eindeutige Begriffsfestlegung ist allerdings für den zentralen Begriff „Burnout“ im Burnoutforschungsfeld nicht gelungen. Der Begriff „Burnout“ändert seine Bedeutung, je nachdem in welchem der vielfach vertretenen theoretischen Kontexte er integriert ist. Auch ist eine fehlende Genauigkeit (Vagheit) hinsichtlich der Bedeutungszuschreibungen innerhalb verschiedener Theorienzusammenhänge zu beklagen.

(Rook 1998: 99, Unterstreichung T.S., im QV unter 8.1.5) 


\section{Beispiel 3 aus dem fachexternen Diskursstrang (Psychologie Heute compact, 27/2011)}

[...] dem Dauerstress aber mit seinen Folgen der Depression und dem körperlichem (sic!) Folgekrankheiten wird keine ICD-Diagnose gerecht. Ganz versteckt findet sich das Erschöpfungssyndrom (Burnout-Syndrom) im Anhang unter Z 73.0, aber man hat sich in diesem Diagnosemanual nicht bemüht, den Begriff genau zu definieren.

(Benkert 2011: 45, Unterstreichung T.S., im QV unter 8.1.7)

\section{Beispiel 4 aus dem fachexternen Diskursstrang (Apotheken Umschau, März 2013) \\ Burn-out: Was genau ist das?}

Die Antwort auf diese Frage spaltet die Fachwelt. Burn-out beschreibt einen chronischen körperlichen und emotionalen Erschöpfungszustand, so viel steht fest. (Mehr im Kapitel Burn-out-Symptome). Doch das Ausgebranntsein gilt offiziell nicht als eigenständige Krankheit. Und vermutlich dürfte Burn-out auch in naher Zukunft keine eindeutige medizinische Diagnose werden, glauben Fachleute. Denn es ist nicht mit umschriebenen, klar definierbaren Krankheitszeichen verbunden. Experten merken auch an, dass das Ausgebranntsein eine große Nähe zur Depression aufweist. ${ }^{155}$

(Apotheken Umschau, 5.3.2013 (= AU 2013, Unterstreichung T.S., Überschrift im Original in Fettdruck, im QV unter 8.1.7)

\section{Beispiel 5 aus dem Artikel „Modekrankheit“ in der Online-Enzyklopädie Wikipedia}

Als Modekrankheiten werden Erkrankungen mit häufig unscharf definierten Symptomen verstanden, die wie eine Mode räumlich oder zeitlich begrenzt gehäuft auftreten. [...]

Ein weiteres Beispiel ist Burn-out, was einen Zustand ausgesprochener emotionaler Erschöpfung mit reduzierter Leistungsfähigkeit bezeichnet - selbst aber nicht als Krankheit gilt. ${ }^{156}$

\section{Beispiel 6 aus dem Artikel „Wie schreibe ich gute Artikel“ in der Online-Enzyklopädie Wikipedia:}

Begriffsdefinition und Einleitung eröffnen den Artikel und leiten zum ersten Abschnitt über. [...]. Bei mehrdeutigen Benennungen ist eine Begriffsklärung sinnvoll und der Hinweis auf die Begriffsklärungsseite angebracht, damit Homonyme unterschieden werden. Der erste Satz ordnet den Gegenstand des Artikels möglichst präzise in seinen sachlichen Kontext ein.${ }^{157}$

Aus diesen Beispielen spricht das Ideal, dass die Bedeutung eines Fachausdrucks, der sich auf ein Phänomen des Bereichs psychischer Gesundheit und Krankheit oder auf einen Diagnosebegriff bezieht, exakt, eindeutig, einheitlich

155 Siehe unter http://www.apotheken-umschau.de/burnout, zuletzt eingesehen Februar 2016. 156 Siehe den Artikel Modekrankheit unter https://de.wikipedia.org/wiki/Modekrankheit (zuletzt eingesehen am 16.11.2019, Unterstreichungen bei Links und Fußnoten wurden entfernt, T.S., siehe auch im QV unter 8.1.8).

157 Online einsehbar unter: https://de.wikipedia.org/wiki/Wikipedia:Wie_schreibe_ich_gute_ Artikel\#Begriffsdefinition_und_Einleitung (zuletzt eingesehen am 23.6.2019, Unterstreichungen bei Links wurden entfernt, T.S., siehe auch im QV unter 8.1.8). 
und verbindlich innerhalb eines Begriffssystems bzw. möglichst kontextunabhängig bestimmbar sein soll (vgl. Felder 2009a: 42/43). Nach Roelcke findet man diesen Anspruch besonders im „Rahmen systemlinguistischer Fachwortschatzkonzeptionen“ (Roelcke ${ }^{3} 2010:$ 69). „Exaktheit“ und „Eindeutigkeit“158 gelten neben anderen Faktoren als ,grundsätzliche Güteeigenschaften fachsprachlicher Lexik“ (Roelcke ${ }^{4}$ 2020: 92, Hervorh. im Original entfernt, T.S.; vgl. auch Wüster ${ }^{3}$ 1991: 73ff. für den Bereich der klassischen Terminologielehre). Besonders Rook in Beispiel 2 plädiert für einen kontextunabhängigen festgelegten „Stellplatz“ des Begriffs 〉Burnout in einem durch Theorie gestützten „semantischen Teilsystem“ (vgl. Felder 2009a: 43).

Die Zustandsbeschreibung des ersten Beispiels zeigt jedoch durch die Kritik auf, dass Fachwörter in verschiedenen Ko- und Kontexten gebraucht werden,

158 Roelcke referiert und diskutiert die Güteeigenschaften „Exaktheit“ und „Eindeutigkeit“ vor dem Hintergrund verschiedener Fachsprachenmodelle (Roelcke ${ }^{4} 2020$ : 92ff.). Unter „Exaktheit“ sei „im Allgemeinen ein möglichst adäquater Bezug fachsprachlicher Ausdrücke zu den Gegenständen, Sachverhalten und Vorgängen des betreffenden menschlichen Tätigkeitsbereichs zu verstehen“ (Roelcke ${ }^{3}$ 2010: 69; vgl. Roelcke ${ }^{4}$ 2020: 93). „Eindeutigkeit und Eineindeutigkeit“ von Fachwörtern bestehe „im Unterschied zu deren Exaktheit“ hingegen „nicht im Bezug zu den Gegebenheiten des betreffenden Faches selbst“, sie bezögen sich vielmehr auf „das Verhältnis von fachlichen Ausdrücken und Bedeutungen [...]. Der älteren, dem systemlinguistischen Inventarmodell verpflichteten Fachsprachenforschung nach“ wiesen „Fachwörter eines Fachwortschatzsystems jeweils genau eine Bedeutung auf (Monosemie), die selbst wiederum allein von diesem Wort repräsentiert wird (Heteronymie)“ (ebd.: 71). Roelcke geht zudem noch auf die Güteeigenschaft der „Eigentlichkeit“ ein, bei der „die semantische Intension des Zeichens und dessen Extension in einem angemessenen Verhältnis zueinander stehen“ sollen (Roelcke 42020: 93). Bei Roelcke (ebd.: 93ff.) findet man eine Zusammenfassung, wie diese drei Gütekriterien in verschiedenen fachsprachlichen Modellen in durchaus kontroverser Weise aufgefasst wurden (im „systemlinguistische[n] Inventarmodell“, im „pragmalinguistische[n] Kontextmodell“ und im „kognitionslinguistische[n] Funktionsmodell“, ebd.). Die Güteeigenschaften „Exaktheit“ und „Eindeutigkeit“ werden hier zusammen aufgeführt, da sie einerseits eng zusammenhängen und andererseits in den analysierten Belegen des Burnout-Diskurses nicht immer deutlich voneinander getrennt, sondern zusammen gefordert werden. Die Unterscheidung dieser Begriffe soll trotzdem beibehalten werden, da mit ihnen verschiedene Ansprüche an den Akt des Definierens einhergehen. 'Eindeutigkeit' soll beispielsweise vor Missverständnissen schützen, sagt aber nichts über das Verhältnis zwischen Sprache und Welt aus. Mit 'Exaktheit' hingegen wird zudem das Verhältnis zwischen Fachausdruck und außersprachlicher Wirklichkeit bewertet. Das Gütekriterium der semantischen 'Eigentlichkeit' hängt mit dem Kriterium der 'Exaktheit' des Fachausdrucks eng zusammen. 'Eigentlichkeit' beurteilt die „Relation zwischen Bedeutung und Gegenstand“ (ebd.). Es geht bei den Gütekriterien 'Exaktheit' und 'Eigentlichkeit' um die Frage, wie exakt und adäquat Ausdruck und Bedeutung den zu definierenden Gegenstand erfassen. Diese Güteeigenschaften werden in Abschnitt „D“ in diesem Kapitel: „Anspruch auf Adäquatheit zwischen Definiens und Definiendum“ noch eingehender beleuchtet. 
wodurch „deren systematische Exaktheit [...] jeweils modifiziert und differenziert“ wird (Roelcke ${ }^{4} 2020$ : 70). Felder spricht in diesem Zusammenhang von dem „trügerischen Eindruck, dass die speziell definierten Fachbegriffe bereits im isolierten Terminus und nicht erst im Satz einen möglichen Sinn erhalten würden“ (Felder 2009a: 43, Hervorh. im Original). Untersuchungen zu verschiedenen wissenschaftlichen Fachsprachen haben gezeigt, dass man in Fachtexten häufig „systematische Vagheit bei kontextueller Exaktheit“ (Roelcke $\left.{ }^{4} 2020: 95\right)$ sowie Synonymie und Polysemie findet (vgl. Roelcke ${ }^{4} 2020$ : $97 \mathrm{ff}$.) ${ }^{159}$ und dass diese für einen dynamischen, multiperspektivischen fachwissenschaftlichen Austausch stünden (vgl. Temmerman 2000: 14 und 132ff.; vgl. Baumann 1998: 374; vgl. Müller/Mell 2020: 193f.). „[S]ystematische Vagheit“ sowie Polysemie und Synonymie von Fachwörtern seien sogar notwendig „für die Herstellung situativ jeweils unterschiedlicher kontextueller Exaktheit“ und Eindeutigkeit innerhalb einzelner fachlicher Äußerungen (Roelcke ${ }^{3} 2010$ : 70ff.; vgl. Köller 2004: 327). Sie erfüllen spezifische Zwecke in Fachdiskursen:

Polysemy is functional in specialised discourse. It is a consequence of changes over a period of time. The search for more profound understanding and the constant discussion over how to name what one knows and understands and what words mean is in the discourse of a community and is a process in time. Polysemy is the result. Even when there is univocity at one time, polysemy may develop depending on the type of category and how it is understood.

(Temmerman 2000: 133)

Eine kognitiv-kommunikative Erklärung für systematische Vagheit und Mehrmehrdeutigkeit bei kontextueller Exaktheit und Eindeutigkeit kann nach Roelcke ( ${ }^{2} 2020:$ 95ff.) ein kognitionslinguistisches Funktionsmodell geben, das davon ausgeht, dass , auch und gerade fachliche Kognition und Kommunikation assoziativ erfolgen“ (ebd.: 95f.). Die Vagheit bzw. Mehrmehrdeutigkeit von Fachwörtern ermögliche „kon- und kotextabhängige Variation“ durch assoziierende Bedeutungs- oder Bezeichnungsvariationen, wodurch wiederum an die spezifische Situation angepasste exakte und eindeutige Ausdrucksweisen gefunden werden könnten (ebd.: 96 und 99). Müller/Mell beschreiben zudem am Beispiel der Bioethikdebatte, dass sich durch spezifische Kombinationen alltags- und fach-

159 Dabei wird in unterschiedlichen Publikationen auf die Unterschiede zwischen technischen und anderen Disziplinen hingewiesen. Fraas schreibt zum Beispiel: „So kann man davon ausgehen, daß Fachwortschätze technischer Disziplinen wesentlich strenger organisiert sind als die Lexik der Geisteswissenschaften“ (Fraas 1998: 428f.; vgl. auch Müller/Mell 2020: 202). 
sprachlicher Ausdrücke für fast jede typische Kommunikationssituation „eine Art neuer Mikrofachsprache“ herausbilden würde (Müller/Mell 2020: 201). ${ }^{160}$

Vor diesem Hintergrund erscheint es sinnvoll und funktional, dass je nach Kontext mit dem Begriff >Burnout eher die Bedeutung 'Prozess' oder 'Endzustand' motiviert wird und dass die Definition für `Burnout dadurch im ersten Fall genetisch, im zweiten eher beschreibend und im dritten Fall mit Bezug auf ein Klassifikationssystem begriffshierarchisch erfolgt. Beispiel 1 zeigt darüber hinaus, dass auch die Kategorisierungen über Hyperonyme oder nächsthöhere Gattungsbegriffe (genus proximum) als Syndrom oder mentale Störung unterschiedlich ausfallen. Dennoch wird der Anspruch einer einheitlichen begrifflichen Verwendungsweise sowohl im Fachdiskurs als auch im medial-öffentlichen Diskurs wiederholt erhoben. ${ }^{161}$ Dies spricht für das Ziel, eine gemeinsame Verständigungsbasis herzustellen und die Wissenskonstituierung zu diesem Gegenstand $\mathrm{zu}$ kontrollieren ${ }^{162}$, beispielsweise durch Praktiken des (expliziten) Zuordnens zum Zweck der Sachverhalts- und Bedeutungsverknüpfung und -fixierung sowie durch Praktiken der Vereinheitlichung, Variantenreduktion und Konsensualisierung. Nicht nur im wissenschaftlichen, sondern auch im öffentlichen Bereich - wie das dritte und vierte Beispiel aus „Psychologie Heute“ und „Apotheken Umschau“ zeigen - sind dies wesentliche Zwecke von Definitionen. So stehen Äußerungen über die Unübersichtlichkeit des Diskurses rund um das Thema „Burnout“ und die nachdrückliche Forderung nach einer Definition dieses Begriffs in engem Wechselverhältnis.

Mit der Forderung nach Exaktheit und Eindeutigkeit geht der Anspruch einher, den (Diagnose-)Begriff und das Phänomen von anderen benachbarten Begriffen/Phänomenen deutlich abgrenzen zu können, was wiederum die eigenständige Existenz als Begriff und/oder Gegenstand gewährleisten soll.

160 Weitere Ursachen für Mehrmehrdeutigkeit (Polysemie und Synonymie) im fachsprachlichen Bereich sind nach Roelcke ( $\left.{ }^{4} 2020: 99\right)$, der steigende Benennungsbedarf innerhalb einzelner Fächer“, „innerfachliche Konzeptions- und Meinungsvielfalt“, „fachsprachliche Interferenzen“, „verschiedene Kommunikationstypen oder Textsorten“ (vgl. hierzu auch Sager 1990: 101) und „semantische Kämpfe“ (vgl. Felder 2006b).

161 Kaschka/Korczak/Broich 2011: 786, Dt. Ärztebl.; Berger/Falkai/Maier 2012: 1366, Dt. Ärztebl., bisher alle Belege im QV unter 8.1.4; Kleinschmidt 2014, DIE ZEIT und Albrecht 2011a, Die ZEIT im QV unter 8.1.6.

162 Definitionen stehen für eine offensichtliche Form des Sich-vor-Augen-Führens von deklarativem Wissen. Wissensbestände können nach Müller „in fachsprachlichen Zusammenhängen durch Definitionen intersubjektiv vereindeutigt und präzisiert werden“ (vgl. Müller 2007: 58). Müller bezieht sich dabei auf Köllers Definition von `Gegenstandswissen`: „Als Gegenstandswissen lassen sich alle Wissensbestände bezeichnen, die wir uns in Form von Propositionen bzw. deklarativen Sätzen präsent machen können und die mithilfe von Definitionen kontrollierbar sind“ (Köller 2004: 250, Hervorhebung im Original). 


\section{B) Anspruch auf Trennschärfe und Deutlichkeit}

\section{Beispiel 1 aus dem frühen fachinternen Diskurs in einem Übersichtsartikel:}

The diversity of burnout cases, definitions and symptoms has contributed to confusion about the separateness of burnout from other related constructs. If the relationship between burnout and constructs like depression and job satisfaction are too high, then the construct of burnout may be just a new name of an old idea.

(Meier 1984: 211/212, Unterstreichung T.S., im QV unter 8.1.5)

\section{Beispiel 2 aus dem späteren fachinternen Diskurs in einem Übersichtsartikel:}

In der jüngeren medialen Berichterstattung scheint der Begriff „Erschöpfung“ omnipräsent zu sein, [...]. Die häufigste Beobachtung aus wissenschaftlicher Perspektive ist aber dabei, dass die Verwendung des Begriffs einer Beliebigkeit unterliegt, die Ihresgleichen sucht. [...] Dieser Artikel soll dazu dienen, die Beschreibung von Erschöpfung im Rahmen verschiedener Syndrome und Krankheiten näher zu beleuchten und damit Gemeinsamkeiten sowie Unterschiede aufzuzeigen, die es erlauben, verschiedene Syndrome voneinander abzugrenzen. ${ }^{163}$ (Dörr/Nater 2013: 69f., PPmP, im QV unter 8.1.4, Unterstreichung T.S.)

\section{Beispiel 3 aus dem medialen Diskurs (SPIEGEL 6/2012):}

Trotzdem verfolgt Berger mit Sorge, welch ein Eigenleben der Begriff Burnout jetzt entwickelt. [...]. Und all das, obwohl Burnout im medizinischen Sinne gar keine Diagnose ist, sondern allenfalls ein anderes Wort für Depression. Der Volksmund aber interpretiert das völlig anders und versteht darunter eine scheinbar neue und eigenständige Krankheit [...].“

(Blech 2012: 124f., DER SPIEGEL, im QV unter 8.1.6, Unterstreichung T.S.)

\section{Beispiel 4 aus dem Artikel „Burnout“ in der Online-Enzyklopädie Wikipedia:}

Die Symptomatik wird allerdings uneinheitlich beschrieben - Burisch identifizierte mehr als 130 Symptome - und überlappt mit der diverser anderer Störungsbilder (z. B. Depression). ${ }^{164}$

\section{Beispiel 5 aus dem medialen Diskurs (SPIEGEL ONLINE, 15.11.2011):}

Burnout an und für sich, also das wirklich ausdefinierte Krankheitsbild, gebe es doch gar nicht, sagte Tim Mälzer mehrfach. Ganz klar unterschied nur er zwischen Dingen, wie er sie erlebt hat, und anderen individuellen Zusammenbrüchen mit anderen Gründen.

(Patalong 2011, SPIEGEL ONLINE, im QV unter 8.1.6, Unterstreichung T.S)

163 Auch Wilms/Borcsa (2009) attestieren Autorinnen und Autoren, die aus fachlicher Perspektive über das Burnout-Phänomen schreiben, ,ein großes Bedürfnis [...], sich durch Klärung der Begrifflichkeit auch von etwas abzugrenzen“ im Vorwort zu einem Themenheft zu >Burnout in der Fachzeitschrift PID (im QV unter 8.1.4).

164 Der Artikel ist einsehbar unter https://de.wikipedia.org/wiki/Burn-out in der Version vom 4.4.2018 (Unterstreichungen bei Links wurden entfernt, T.S., siehe auch im QV unter 8.1.8). 


\section{Beispiel 6, DIE ZEIT (Online-Ausgabe), 08.12.2011:}

Die Mindestforderung der wissenschaftlichen Medizin an ein Syndrom, nämlich es spezifisch, von anderen abgrenzbar zu definieren, wurde bislang nicht erfüllt. Bis auf Weiteres bleibt Burn-out deshalb ein schillerndes Phänomen, das sehr häufig gesichtet wird, ohne dass jemand zu sagen weiß, um was genau es sich dabei handeln soll.

(= Pawelzik 2011, DIE ZEIT, im QV unter 8.1.6, Unterstreichung T.S.)

\section{Beispiel 7, FAZ, 06.10.2010, Nr. 232, S. N1:}

Jeder hat ein intuitives Verständnis davon, aber weder die internationale Klassifikation der Krankheiten noch das „Diagnostische und Statistische Handbuch psychischer Störungen“ listen Burnout als eigenständige Erkrankung. Es fehlt auch ein allgemein anerkanntes Instrument, um die Störung von anderen Krankheiten, etwa der Depression und den Angsterkrankungen, abzugrenzen. Trotzdem wird sie laufend diagnostiziert.

(Kaulen 2010, FAZ, im QV unter 8.1.6, Unterstreichung T.S.)

Alle Beispiele thematisieren die semantische Nähe zwischen dem Konzept >Burnout und anderen „Zusammenbrüchen“ bzw. medizinisch-psychologischen Konzepten wie >depression/Depression`, ১job satisfaction/Arbeitszufriedenheit` und die bei Dörr/Nater (2013) im weiteren Kontext zusätzlich besprochenen Konzepte $>$ Neurasthenie $<$ und $>$ chronic fatigue syndrome (vgl. Dörr/Nater 2013, PPmP, im QV unter 8.1.4). Dabei geht es jeweils auch um die Frage, ob hinter dem Ausdruck Burnout ein 'eigenständiges', 'neues' Konzept/Phänomen steht oder ob er ,nur' eine Bezeichnungskonkurrenz zu Depression, chronischer Erschöpfung oder Neurasthenie darstellt. ${ }^{165}$ Wenn versucht wird, wie im zweiten Beispiel gefordert, diese pathologischen Phänomene voneinander abzugrenzen, dann geht es auch um die Frage, welchen Platz die Phänomene jeweils zum sog. >Normalzustand einnehmen. Diese strukturierende Funktion leisten beispielsweise sprachliche Praktiken der Quantifizierung oder Gradierung (vgl. dazu die Analysen in den Kapiteln 6.2.2.1-6.2.3.3), indem sie Eigenschaften oder Auffälligkeiten einen Platz auf einer Skala zuweisen. Das Symptom der `Erschöpfung ‘ wird in den Beschreibungen des Burnout-Syndroms überwiegend durch Adjektive wie totale, anhaltende, völlige oder Phrasen wie Bedürfnis nach immer mehr Ruhepausen gesteigert und dadurch von der ‘normalen’ Erschöpfung oder einer Belastungsepisode

165 Die Frage, ob eine Definition zur Bildung eines neuen Begriffs beitragen bzw. ein neues (empirisches) Phänomen umgrenzen sollte (D. im engeren Sinn) oder ob sie auch ,nur` eine alternative, exaktere „Explikation“/ Bezeichnung für einen gegebenen Begriff darstellen kann (D. im weiteren Sinn), findet sich an verschiedenen Stellen in der Literatur über den Begriff der >Definition ‘. (Vgl. die vierstellige Unterscheidung bei Kant in der Kritik der reinen Vernunft (Kant, KrV B 755 ff.); auch Groeben/Westermeyer unterscheiden zwischen `Definition « und `Explikation in ihrer Monografie zu „Kriterien psychologischer Forschung“(Groeben/Westmeyer 1975: 50ff.).) 
durch >Stress` abgegrenzt. Eine weitere Abgrenzung nach oben hin $\mathrm{zu}$ einem noch schwerwiegenderen Erschöpfungssyndrom ist durch die nicht mehr weiter zu steigernden Zustandsprädikatoren völlig und total allerdings kaum möglich.

Welche Bedeutung die Frage der Eigenständigkeit bzw. Spezifik des Gegenstandes und Konzeptes >BuRNOUT< besitzt, zeigen darüber hinaus Studien im Fachdiskurs, die überprüfen, inwiefern Messdaten konstruktnaher und konstruktferner Testverfahren mit den Daten von Burnout-Messinstrumenten korrelieren (Büssing/Perrar 1992; Demerouti/Nachreiner 1996, beide im QV unter 8.1.5; Neubach/Schmidt 2000; Reime/Steiner 2001, beide im QV unter 8.1.4). Dieser Anspruch, die zu erforschenden Phänomene voneinander deutlich abzugrenzen, geht einher mit der Forderung nach Wohlumgrenztheit. ${ }^{166}$

\section{C) Anspruch auf angemessene Umgrenztheit durch die Konzentration auf wesentliche bzw. grundlegende Faktoren}

\section{Beispiel 1 aus dem fachinternen Diskursstrang aus einem Kompendium zum Status quo der Burnout-Forschung 1998 von Schaufeli/Enzmann}

In most early writings burnout was 'defined' by merely summing up its symptoms [...]. Such laundry $\underline{\text { lists }}^{167}$ are problematic since they are inevitably selective. Clearly, it is quite impossible to include all symptoms of burnout into one definition! In addition, by listing

166 Diese Kriterien der Eindeutigkeit, Exaktheit, Distinktheit, Wohlumgrenztheit und damit auch Klarheit im Moment der Vergegenwärtigung einer Idee oder eines Begriffs haben lange Tradition in der europäischen Erkenntnistheorie. Besonders deutlich formuliert sie Descartes in seinen „Principia philosophiae“ mit der Doppelformel zu „Klarheit und Deutlichkeit“, die auch in seinen Meditationen argumentativ von Bedeutung ist: „Denn zu einer Wahrnehmung, auf die ein sicheres und unzweifelhaftes Urteil gestützt werden kann, ist nicht nur erforderlich, dass sie klar ist, sondern auch, dass sie deutlich ist. Klar nenne ich die Wahrnehmung, die dem aufmerksamen Geist präsent und offenkundig ist, [...]. Deutlich nenne ich aber die Wahrnehmung, die, wenn sie klar ist, von allen anderen so getrennt und präzise ist, dass sie überhaupt nichts anderes enthält als das, was klar ist“ (Principia philosophiae I, art. 45, in der Übersetzung und zitiert nach Descartes 2004: 273). Diese beiden Kriterien seien die Grundvoraussetzungen wahrer Erkenntnis. Dass im Burnout-Diskurs diese erkenntnistheoretischen Kriterien eingefordert werden, spricht für die Annahme, dass Diskurse - hier auf der einen Seite der Diskurs über Erkenntnistheorie und auf der anderen Seite der Diskurs über das Phänomen BURNOUT - symbolisch miteinander vermittelt sind. Die Kriterien der Eindeutigkeit, Exaktheit und Distinktheit spielen auch eine wichtige Rolle in der klassischen Terminologielehre, siehe Kapitel 4.2.4.

167 "laundry list" wird informell im amerikanischen Englisch gebraucht für "a lengthy, inclusive list of data, matters for consideration, etc., often one regarded as unorganized or showing a lack of necessary selectiveness." American English Dictionary von Collins, siehe: http://www. collinsdictionary.com/dictionary/american/laundry-list, (zuletzt eingesehen am 16.11.2019). 
symptoms a rather static picture emerges of burnout as a particular negative mental state instead of a process that develops over time. In principle the first drawback can be avoided by selecting the most characteristic core symptoms of burnout as is done in so called state definitions. The second drawback can be avoided by describing the dynamic process of the burnout syndrome, as is done in so called process definitions.

(Schaufeli/Enzmann 1998: 31, im QV unter 8.1.5, Unterstreichung T.S.)

Beispiel 2 aus dem fachinternen/fachexternen Diskursstrang aus einem Übersichtswerk von M. Burisch, das sich an Fachleute und interessierte Laien wendet

Das schwerwiegendste Hindernis für eine fundierte Erforschung des Burnout-Syndroms stellte zweifellos das Fehlen einer handhabbaren Definition dar, die überzeugen könnte (Maslach 1982b). Alle einschlägigen Versuche waren entweder zu umfassend oder zu spezifisch, was anfangs aus der damals überwiegenden Orientierung auf rasche Interventionen zu erklären war.

(Burisch ${ }^{5}$ 2014: 14, im QV unter 8.1.6, Unterstreichung T.S.)

Beispiel 3 aus dem fachexternen Diskursstrang aus der FAZ vom 16.03.2012, Gastbeitrag eines Facharztes

Was die Diagnose-Frage anbelangt: [...] derzeit werden mehr als 130 mögliche Burn-outSymptome diskutiert, keines davon sei obligat.

(Hillert 2012: 65, FAZ, im QV unter 8.1.6, Unterstreichung T.S.)

\section{Beispiel 4 aus einer Pressemitteilung des Vorstandsvorsitzenden der „Deutschen De- pressionshilfe“}

Der Begriff Burnout ist nicht klar definiert und in den maßgeblichen internationalen Klassifikationssystemen gibt es keine Diagnose Burnout. Entsprechend liegen für die bunten psychischen Störungen, die alle unter Burnout zusammengefasst werden, auch keine Behandlungen mit Wirksamkeitsbelegen aus methodisch guten Studien vor.

(Hegerl/Stiftung Deutsche Depressionshilfe 2011: 1, im QV unter 8.1.9, Unterstreichung T.S.)

\section{Beispiel 5 aus dem Artikel „Wie schreibe ich gute Artikel“ in der Online-Enzyklopädie} Wikipedia

Begriffsdefinition und Einleitung eröffnen den Artikel und leiten zum ersten Abschnitt über. Sie sollen das Lemma als Bezeichnung klären und den Begriff in seiner Grundbedeutung erläutern.[...].

Unmittelbar darauf sollte eine kurze Einleitung mit einer Zusammenfassung der wichtigsten Aspekte des Artikelinhalts folgen. Die Einleitung soll einen kurzen Überblick über das Thema ermöglichen und das Lemma in Grundzügen erklären. [...] $]^{168}$

Das erste Beispiel von Wilmar Schaufeli und Dirk Enzmann stellt verschiedene Definitionspraktiken/-methoden einander gegenüber und bewertet sie im Hin-

168 Online einsehbar unter: https://de.wikipedia.org/wiki/Wikipedia:Wie_schreibe_ich_gute_ Artikel\#Begriffsdefinition_und_Einleitung (zuletzt eingesehen am 23.6.2019, im QV unter 8.1.8, Unterstreichungen als Markierung von Links im Original). 
blick auf ihre perspektivierenden Wirkungen: Eine mehr oder weniger lange, ungeordnete Aufzählung der Symptome sei unvermeidlich selektiv und dadurch problematisch. In Beispiel 3, dem Gastbeitrag eines Facharztes in der FAZ, wird in diesem Zusammenhang zudem das Problem angesprochen, wie man zu ,obligaten“ oder anders ausgedrückt notwendigen und hinreichenden definitorischen Merkmalen gelange. In den Belegen scheinen sich verschiedene Ansichten zu kreuzen, die im Fall der notwendigen und hinreichenden Bedingungen in Beleg 3 auf die strukturalistisch begriffslogisch geprägte Tradition der Merkmalssemantik verweisen (vgl. Busse 2009: 41-49). Die Forderung von Schaufeli/Enzmann (1998: 31, siehe Beispiel 1), dass „state definitions“ die „most characteristic core symptoms“ auswählen und präsentieren sollten, schließt wiederum an Beobachtungen prototypischer Semantiktheorien an (vgl. im Überblick Busse 2009: 49-59).

Matthias Burisch hat sich mit Symptomlisten verschiedener Autorinnen und Autoren in seiner mehrfach aufgelegten Monografie zum Burnout-Syndrom eingehend befasst. Das obige Zitat verdeutlicht, dass eine handhabbare Definition nach Burisch auf ein Konzept mittlerer Abstraktion zurückgreifen sollte. Im Hinblick auf das Ziel, über die Definition eine Verständigungsbasis zu schaffen, erscheint es sinnvoll, dass je nach Adressatengruppe unterschiedliche Abstraktionsgrade angewendet werden. Eine vergleichbare Variation zwischen Abstraktion und Konkretisierung hat Andreas Liebert für die Verwendung metaphorischer Modelle in wissenschaftlichen und populärwissenschaftlichen Texten festgestellt. Liebert zeichnet durch den Vergleich von Metaphernmodellen in Texten im „Übergangsfeld ,Fach Nichtfach““ zum Aids-Virus nach, dass die „weniger fachlichen Texte“ an den ,abstrakte[n] Schemata (Protometaphern)“ der eher fachlichen Texte ansetzen und je nach Adressat „in eine bestimmte semantische ,Richtung“ expliziert“ und dadurch „taxonomisch auf der [...] subordinierten Ebene“ angesiedelt werden (vgl. Liebert 1996: 808f.).

Der nächste Kritikpunkt in Äußerungen von Diskursakteuren und -akteurinnen über begriffliche Fassungen bzw. Definitionen des BuRnouT-Syndroms berührt die Frage, welche Größen zueinander darin in Beziehung gesetzt werden und wie adäquat diese Zuordnung ist.

\section{D) Anspruch auf Adäquatheit zwischen Definiens und Definiendum}

Beispiel 1 aus dem fachinternen/fachexternen Diskursstrang aus einem Übersichtswerk von Burisch, das sich an Fachleute und interessierte Laien wendet

Bei genauerem Hinsehen erweist sich die Metapher »Burnout« übrigens als nicht allzu treffend, selbst dann, wenn man das Wort mit »Durchbrennen« übersetzte, was korrekter wäre. Durchbrennen können Sicherungen oder Stromleitungen, aber beides geschieht abrupt, 
und der Effekt ist sofortiger Stillstand, nicht die oft jahrelange Quälerei des Burnout. [...]. Was dagegen psychologisch-metaphorisch mit Burnout gemeint ist, ist eine lang dauernde zu hohe Energieabgabe für zu geringe Wirkung bei ungenügendem Energienachschub etwa so, als wenn eine Autobatterie nicht mehr über die Lichtmaschine nachgeladen wird, dennoch aber Höchstleistungen abgeben soll. [...] Die deutsche Redewendung »die Kerze an beiden Enden anzünden « käme der Sache nahe, ist aber umständlich und trifft ebenfalls nicht den Kern der Sache. »Innere Erschöpfung« wäre gar nicht schlecht, klingt aber zu wenig prägnant. Bleiben wir also bei Burnout.

(Burisch ${ }^{5}$ 2014: 9-10, im QV unter 8.1.5; Unterstreichungen T.S.)

\section{Beispiel 2 aus dem fachinternen Diskursstrang aus einer Studie der Fachzeitschrift „Psychologie in Erziehung und Unterricht“"}

Die Vielzahl dieser antezedenten Merkmale wird praktischerweise in der Metapher zusammengefasst: „Ein Mensch muß ,entflammt‘ gewesen sein, um ausbrennen zu können“ (Pines, Aronson \& Kafry, 1981, dt. 1992, S. 13). Die Metapher benutzen seither - zumindest als Subtext - so gut wie alle Autoren, die sich mit dem Anfangszustand des Ausbrennens befassen. Über ein Jahrzehnt danach und später wird die Metapher tradiert, u. a. von Rohner [...], der sie auf Lehrpersonen bezieht: „Ausbrennen kann nur, wer einmal Feuer gefangen hat.“ Aber gerade bei Lehrpersonen haben wir die Beobachtung gemacht, daß diejenigen, die sich für ihren Beruf und für ihre Schüler begeistern können, eben nicht ausbrennen. (...). So besteht erheblicher Zweifel an der Gültigkeit der genannten Metapher.

(Schmitz/Leidl 1999: 302f., PiEU, im QV unter 8.1.4; Unterstreichungen T.S.)

\section{Beispiel 3 aus einer Broschüre der IG-Metall für Betriebsräte zum Thema „Burnout“}

Um die Symptomatik zu veranschaulichen, wird gern der Motorsport herangezogen, bei dem es Burnout tatsächlich gibt: Die Räder drehen bei angezogener Bremse durch, der Motor läuft auf Hochtouren und alle Bauteile drohen zu verschleißen.

Der Akku läuft leer [Zwischenüberschrift, Fettdruck entfernt T.S.]

Andere sagen: Jemand fährt auf seinen Felgen oder an seinem Limit, steht ständig unter Strom und fühlt sich gleichzeitig wie gelähmt. Dr. Dagmar Ruhwandl, Fachärztin für Psychiatrie und Psychotherapie und Lehrbeauftragte an der Technischen Universität München, greift auf das Beispiel des Akkus zurück: Der Akku ist leer oder lässt sich womöglich nicht mehr aufladen.

Wie auch immer: Jeder Mensch hat begrenzte Kräfte und wenn die bis zum Äußersten ausgereizt sind, ziehen Körper und Seele die Reißleine.

(IG-Metall/Böhm 2011: 6, im QV unter 8.1.9, Unterstreichungen T.S.)

Im fachexternen Diskurs finden sich insgesamt weniger Beispiele, in denen die Adäquatheit verschiedener Metaphern zur definitorischen Beschreibung der Symptome kritisiert oder bewertet wird, aber es finden sich Beispiele, die die Adäquatheit des Hyperonyms Krankheit/Erkrankung - mit Bezug auf Stimmen im Fachdiskurs - und Krankheitsbezeichnungen, die „eine angenommene Ursache“ (AU 2011b) im Namen tragen, in Frage stellen: 


\section{Beispiel 4 aus FAZ.NET vom 8.3.2010}

[...] Im strikten Sinn handelt es sich beim Burnout-Syndrom um keine Krankheit, sondern um einen „Zustand körperlicher, psychischer und geistiger Erschöpfung, der durch normale Erholungszeiten nicht mehr kompensiert werden kann“, wie der Frankfurter Psychoanalytiker Hansjörg Becker erklärt. (= Meck 2010, FAZ, im QV unter 8.1.6, Unterstreichungen T.S.)

\section{Beispiel 5 aus dem fachexternen Diskursstrang aus der FAZ vom 16.3.2012, Gastbei- trag eines Facharztes}

Was die Diagnose-Frage anbelangt: Der Psychotherapeut Herbert Freudenberger 'entdeckte' Burn-out 1974 nach sehr langen Arbeitstagen ... an sich selber. Er ging davon aus, dass Burn-out keine Erkrankung, sondern ein aus Überlastungen resultierendes Phänomen eigener Art und die Symptomatik bei jedem anders sei. Eine medizinische Diagnose setzt klare Kriterien voraus; [...] Auch das Postulat einer spezifischen Burn-out-Entwicklung (,nur wer entflammt war ... "), lies [sic!] sich empirisch nicht bestätigen. Im Gegenteil: Wer mit viel Spaß und genügend Ellenbogen im Beruf steht, der hat gute Chancen, sich nach Jahren ebenso wohl zu fühlen - und umgekehrt!

(Hillert 2012: 65, Unterstreichung T.S.)

\section{Beispiel 6 von www.apotheken-umschau.de vom 02.03.2011 (abgerufen am 24.11.2012)}

Sowohl der Begriff „Burnout-Syndrom“ als auch „Erschöpfungsdepression“ sind problematisch, weil man bereits mit der Bezeichnung des Zustandes eine angenommene Ursache in den Vordergrund stellt.

Es ist aber bekannt, dass meist vielfältige Ursachen bei der Entstehung einer Depression berücksichtigt werden müssen und nicht eine Ursache allein in den Vordergrund gestellt werden soll.

(= AU 2011b, im QV unter 8.1.7, Unterstreichungen T.S.)

In den Beispielen 1, 2 und 5 wird kritisiert, dass die Metapher >Burnout und damit einhergehende Bedeutungsaspekte, Interpretationsperspektiven und Verknüpfungen zu anderen Zeichenobjekten bzw. Sachverhalten zu einer Konstruktannahme führen, die nicht der beobachteten und erlebten ,Wirklichkeit‘ entspricht bzw. in bestimmten Merkmalen zu wenig Ähnlichkeit mit ihr aufweise und dadurch die Güteeigenschaften der Exaktheit und Eigentlichkeit (vgl. Anspruch A) nicht erfülle. Kern der Kritik ist, dass durch das ikonisch-metaphorische Zeichen ein Konzept und mit ihm Attribute aufgerufen werden, die zu sinnlichen Eindrücken des Phänomens zu wenig Ähnlichkeit aufweisen oder sogar in Widerspruch dazu stehen (vgl. Kap. 2.2.2). Die Beziehung zwischen Repräsentiertem und Repräsentierendem wird als inadäquat bewertet. Anhand welcher Kriterien die Adäquatheit dieser Relation beurteilt wird, hängt davon ab, „ob man Repräsentationsfunktionen [...] ontologisch oder funktional, statisch oder dynamisch, kausal oder konventionell“ verankert (Köller 2004: 220). Die in den Beispielen vorgetragene Kritik scheint ontologische Maßstäbe anzulegen. Denn es wird die Annahme impliziert, dass es ein „ontologisch autonom[es]“ Objekt gebe, das (inter)subjektiv wahrnehmbar sei und für das die angemessene Übersetzung bzw. 
„Transkription“ gefunden werden müsse. ${ }^{169}$ Die in den Beispiel 4 und 5 sichtbar werdende Kritik stützt sich hingegen auf Maßstäbe, die im Fach per Konvention gelten, damit von einer Krankheit gesprochen werden kann. Wenn diese nicht erfüllt sind, dann wird dieses Hyperonym für den Begriff `Burnout` zurückgewiesen (vgl. dazu Kap. 6.2.2.2; 6.2.3.1 und 7.3). In Beispiel 6 wird kritisiert, dass der zu definierende Ausdruck schon eine Annahme über die Ätiologie des Symptombildes transportiere, die jedoch in ihrer Monokausalität als inadäquat zurückgewiesen wird.

In diesen Beispielen wird nicht nur das durch die Metapher konstituierte Verhältnis zwischen Sprache und Welt reflektiert, sondern auch innersprachliche Beziehungsgefüge werden hinsichtlich ihrer Exaktheit bzw. Adäquatheit beurteilt. Wenn Burisch schreibt, durchbrennen können Sicherungen und Stromleitungen, so verweist er auf Kookkurrenzpartner des Verbs durchbrennen ${ }^{170}$, die als Subjektkomplemente zu den im Diskurs referierten PERSONEN, DIE DURCHODER AUSBRENNEN, in einem paradigmatischen Beziehungsgefüge stehen und deren denotative und konnotative Aspekte ('Plötzlichkeit des Geschehens') sich auf die 'neue' Verwendungsweise ,unsachgemäß' auswirkten. Schmitz und Leidl verweisen mit ihrer Kritik an der metaphorischen Implikation ein Mensch muss entflammt gewesen sein, um ausbrennen zu können ebenfalls auf sprachimmanente Kohäsionsstrukturen. Denn zum einen indiziert das Verb ausbrennen semantisch-ontologisch, dass etwas 'begonnen hat zu brennen'. Zum anderen

169 Nach Ludwig Jäger (2012a: 312) beruht diese Annahme auf der Vorstellung, dass ,Transkription“ als ein „sekundäres[s] Verfahren oder Verfahrensprodukt“ angesehen wird, das sich auf ein „vorgängige[s] Bezugsobjekt“ bezieht, das „ontologisch selbstständig“ ist und von „allen möglichen Formen der Transkription unberührt und durch verschiedene Transkriptionen hindurch mit sich identisch“ bleibt. Andreas Gardt führt diese Denktradition auf das „Axiom vom Primat der Dinge“ zurück (Gardt 1999: 465). Der zeichen- und medientheoretische Begriff der Transkription Jägers relativiert „die Idee eines von seiner medialen Realisierungsgestalt unabhängigen, ,ursprünglichen“ [...] Einfalls“, Ereignisses oder „Originals“. Diese würden der Transkription zwar vorausgehen. Jedoch erst durch die Transkription erhielten sie den Status von „Skripte[n]/ Präskripte[n]“ (Jäger 2012a: 312). In den unter „D) Anspruch auf Adäquatheit zwischen Definiens und Definiendum“ zitierten Diskursausschnitten erscheint das >Definieren als sekundäres, transkribierendes Verfahren eines ontologisch selbstständigen Phänomens, das empirisch erlebbar und mit geeigneten Methoden nachweisbar sei. Dadurch wird dem Gegenstand auch eine „Bedeutung an sich“ zugeschrieben (vgl. Busse 2009: 66).

170 Eine Abfrage zum Verb durchbrennen auf der Kookkurrenzdatenbank „CCDB - V3.3: Eine korpuslinguistische Denk- und Experimentierplattform“ von Cyril Belica (Leibniz-Institut für Deutsche Sprache) ergab, dass Sicherung(en) und durchbrennen statistisch eine dominante Wortverbindungsstruktur darstellen. Bei dem Verb ausbrennen erscheinen Gegenstände wie Scheunen, Pkws und Räume etc. als dominante Kookkurrenzpartner. http://corpora.ids-mannheim.de/ $\mathrm{ccdb} /$, (abgerufen für die Verben durchbrennen und ausbrennen am 16.11.2019). 
reicht die Verknüpfung der Konzepte >Feuer/Brennen/Flammen` mit >Psyche im weiteren und >Motivation/Leidenschaft ` im engeren Sinn kulturgeschichtlich weit zurück, woraus, wie die Autorinnen kritisch anmerken, 'unsachgemäße' Annahmen für die Erforschung dieses psychischen Phänomens entstehen könnten. Im Beispiel der ZEIT wiederum scheint die Bezeichnung Ausgebranntsein mit Bedeutungsaspekten wie 'Dauer' und 'höheres Lebensalter' einherzugehen, was zu metaphorischen Verwendungsweisen des Verbs ausbrennen in Texten des 17. Jahrhunderts passen würde (zur historischen Dimension der metaphorischen Verwendung von ausbrennen siehe Kap. 6.1.2 dieser Arbeit).

Die referierte Kritik zeigt, dass definitorische Interpretationen stets in Beziehung treten zu vorangegangen „[S]prachliche[n] Objektivationen von Sachverhalten“ (Köller "1997: 32) und dass Begriffsbestimmungen bzw. Definitionen überzeugender wirken, wenn sie zu letzteren passen und sich verschiedene, das Definiendum repräsentierende Zeichen zu einem „dynamischen Sinnbildungsereignis“ ergänzen (vgl. Köller 2004: 244).

Dass Burisch trotz seiner Kritik weiterhin für den Ausdruck Burnout plädiert, zeigt, dass er eine Lexikalisierung der entlehnten Metapher Burnout, die mit der Abschwächung des ,ursprünglichen'Sinns einherginge, für möglich hält. Zugleich nimmt er auf dieser Basis einen Sachverhalts- und Bedeutungsfixierungsversuch über den Vergleich mit einer Autobatterie vor, die trotz hoher Energieabgabe zu wenig Leistung erbringt und nicht nachgeladen werden kann. Denn in diesem Bild sieht er die 'realen' Kräfteverhältnisse des Burnout-Phänomens adäquater, d. h. strukturell ähnlicher, widergespiegelt.

Das Moment einer 'negativen' >Bilanz‘, das im Zitat von Burisch und der IG-Metall durch den Batterie-Vergleich betont wird, erscheint in variierter Form an vielen Stellen im Burnout-Diskurs (vgl. Kap. 6.2.3.1 und 6.2.4.2). Die Häufigkeit der Verwendung dieses Konzepts durch verschiedene Diskursakteurinnen und -akteure erhöht seinen Geltungsanspruch und verleiht ihm intersubjektive Gültigkeit - ein Kriterium, das ebenfalls im Zuge der Bewertung der Definition des Burnout-Phänomens wiederholt gefordert wird.

\section{E) Anspruch auf allgemeine Gültigkeit, Validität und Intersubjektivität}

\section{Beispiel 1 aus dem fachinternen Diskursstrang aus dem Handbuch Betriebliche Ge- sundheitsförderung}

„Mangels einer allgemein verbindlichen Definition benutzen die meisten Autoren die Begriffsbestimmung, die dem von ihnen jeweils verwandten Meßinstrument zugrunde liegt.“

(Gusy/Kleiber 1998: 317, im QV unter 8.1.2; Unterstreichungen T.S.) 


\section{Beispiel 2 aus dem fachinternen Diskursstrang aus einem Artikel der Zeitschrift für Arbeits- und Organisationspsychologie}

Diese multidimensionale Definition hat zu einer bis heute andauernden Diskussion um die Konstruktvalidität des MBI und die Bedeutsamkeit der einzelnen Dimensionen des Burnout-Syndroms geführt.

(Neubach/Schmidt 2004: 25, ZfAO, im QV unter 8.1.4; Unterstreichungen T.S.)

\section{Beispiel 3 aus dem medialen Diskursstrang aus einem Artikel der FAZ}

Anders als die Depression ist der Burnout gar keine anerkannte Krankheit. Schon seine Definition ist unter Ärzten umstritten, häufig wird eine allgemeine Erschöpfung und Antriebslosigkeit dahinter verstanden, oft begründet mit beruflicher Überlastung.

(Astheimer 2014b, FAZ, im QV unter 8.1.6 Unterstreichungen T.S.)

Das letzte Beispiel bemisst die Geltung des Begriffs >Burnout ‘ durch den Vergleich mit anderen anerkannten Krankheiten wie z. B. der Depression oder Neurasthenie. Die Anerkennung letzterer beruht darauf, dass sie in international anerkannten Manualen (ICD 10 und DSM- ${ }^{171}$ ) klassifiziert sind, in denen sich operationale Definitionen mit expliziten Ein- und Ausschlusskriterien finden, die von einem Forschungsteam erarbeitet und nach Prüfung durch weitere Expertinnen und Experten deklariert wurden (vgl. Saß/Saß-Houben 2005: 137f.). Die Allgemeingültigkeit beruht folglich auf Konvention und wird durch den internationalen Gebrauch und damit durch die Autorität der Manuale in der Behandlungs- und Verschreibungspraxis bekräftigt. Der Bezug auf Klassifizierungsmanuale (siehe Beispiel 3) ist besonders in diagnostischen Debatten relevant. Wenn ein Phänomen oder Begriff wie >BURNOUT< in anderen Fachbereichen wie der Arbeits- und Organisationspsychologie erforscht wird, dann ist der Bezug auf die internationalen Klassifizierungsmanuale nicht zwingend erforderlich. Studien dieser Fachbereiche verwenden ein Messinstrument, z. B. den Maslach Burnout Inventory, und akzeptieren damit die operationale Definition, die diesem zugrunde liegt. Aus dieser im Zitat dargelegten Praxis kann

171 Die erste Abkürzung referiert auf die "International Statistical Classification of Diseases and Related Health Problems”. Meist wird die kürzere Form “International Classification of Diseases (ICD)" verwendet. Die aktuelle deutsche Version, die ICD-10-GM ist abrufbar unter: https://www. dimdi.de/static/de/klassifikationen/icd/icd-10-gm/kode-suche/htmlgm2019/, Stand Juni 2019. Die ICD-11 wurde im Mai 2019 von der 72. Weltgesundheitsversammlung (WHA72) verabschiedet und soll am 1. Januar 2022 in Kraft treten (https://www.dimdi.de/dynamic/de/klassifikationen/ icd/icd-11/, Stand Juni 2019). Die zweite Abkürzung bezieht sich auf die aktuelle Fassung des „Diagnostic and Statistical Manual of Mental Disorders (DSM-V)“, herausgegeben von der American Psychiatric Association. Die aktuelle deutsche Fassung „Diagnostisches und Statistisches Manual Psychischer Störungen - DSM-5“ wurde 2015 von Peter Falkai und Hans-Ulrich Wittchen herausgegeben (siehe im QV unter 8.1.3). 
man das Ideal ablesen, dass das Phänomen möglichst objektiv, d. h. unabhängig vom Forschenden, erfasst und definiert werden soll. Dass dieser Weg jedoch ebenfalls keine Garantie für allgemeine Anerkennung bietet, zeigen Diskursbeiträge (siehe Beispiel 2 oben), die die Validität und Reliabilität dieser Messinstrumente in Frage stellen. ${ }^{172}$ Die verschiedenen fachlichen Zugänge (Diagnostik und empirische Forschung über Fragebogeninstrumente) stehen teilweise in einem engen Wechselverhältnis, wenn Fragebogeninstrumente wie der Maslach Burnout Inventory auch zu diagnostischen Zwecken eingesetzt werden. Die verschiedenen definitorischen Grundfunktionen, die man in Texten verschiedener psychologischer Fachbereiche findet, werden im Analyseteil der Arbeit ausführlich behandelt werden (siehe Kap. 6.2.2.2 und 6.2.4.2; vgl. auch Kap. 4.3.2 und 4.3.3 dieser Arbeit).

In der vorliegenden Arbeit soll untersucht werden, welche sprachlichen Mittel und Praktiken im Diskurs, z. B. kommentierende Reformulierungen oder Bezüge auf Autoritäten, gruppierende, vereinheitlichende und den Geltungsanspruch verstärkende Wirkungen entfalten. Denn auf diese Weise kann das Spektrum der möglichen Definitionsvarianten reduziert werden, wodurch der Eindruck von Konsens und damit intersubjektiver Gültigkeit entstehen kann.

Schließlich finden sich Textbeispiele im Diskurs, die kritisieren, dass einige Definitionen eine bewertende emotionalisierende Ebene besäßen. Dies könne sich, wie die Deutsche Gesellschaft für Psychiatrie und Psychotherapie, Psychosomatik und Nervenheilkunde e.V. (DGPPN) im folgenden Textbeleg (siehe Beispiel 1 unten) beanstandet, auf benachbarte Begriffe wie die >Depression ` auswirken und zu Stigmatisierungstendenzen führen. Auch Ulrich Hegerl hat als Vorstandsvorsitzender der Stiftung Deutsche Depressionshilfe in Interviews auf diese Gefahr hingewiesen (vgl. dazu z. B. ein Interview im SPIEGEL, = Kramer 2011, im QV unter 8.1.6), und medial wird darüber berichtet, dass im Begriff >Burnout` bzw. dem >Ausbrennen` „Leistung und Engagement“ nachhallten (FAZ.NET 02.03.2012, = Belz 2012, im QV unter 8.1.6). An diesen Beispielen zeigt sich, dass mit dem Definitionsakt praktische und handlungsorientierende Überlegungen einhergehen. Vor diesem Hintergrund wird für das wissenschaftliche Definieren wie für die wissenschaftliche Textproduktion überhaupt ${ }^{173}$, aber auch für Krankheits-Definitionen in der Öffentlichkeit, eine unpersönliche Ausdrucksweise befürwortet:

172 Z. B. Büssing/Perrar (1992), im QV unter 8.1.5; Demerouti/Nachreiner (1996), im QV unter 8.1.5; Neubach/Schmidt (2000), ZfAO, im QV unter 8.1.4).

$173 \mathrm{Zu}$ den Kriterien von Fachsprachlichkeit und Wissenschaftskommunikation siehe Roelcke 2010; Busch-Lauer 2009: 1731ff.; Wolf 2009: 1713ff. 


\section{F) Anspruch auf eine neutrale, objektorientierte Sachverhaltskonstitution/ Begriffsbildung}

\section{Beispiel 1 aus dem Positionspapier der Deutschen Gesellschaft für Psychiatrie und Psychotherapie, Psychosomatik und Nervenheilkunde vom 09.03.2012}

Bei der Berichterstattung in den Medien wird zum Teil eine Krankheitsdefinition gefördert, die den Begriff Burnout mit einer Erkrankung der Leistungsträger und der „Starken“ gleichsetzt, den Begriff Depression dagegen mit einer Erkrankung der (anlagebedingt) „Schwachen“ verknüpft. Diese Bewertung trifft nicht zu und bringt zudem die Gefahr einer neuen Stigmatisierung depressiv erkrankter Menschen mit sich.“ ${ }^{174}$

(DGPPN 2012, im QV unter 8.1.9, Unterstreichung T.S.)

\section{Beispiel 2 aus der Zeitung DIE ZEIT vom 19.11.2009}

Wie groß die Stigmatisierung der Krankheit [Bezug auf Depression, T.S.] noch immer ist, zeigt, dass ihr schon vor über 30 Jahren ein anderer Name verpasst wurde: Burn-out-Syndrom, eine chronische Überlastungsstörung, die weniger dramatisch klingt. Tatsächlich aber sind die Symptome fast deckungsgleich. Mehr als die Hälfte der Burn-out-Patienten sind in Wahrheit depressiv. Nur haftet dem Burn-out-Syndrom nicht der Makel des Versagens an. Im Gegenteil: Die Betroffenen gelten als Helden der Arbeit, die sich durch übermäßigen Einsatz im Job verschlissen haben.

(Bahnsen 2009, DIE ZEIT, im QV unter 8.1.6, Unterstreichung T.S.)

Zusammenfassend ließen sich aus den Diskursausschnitten empirisch sechs Kriterien herleiten, die für eine,gute' Definition des Phänomens, Ausdrucks, Begriffs >BURNOUT< von Diskursakteuren und -akteurinnen hauptsächlich im innerfachlichen, aber auch öffentlichen Diskurs gefordert wurden: Anspruch auf Exaktheit und Eindeutigkeit, Trennschärfe und Deutlichkeit, angemessene Umgrenztheit, Adäquatheit zwischen Definiendum und Definiens, intersubjektive Gültigkeit sowie eine emotionsfreie Sachverhaltskonstitution. Diese Kriterien gehen teilweise auch ineinander über. Sie werden nicht nur für Definitionen im Bereich von Gesundheit und Krankheit gefordert, sondern ähneln den Gütemaßstäben wissenschaftlicher Fachwortschätze und Begriffsbildung (vgl. Groeben/Westmeyer 1975: 37; Roelcke ${ }^{3} 2010$ : 55ff.; siehe Kap. 4.2.3-4.2.4). Die Definitionskriterien, die aus dem Diskurs über das „Burnout-Syndrom“ extrahiert wurden ${ }^{175}$ (= Metadiskurs zum Definieren), stehen jedoch nicht nur für allgemeine Gütekriterien

174 Das Positionspapier ist einsehbar unter: https://idw-online.de/de/news467247 (zuletzt eingesehen am 31.3.2021).

175 Die Liste der analysierten Kriterien erhebt nicht den Anspruch der Vollständigkeit und ist offen für Erweiterungen. Sie basiert auf Texten des dieser Arbeit zugrunde liegenden Korpus. Dieses besteht aus Beiträgen verschiedener psychologischer und medizinischer Fachrichtungen, populärwissenschaftlicher Literatur und Medientexten von Mitte der 1970er Jahre bis 2017, siehe ausführlich Kap. 5.1.2-5.1.3. 
wissenschaftlicher Begriffsbildung und Definition, sondern sie führen zugleich zu diskurs- und bereichsspezifischen Konstellationen - inhaltlich wie formal. So ist es das Ziel dieser Arbeit herauszuarbeiten, welche Praktiken beispielsweise zur Abgrenzung oder Umgrenzung psychosomatischer und sozialer Phänomene eingesetzt werden, welche definitorischen Verknüpfungen in diesem Bereich als adäquat gelten und welchen Instanzen (z. B. Institutionen, Diskursgemeinschaften, Spitzmüller/Warnke 2011: 181) eine legitimierende Wirkung zukommt.

\subsubsection{Definieren in wissenschaftsgeschichtlichen und -theoretischen Zusammenhängen}

Wissenstheoretische Überlegungen zum Definieren berufen sich in den meisten fachwissenschaftlichen Übersichtsartikeln auf die „klassische, sog. aristotelische Definition“ (Roelcke ${ }^{3} 2010$ : 62; vgl. Kniffka/Roelcke 2016: 62f.; Cramer 2011: $13 ; ;^{176}$ Nobis 1972). Diese ist bis heute wirkmächtig durch ihre Beschreibung, eine Definition bestehe aus der Angabe des nächsthöheren Gattungsbegriffs (genus proximum) und der "spezifizierenden Artkennzeichnung (= differentia specifica)“ (Bußmann ${ }^{3} 2002:$ 148; vgl. auch Roelcke ${ }^{3} 2010: 62$ ). ${ }^{177}$

Nicht immer wird dabei der historische Kontext mit überliefert, in welchem diese Art der Definition aufgestellt und weiterentwickelt wurde. Wiegand (1989: 547)

176 Für Irene Cramer (2011: 15) stellen die platonischen Dialoge, in denen Sokrates mit Gesprächspartnern Was-ist-Fragen diskutiert, eine intuitive Vorstufe für das aristotelische Definitionsschema dar. Sie schreibt über den Dialog „Theaitetos“: „Theaitetos verfährt - scheinbar intuitiv - bei seinen Definitionsvorschlägen so, wie Aristoteles das später für Definitionen explizit fordern wird [...]. Ausgehend von dem zu definierenden Wort sucht er nach einem passenden Oberbegriff (Wahrnehmung, Meinung) und fügt anschließend in seinem zweiten bzw. dritten Definitionsvorschlag Unterscheidungsmerkmale (wahr, mit Erklärung) hinzu.“ Auf die enge Verbindung zwischen Was-ist-Fragen und Definitionen verweist auch Köller (2004: 677): Nach ihm mühten sich schon die Gesprächspartner des Sokrates mit diesen „Was-ist-Fragen“, denen sie mit „Wesensdefinitionen in Form von Begriffsdefinitionen“ beizukommen suchten. Zur Analyse dieser Fragen im Burnout-Diskurs siehe Kap. 6.2.2.2 und Kap. 6.2.3.1.

177 Vergleiche bei Aristoteles zu dieser Bestimmung von Definition den Abschnitt in der Topik, Buch I, 8, 103 b 15f. (siehe Aristoteles, hrsg. von Tim Wagner und Christoph Rapp 2004). Diese Definitionsformel blieb nicht unwidersprochen. Greta Stanaitytė beschreibt Leibniz' Kritik an dieser Art des Definierens: „Ihm [Leibniz, T.S.] zufolge ist es nicht immer möglich, eine Bestimmung dieser Angaben innerhalb einer Definition durchzuführen“, denn die Zuordnung, welche Angaben zum nächsthöheren Gattungsbegriff zugehörten und welche das unterscheidende Merkmal darstellten, sei bisweilen schwierig (Stanaitytè 2005: 23). Leibniz habe daraufhin „das Gewicht [...] auf die (Wesens)Merkmale verlagert“. Eine Definition sei ,gelungen, wenn sie die wesentlichen Merkmale des Definiendums auflistet“ (Stanaitytė 2005: 23-24 mit Bezug auf Leibniz 1996). 
schreibt, die klassische Definitionsauffassung sei nur verständlich im Zusammenhang bestimmter „Ordo“-Lehren und mit weiteren Bedingungen der traditionellen Logik zur Beurteilung der Qualität einer Definition verknüpft. ${ }^{178}$ So sollen Definitionen nach Aristoteles zum Beispiel eine Wesensbestimmung leisten (vgl. Dubislav 1981: 2-7), weder zirkulär noch negativ und „hinreichend klar und scharf“ (Wiegand 1989: 547) und „prägnant, kurz und gleichzeitig präzise“ formuliert sein (Cramer 2011: 84 mit Bezug auf Abelson 1967: 322). Zum Zusammenhang der Ordo-Lehren zitiert Wiegand zudem aus Weinberger/Weinberger (1979: 181):

Die traditionelle Charakteristik der klassischen Definition geht von der bereits überwundenen Vorstellung aus, daß es eine geordnete Gesamthierarchie der Begriffe gibt, in der der einzelne Begriff bei der klassischen Definition dadurch bestimmt wird, daß seine Stelle in dem Gesamtgefüge - nämlich seine Einordnung in eine Gattung und sein artbestimmendes Merkmal - angegeben werden.

Auch die Unterscheidung zwischen einer Real- bzw. Wesens- und Nominaldefinition, die man in vielen fachwissenschaftlichen Hand- und Wörterbüchern sowie in der Fachliteratur zur Terminologie- und Definitionslehre findet, wird auf Aristoteles zurückgeführt (vgl. Nobis 1972: 31; Wirtz ${ }^{18}$ 2014: 355; Bußmann ${ }^{3} 2002$ : 148; Prechtl ${ }^{5}$ 2016: 131; Metschl 1999: 98). ${ }^{179}$ Diese Unterscheidung basiert auf unterschiedlichen Sprachauffassungen im Verhältnis zur außersprachlichen Wirklichkeit und wirkt sich auf die Ansprüche, die implizit oder explizit an den Akt des Definierens bzw. der Begriffsbestimmung gestellt werden, aus. Roelcke schreibt

178 Wiegand überprüft, in wieweit Bedeutungsparaphraseangaben in einsprachigen Wörterbüchern die Bedingungen der klassischen Definition im Sinne der traditionellen Logik erfüllen können (die „wichtigsten“ Bedingungen zitiert er u. a. nach Kutschera/Breitkopf ${ }^{4}$ 1979: 139ff.). Er kommt zu dem Resümee, nur Bedingung 3, etwas nicht negativ zu definieren, sei erfüllbar. Denn ein Lexikograf könne nicht „das Wesen“ eines Begriffs bestimmen (Bed. 1), Zirkularität könne in der einsprachigen Lexikografie aufgrund der nicht aufzubrechenden semantischen Geschlossenheit nicht grundsätzlich vermiedenen werden (Bed. 2) und das Kriterium „hinreichend klar und scharf“ könne ebenfalls nicht erreicht werden, da „es sich bei natürlichen Sprachen nicht um vollständig interpretierte Sprachen handelt“ (Wiegand 1989: 547). Vgl. auch Kap. 4.2.2 und 4.2.4 dieser Arbeit.

179 Die Unterscheidung zwischen Wesens- und Nominaldefinition wird auf Aristoteles zurückgeführt (Anal. post., II, 10, 93 b, 30-35). Aristoteles unterscheidet in Bezug auf die Umgrenzung/

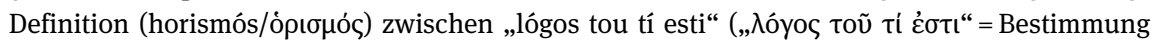

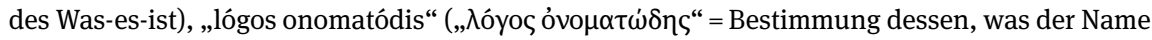

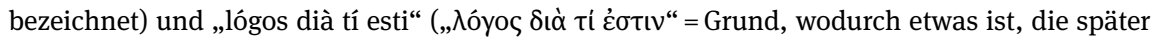
so genannte definitio causalis), vgl. Nobis 1972: 31; siehe die Übersetzung von W. Detel von Anal. post., II, 10, 93 b, 30 bis 94a, 10 (= Aristoteles 2011: 154-157). 
hierzu, die Nominaldefinition gehe mit einer ,idealistischen“"180 und die Realdefinition mit einer „realistischen“ Sprachauffassung einher:

Unter einer Nominaldefinition ist die sprachliche Festlegung einer (sprachlichen) Bedeutung, unter einer Realdefinition die sprachliche Festlegung eines (übereinzelsprachlichen) Begriffs zu verstehen.

(Roelcke ${ }^{3}$ 2010: 61)

Mit dem Ausdruck Begriff beziehe man sich im Rahmen einer ,alltagsnahe[n] Sprachauffassung“ auf eine „übersprachliche (oder zumindest: übereinzelsprachliche) Vorstellung von Gegenständen der außersprachlichen Wirklichkeit“ (Roelcke 32010: 61). Bei einer Realdefinition wird demnach mithilfe „sprachlicher Ausdrücke ein Bezug zu Gegenständen der externen Welt hergestellt“ (Mangold 2003: 368). Eine wichtige Funktion des Definierens ist dabei - in Anlehnung an die Situation, dass Personen sich über "neuartige und mehrdeutige Objekte“ unterhalten (ebd.) -, dass „der Partner des Sprechers [...] das beschriebene bzw. benannte Objekt identifizieren“ kann (ebd.), so wie auch der definite Artikel „ein Substantiv bzw. den damit gebildeten Ausdruck [...] als hinreichend identifiziert oder ,bestimmt'“" kennzeichnet (DUDEN ${ }^{72006:}$ 299).

Wenn man Nominaldefinitionen wie Roelcke als „sprachliche Festlegung einer (sprachlichen) Bedeutung“ (Roelcke ${ }^{3} 2010: 61$ ) versteht, dann kann man folgende Sprachhandlungen mit Nominaldefinitionen vergleichen: „lexikographische Definitionen“, d.h. zu einem Lemmazeichen verfasste „semantische Kommentare“ in einem (allgemeinen einsprachigen) Bedeutungswörterbuch (vgl. Wiegand 1989: 530ff) oder auch Bedeutungs(paraphrase)angaben zu Wörtern oder Bezugsgegenständen in der alltäglichen Kommunikation in handlungssemantischen Kontexten, z. B. bei möglichen Verständnisstörungen (vgl. Wiegand 1989: 552ff.).

Im Fachdiskurs zum Thema „Burnout“ findet man Beispiele sowohl für Nominalals auch für Realdefinitionen. Im Text „Staff Burn-Out“ von Freudenberger (1974, im QV unter 8.1.5), der - wie in Kapitel 4.2.1 schon erwähnt - häufig als Gründungstext des Phänomens erscheint, wird Burnout zunächst rein nominal definiert und danach mit einem 'realen' Phänomen der außersprachlichen Wirklichkeit verglichen:

The dictionary defines the verb "burn-out" as "to fail, wear out, or become exhausted by making excessive demands on energy, strength, or resources.” And that is exactly what happens when a staff member in an alternative institution burns out for whatever reasons and becomes inoperative to all intents and purposes.

(Freudenberger 1974: 159f., Unterstreichung T.S.)

180 Nominaldefinitionen lassen offen, „ob das Definierte in den Bereich des Möglichen fällt“ (Metschl 1999: 98). Dies bedeutet jedoch nicht zwingend, dass diese Definitionen mit einer idealistischen Sprachauffassung einhergehen. 
In der weiteren Analyse wird $\mathrm{zu}$ zeigen sein, welche Definitionsweisen von Autorinnen und Autoren des Burnout-Diskurses verwendet werden und welche Sprache-Welt-Auffassungen damit einhergehen. Die Definitionslehren, die auf Aristoteles folgten, unterschieden sich schon früh darin, ob sie eine Unterscheidung zwischen Real- und Nominaldefinitionen zugrunde legten oder diese anzweifelten und darin, welche weiteren Differenzierungen sie jeweils vornahmen (Nobis 1972: 32). Die Entwicklung und Diversität der Definitionslehren und -ansätze in Philosophie- und Wissenschaftsgeschichte seit der Antike und die dabei aufgestellten strengen oder weniger strengen Definitionsprinzipien $^{181}$ können in diesem Abschnitt nicht einzeln und erschöpfend dargelegt werden (siehe im Überblick Nobis 1972: $31 \mathrm{ff.}$; Gabriel 1972: $35 \mathrm{ff}$.), einige dieser Gütekriterien wurden in Kapitel 4.2.2 im Rahmen der Erwartungen, die von Stimmen im Burnout-Diskurs an die Tätigkeit des Definierens gestellt werden, schon diskutiert. Um einen Eindruck von der Vielfalt der Kategorisierungsbemühungen in Bezug auf die Tätigkeit des Definierens im wissenschaftstheoretischen Bereich zu erhalten, seien im Folgenden zwei zeitlich weit auseinander liegende Einteilungen zitiert. Nobis (1972) berichtet über die im Mittelalter zur Verfügung stehenden Definitionslehren von Marius Victorinus und Isidor von Sevilla:

Beide Werke kennen 15 Arten von D., [...]. Es sind dies die D., von denen vier mit denen von Aristoteles für eine wissenschaftliche D. zugelassenen Weisen übereinstimmen. Es sind

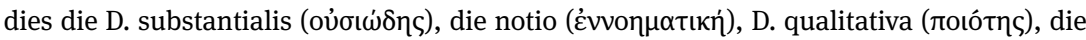

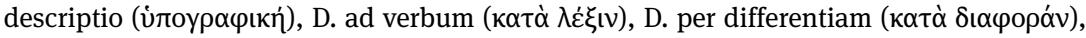

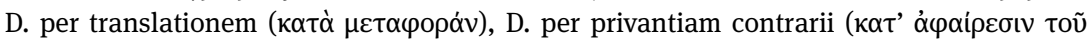

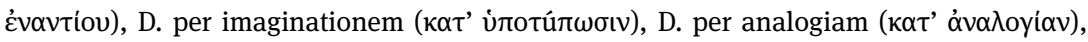

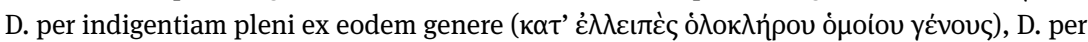

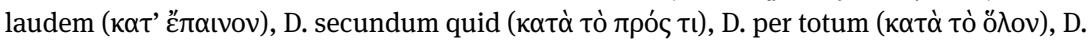

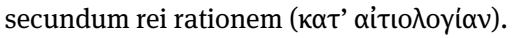

(Nobis 1972: 32)

Einige dieser Definitionsarten sind aus heutiger Sicht nicht mehr ohne Weiteres verständlich (z.B. die Wesensdefinition (D. substantialis), die das eigentümliche Merkmal eines Gegenstands angibt, oder die „notio“ ('Vorstellung'), die durch die Angabe eines Kennzeichens eine Vorstellung von etwas vermittelt) ${ }^{182}$,

181 Zum Beispiel wird in der Literatur teilweise gefordert, dass das Definiendum ,überall durch das Definiens ersetzbar sein“ sollte (Cramer 2011: 84; Stanaitytė 2005: 33) oder dass Definitionen nur dann Definitionen im engeren Sinn sind, wenn sie zur Bildung eines neuen Begriffs beitragen.

182 Bei Flavius Magnus Aurelius Cassiodorus Senator, der im 6. Jahrhundert nach Christus eine „Einführung in die geistlichen und weltlichen Wissenschaften (Institutiones divinarum et saecularium litterarum)“ schrieb und die im Olms-Verlag in einer Übersetzung von Andreas Pronay 
andere hingegen wirken spontan plausibel bzw. auch heute gebräuchlich, wie zum Beispiel die Definition durch Beschreibung („descriptio“), durch Angabe der Beschaffenheit („qualitativa“), durch Angabe eines anderen bedeutungsähnlichen Ausdrucks (,ad verbum“), durch Unterscheidung (,per differentiam“), durch Übertragung (,per translationem“), durch Negation des Gegenteils (,per privantiam contrarii“), durch eine Skizze (,per imaginationem“), durch Analogie (,per analogiam“) oder durch Angabe der Ursache („secundum rei rationem“). Überschneidungen $\mathrm{zu}$ diesen Arten findet man in den verschiedenen Typen von Bedeutungsparaphraseangaben, die Töpel für die lexikografische Arbeit an Bedeutungswörterbüchern zusammengestellt hat (vgl. die Übersicht im folgenden Kapitel 4.2.4 und Töpel 2014: 302f.).

Als zeitgenössische Zusammenstellung von Definitionsarten sei abschließend aus dem Lexikoneintrag von Prechtl des Lexikons „Sprache“ zitiert:

D. werden hinsichtl. ihrer Verwendungsweisen unterschieden: (a) die deskriptive (feststellende) D. rekurriert auf die allgemein akzeptierte Bedeutung; (b) die stipulative (festsetzende) D. stellt eine Vereinbarung hinsichtl. der Verwendungsweise eines Ausdrucks dar; (c) die ostensive (hinweisende) D. legt die Verwendungsweise eines Ausdrucks durch Aufzählen geeigneter Beispiele fest; (d) die operationale D. durch Bezug auf ein bestimmtes Meß- oder Untersuchungsverfahren (z. B. den Begriff der Intelligenz durch den Intelligenztest).

(Precht1 52016: 131)

Die Aufzählung (a) bis (c) bei Prechtl bezieht sich auf verschiedene Arten von Nominaldefinitionen, (d) hingegen bezieht sich auf ein übereinzelsprachliches methodisches Verfahren mit dem Anspruch, Bezug zu den Gegenständen zur Realität der Außenwelt herzustellen. ${ }^{183}$ Operationale Definitionen werden insbesondere in den empirischen Studien des fachlichen Diskurses häufig verfolgt und in Handbüchern zur Theorieentwicklung und empirischen Methodik empfohlen (vgl. Astleitner 2011: 128ff.; Diaz-Bone/Weischer 2015: 83). Weitere noch heute gebräuchliche Definitionsformen listet Cramer (2011) auf.

Dieser Einblick in verschiedene Definitionsarten weist auf eine Formenvielfalt hin, die im Analyseteil dieser Arbeit durch Manifestationen an der Sprachoberfläche zu ermitteln ist. Einen ersten Eindruck sprachlicher Realisierungsformen von Definitionen gibt das folgende Kapitel, indem es den Stand der linguistischen und terminologischen Forschung zum Thema „Definieren/Definition“ darstellt.

vorliegt, finden sich ausführliche Erläuterungen zu den 15 genannten Definitionsarten (Cassiodorus Senator/Pronay 2014: 129-134).

183 Zur Entstehung der operationalen Definition, die auf den Physiker Percy Williams Bridgman zurückgeht, siehe Cramer (2011: 33f.). 


\subsection{4 >Definieren` als Gegenstand linguistischer und terminologischer Forschung und Praxis}

Der folgende Überblick zur Beschäftigung mit dem Thema „Definieren“ in der Fachsprachenlinguistik und Terminologieforschung hat zum Ziel, aufzuzeigen, welche Bereiche der Linguistik sich mit „Definieren“ und „Definitionen“ bisher überwiegend beschäftigt haben, welche (kritischen) Diskurse und Forschungsfragen daraus erwachsen sind, und anknüpfend daran, welchen Beitrag die vorliegende Arbeit zum Forschungsgegenstand des Definierens leistet. Da sowohl die Fachsprachenforschung als auch die Terminologieforschung eine hohe Publikationsdichte aufweist, kann in diesem Überblick keine Vollständigkeit gewährleistet werden, sondern es steht vielmehr das Bemühen im Vordergrund, wichtige Entwicklungs- und Diskussionslinien zu skizzieren.

Die Tätigkeit des Definierens und Definitionsarten werden in der Linguistik traditionell vor allem im Bereich der (Fach-)Lexikologie und -grafie und an der Schnittstelle zur Terminologielehre und -arbeit sowie Terminografie reflektiert und praktiziert. Die Ausdrücke Fachwort und Terminus werden nach Fraas (1998) mitunter unterschieden, ,wobei ein Fachwort den Status eines Terminus erreicht, wenn seine Bedeutung durch eine Definition genau festgelegt ist“ (Fraas 1998: 429). Diese Unterscheidung habe sich in der Fachsprachenforschung jedoch aufgrund mangelnder Praktikabilität nicht etablieren können, und so würden die Benennungen Terminus und Fachwort selbst in der DIN-Norm 2342 (in der Fassung von 1986) synonym verwendet (vgl. ebd.). Auch Roelcke verwendet diese synonym, wenn er schreibt: „Die spezifische Bedeutung von Fachwörtern bzw. Termini wird in der Regel durch Definitionen bestimmt und festgelegt (Roelcke ${ }^{4}$ 2020: 69). In dieser Arbeit werden Terminus und Fachwort ebenfalls synonym verwendet. Die von Fraas angesprochene Unterscheidung weist jedoch auf unterschiedliche Forschungstraditionen hin, wobei die Terminologieforschung und -erarbeitung stärker dem Pol der „bewußte[n] Terminologieregelung (z. B. Normung von Terminologien auf der Grundlage von Begriffssystemen unter mehr oder weniger strikter Festlegung von Benennungsregeln)“ zuneigt (Galinski/Budin 1999: 2185), wobei es aber auch die „[d]eskriptive TerminologieErarbeitung“ gibt, die bestehende Terminologien rekonstruiert (vgl. ebd.). Die Fachsprachenforschung und Fachlexikografie wird stärker dem deskriptiven Pol zugeordnet (vgl. Adamzik 2018: 22 mit Bezug auf Roelcke ${ }^{32010: ~ 127 ; ~ v g l . ~ a u c h ~}$ Roelcke ${ }^{4}$ 2020: 160 und 168f.). Als Teil Angewandter Linguistik strebt sie jedoch auch eine Verbesserung fachsprachlicher Kommunikation an (vgl. Roelcke ${ }^{4} 2020$ : 40), und Wörterbücher als Hilfsmittel haben ursprünglich „eine praktische und damit auch präskriptive Funktion“ (Adamzik 2018: 12). 
Einige Kriterien, die als Gütekriterien fachsprachlicher Lexik in der Fachsprachenforschung und Terminologielehre auch in Bezug auf Definitionen von Fachwörtern und Termini untersucht und teilweise kontrovers diskutiert werden, wurden schon in Kapitel 4.2.2 und 4.2.3 im Kontext der Erwartungen an die Tätigkeit des Definierens von Stimmen des Burnout-Diskurses vergleichend und kontrastierend erläutert: wie zum Beispiel Exaktheit, Eindeutigkeit, Eigentlichkeit, Deutlichkeit, Unterscheidbarkeit, Kürze bzw. Konzentration auf wesentliche oder auch notwendige und hinreichende Merkmale und Neutralität. ${ }^{184}$

Sichtet man verschiedene terminologische Ansätze und reflektiert dabei besonders die Kritik pragmatischer und soziokognitiver terminologischer Ansätze (z. B. Sager 1990 und Temmerman 2000) an der klassischen präskriptiven Terminologielehre und Terminografie in der Tradition der Wiener Schule (vgl. Wüster ${ }^{3} 1991$ ), so wird deutlich, dass diesen Ansätzen unterschiedliche Theorien zum Verhältnis von Sprache, Denken bzw. Kognition und Wirklichkeit und damit verbunden auch unterschiedliche Semantiktheorien zugrunde liegen (vgl. Kap. 2.1.1). Für Eugen Wüster geht die Terminologiearbeit von Begriffen und deren scharfer Abgrenzung aus, wobei das „Reich der Begriffe [...] unabhängig vom Reich der Benennungen (= Termini) angesehen“ wird (Wüster $\left.{ }^{3} 1991: 1\right) .{ }^{185}$ Die „sprachtheoretische Grundlage“ der klassischen Terminologielehre mit Bezug auf die Arbeiten Eugen Wüsters besteht demnach:

in einem einfachen systemlinguistischen Inventarmodell bei einer realistischen Sprachauffassung [...]. Den zentralen Ausgangspunkt der Überlegungen stellt dabei [...] die traditionelle Begriffslogik dar: Ein Begriff wird hierbei als so etwas wie eine kognitive Repräsentation von Gegenständen als Einheiten der außersprachlichen Wirklichkeit aufgefasst, die unabhängig von Sprache besteht. Ein solcher übereinzelsprachlicher oder gar außersprachlicher Begriff steht dabei in verschiedenartigen Beziehungen der Über-, Neben- und Gegenordnung zu anderen Begriffen und bildet mit diesen zusammen ein Begriffssystem.

(Roelcke ${ }^{4} 2020:$ 157; 160)

Für Wüster ist eine „Definition (Begriffsbestimmung) im weiteren Sinne [...] die Beschreibung eines Begriffs durch bekannte Begriffe, und zwar meist mit Hilfe

184 Vgl. für die Liste von Gütekriterien Roelcke ('2020: 92) und Arntz/Picht/Schmitz (72014: 71-75). 185 Die Definitionen von Begriff in der DIN-Norm 2342 (in der Fassung von 1992) und der internationalen Grundsatznorm ISO 1087-1 (2000) orientieren sich nach Arntz/Picht/Mayer ( ${ }^{6} 2009$ : 43f.) an der Theorie Wüsters (vgl. Wüster ${ }^{3} 1991:$ 8). Wüster definiert Begriff als „das Gemeinsame, das Menschen an einer Mehrheit von Gegenständen feststellen und als Mittel des gedanklichen Ordnens ('Begreifens') und darum auch zur Verständigung verwenden. Der Begriff ist somit ein Denkelement“ (ebd.). Vgl. zur Definition von Begriff in der DIN-Norm 2342 in der Fassung von 2011 Arntz/Picht/Schmitz (2014: 40 und 48f.). 
von Worten“ (Wüster ${ }^{3} 1991:$ 33). Die bekannten Begriffe werden in den Definitionen nach logischen Möglichkeiten der Neben-, Über- und Unterordnung miteinander verknüpft und ergeben je nach logischer Verknüpfung Inhalts- und Umfangsdefinitionen. Nach Arntz/Picht/Schmitz (72014: 67) sind des Weiteren Teil-Ganzes-Relationen, die Bestandsdefinitionen zugrunde liegen, für die praktische Terminologiearbeit von Bedeutung. Die Inhaltsdefinition ähnelt dem aristotelischen Schema:

Sie geht von einem bekannten Oberbegriff aus und nennt die einschränkenden Merkmale ${ }^{186}$, die den zu definierenden Begriff kennzeichnen und von den anderen Begriffen derselben Reihe unterscheiden.

(Wüster ${ }^{3} 1991: 34$ )

Umfangsdefinitionen bestehen nach Wüster „in der Aufzählung des Begriffsumfangs, d. h. aller Unterbegriffe, die im Begriffssystem auf derselben Stufe stehen“ (ebd.: 35). Bei Bestandsdefinitionen werden ,alle auf derselben Hierarchiestufe stehenden Teilbegriffe des Begriffs aufgezählt“ (Arntz/Picht/Schmitz ${ }^{7} 2014: 67$ ). Die definitorischen sprachlichen Zuordnungen sollen im Bereich der Terminologie eindeutig, einheitlich und möglichst sprachbeständig sein (ebd.: 87ff.; 93 und 105).

Die nationale und internationale Normung orientiert sich an diesem sprachtheoretischen Hintergrund, da auch dort „die Klärung der Begriffe an erster Stelle“ stehe, wie Arntz/Picht/Schmitz (72014: 48) erläutern: „,[E]rst wenn klar ist, worüber man spricht, ist es sinnvoll zu überlegen, wie man den betreffenden Begriff am zweckmäßigsten benennen kann“ (ebd.). Einschränkend wird in der DIN 2342 in der Fassung aus dem Jahr 2011 (zitiert nach Arntz/Picht/Schmitz ${ }^{7} 2014$ : 49) jedoch hinzugefügt, dass Begriffe zwar nicht an einzelne Sprachen gebunden, jedoch von dem jeweiligen gesellschaftlichen und/oder kulturellen Hintergrund einer Sprachgemeinschaft beeinflusst seien (ebd.: 49). Diese Aussage erscheint paradox, da kulturelle Werte und gesellschaftliche Überzeugungen in hohem Maße sprachlich ausgetauscht und verhandelt werden (vgl. Günthner/ Linke 2006: 19; vgl. dazu auch Kap. 2.2.1).

Die Kritik an dieser Art terminologischer Normung aus der Perspektive neuerer terminologischer Ansätze und empirischer Arbeiten zum Gebrauch von Fachwörtern bzw. Termini (vgl. Sager 1990; Temmerman 2000; Gledhill 2000: 20ff.; Müller/ Behr/Steffek 2019: 106; 108ff.; zusammenfassend Reinart/Pöckl 2015: 73; Roelcke

186 „Merkmale“ bzw. „Ordnungsmerkmale für Begriffe“ hängen nach Wüster vom jeweiligen Sachgebiet ab. Er unterteilt sie in „Eigenmerkmale (inhärente Merkmale)“, die man am Gegenstand selbst erkennen könne, und „Beziehungsmerkmale (Relationsmerkmale)“, die die Beziehung des Gegenstands zu anderen Gegenständen beträfen (Wüster ${ }^{3} 1991:$ 16f.). 
42020: 94ff; 160) ähnelt Kritikpunkten, die Wiegand (1989: 543-546) allgemein an Grundannahmen der strukturellen Merkmalssemantik und ihrer Orientierung am klassischen Definitionsschema für Bedeutungsparaphraseangaben in allgemeinen einsprachigen Wörterbüchern übt. Diese Kritikpunkte seien im Folgenden verbunden und stichpunktartig resümiert:

Merkmalssemantische Konzeptionen gehen nach Wiegand überwiegend davon aus, „daß die lexikalische Semantik unter Rückgriff auf Entitäten begründet werden muß, die nicht einzelsprachlich sind“, und dass die „Bedeutung von minimalsignifikativen Sprachzeichen [...] restfrei zerlegbar“ sei (Wiegand 1989: 544). Die Frage sei dann jedoch, von „welcher Existenzweise diese Entitäten“ seien bzw. aus welcher Perspektive heraus (,philosophische, biologische, neurophysiologische, psychologische, logische, kybernetische u.a.") diese interpretiert würden (ebd.). Die Suche von Lexikografinnen und Lexikografen nach einem „genus proximum“ sei häufig problematisch, da man dabei durchaus auf mehrere genera proxima treffe, denen in der jeweiligen Sprache zudem teilweise „kein lexikalisierter Ausdruck“ entspreche und bei den einschränkenden Merkmalen teilweise die Einhaltung einer bestimmten Reihenfolge notwendig erscheine (vgl. ebd.: 549f.). Temmerman kritisiert aus einem ähnlichen Duktus heraus insbesondere mit Bezug auf Prinzipien der Terminologielehre der Wiener Schule, dass diese davon ausgehe, dass die übereinzelsprachlichen Konzepte bzw. Begriffe („concepts“) und ihre Eigenschaften („characteristics“) festumrissen (,clear-cut“) seien und dass ihr Platz im Begriffssystem durch Vergleich der Begriffsmerkmale (,comparison of characteristics“) und die Erkenntnis logischer und ontologischer Beziehungen eindeutig beschrieben werden könne (vgl. Temmerman 2000: 6ff.). Beobachtungen ihrer Forschung hätten jedoch gezeigt, dass viele Konzepte bzw. Kategorien (insbesondere „activities“ und „,collective categories“) nicht festumrissen und eindeutig, sondern unscharf („fuzzy“) bzw. flexibel („flexible“) seien und skalare statt binäre Merkmale sowie unterschiedliche Maße der Kategorienzugehörigkeit zeigten, was für Familienähnlichkeit und eine prototypische Struktur dieser Kategorien spreche (ebd.: 8; 64f.; 81ff.; 84f.; 91ff.). Sie könnten dadurch nicht über eine im klassischen Sinn intensionale oder extensionale Definition mit notwendigen und hinreichenden Merkmalen beschrieben werden. Auch Roelcke hält dem systemlinguistischen Modell und dessen Idealen der „Exaktheit, Eindeutigkeit und Eigentlichkeit von Fachwörtern“ in einem festen Begriffssystem entgegen, dass ,in der Wirklichkeit oft terminologische Vagheit, Mehrdeutigkeit und Bildhaftigkeit“ in der Fachkommunikation und sogar auch „in der Terminologie der Terminologielehre selbst“ anzutreffen seien (Roelcke ${ }^{4} 2020: 160$ ). Zudem sei die ,radikal-realistische Variante der Außersprachlichkeit von Begriffen weder erkenntnistheoretisch noch kognitionspsychologisch hinreichend gesichert“ (ebd.). 
Einige terminologische Ansätze seit den 1990er Jahren und empirische Analysen zum Gebrauch von Fachwörtern bzw. Termini gehen demnach davon aus und betonen,

- dass Termini in ihren spezifischen Ko- und Kontexten in den Fachtexten selbst analysiert werden müssen (vgl. Sager 1990: 45; 58f.; vgl. Temmerman 2000: 224; Gledhill 2000: 24; Müller/Mell 2020: $197 \mathrm{f.;}{ }^{187}$

- dass je nach Konzept bzw. Definiendum, Definitionszweck, Fachkultur und -bereich, Nutzeranforderungen oder Textsorte unterschiedliche Definitionsformen erscheinen bzw. erforderlich sein können (Sager 1990: 42f.; 45; Temmerman 2000: 226; 24 mit Bezug auf Sager 1990: 101);

- dass Termini nicht als „Repräsentationsformate unveränderlicher Begriffe mit klarer Extension zu charakterisieren“ sind, wenn man sie in ihrer „Entwicklungsdynamik“ bzw. „synchrone[n] und diachrone[n] Variation“ untersucht (Müller/Mell 2020: 191; 193f.; vgl. Gledhill 2000: 23ff.; vgl. Temmerman 2000: 133; 139-150; Müller/Behr/Steffek 2019: 105ff.); und dass die „TerminologieErarbeitung“ ebenfalls dynamisch erfolgen sollte, z. B. dadurch, dass sie die unterschiedlichen „soziokommunikativen Gegebenheiten in akademischen Fachdiskursen unterscheidet“ (Müller/Mell 2020: 202) oder die historische Entwicklung und Veränderung von Termini beschreibt (vgl. Müller/Mell 2020: 203; Galinski/Budin 1999: 2186; Temmerman 2000: 230);

- dass Synonymie, Polysemie, Homonymie und metaphorischer Sprachgebrauch in Fachtexten nicht nur in Ausnahmefällen vorkommen und für den wissenschaftlichen Austausch funktional sind, um beispielsweise unterschiedliche Gesichtspunkte (aus verschiedenen Fachbereichen) auf zu definierende Sachverhalte, Erkenntniszuwachs oder Interessen zu benennen und in semantischen Kämpfen auszuhandeln (siehe Frawley 1982: 118; Fraas 1998: 432 mit Bezug auf Wiese 1984 zur reichhaltigen Synonymie in der Fachsprache der Medizin; vgl. dazu auch Temmerman 2000: 43-46 in Bezug auf Vokabular der „life sciences“; Felder 2006b zu semantischen Kämpfen in verschiedenen Wissensdomänen; Gledhill (2000: 24f.) zu Metaphern im wissenschaftlichen Schreiben und in medizinischer Terminologie; im Überblick auch Roelcke ${ }^{4} 2020$ : 99);

187 Für Adamzik sind deskriptiv erarbeitete Wörterbücher (auch im fachsprachlichen Bereich) „grundsätzlich sekundäre metasprachliche Artefakte“. Die Forderung, man dürfe „nicht (mehr) nur die Fachwörter isoliert oder in kleinen Begriffssystemen“ betrachten und „Verbaldefinitionen für das Wesentliche“ halten, sondern müsse „ihre Verwendung in Texten und Handlungszusammenhängen [...] untersuchen“, stellt für Adamzik einen nur vermeintlichen Paradigmenwechsel dar. Denn diese Forderung übersehe, dass Fachwörter und Definitionen „überhaupt erst aus Fachtexten kommen und selbstverständlich dazu dienen, sich denkerisch bzw. kognitiv mit der Wirklichkeit auseinanderzusetzen“ (Adamzik 2018: 288, Hervorhebung im Original). 
- dass die Terminologie nicht prinzipiell zwischen Fach- und Alltagssprache unterscheide (vgl. Temmerman 2000: 32 mit Bezug auf Boulanger 1995: 197; vgl. Müller/Behr/Steffek 2019: 106; vgl. Reinart/Pöckl 2015: 73; vgl. Müller/ Mell 2020: 198) und dass die Terminologie nicht nur Inhalts- und Umfangsdefinitionen im oben beschriebenen Sinne, sondern weitere Definitionsformen zulassen solle, mit den Worten Sagers ,the full range of definitions currently being used both in lexikography and terminology (Sager 1990: 42).

Um unterschiedlichen Formen des Definierens und ihrer Erforschung im Bereich der Linguistik weiter auf den Grund zu gehen, werden im Folgenden weitere Ansichten aus der Lexikografie zur lexikografischen Definition referiert.

Einen Überblick zur „lexikographischen Definition im allgemeinen einsprachigen Wörterbuch“ findet man bei Wiegand (1989) und Kolde (2001). Gottfried Kolde stellt in seinem Überblick zur „Geschichte der lexikographischen Definition im allgemeinen einsprachigen Wörterbuch des Deutschen“ dar, welchen Wert Lexikografen seit Adelung Bedeutungsangaben in einsprachigen Wörterbüchern zuerkannt haben. Die von Johann Christoph Adelung angestoßene Tradition, ,den Begriff eines jeden Wortes und einer jeden Bedeutung desselben auf das genaueste zu bestimmen“ (Adelung [21793] 1970: VI), sei durch Jacob Grimms Bemerkung vom „geschlepp langweiliger definitionen“ ( ${ }^{1} \mathrm{DWB}, \mathrm{Bd}$. 1, 1854: XL) und die im 19. Jahrhundert übliche „Ausrichtung der germanistischen Lexikographie auf die Wortgeschichte“ (Kolde 2001: 283) erst einmal wieder zu Ende gegangen. Kolde spricht auf dieser Grundlage sogar von einem „Fehlen einer kontinuierlich gewachsenen Kultur der lexikographischen Definition“ (Kolde 2001: 281) in allgemeinen einsprachigen deutschen Wörterbüchern bis hinein in die Mitte des 20. Jahrhunderts. Er plädiert auf der Basis des Status quo von 2001 dafür, dass lexikografische Definitionen im Hinblick auf ihre Angemessenheit von fachlicher Seite stärker reflektiert und diskutiert werden müssten. Es wäre beispielsweise zu fragen, wie eng die Definitionen sich an der Lebenswelt und den Bedürfnissen ihrer Rezipienten/Rezipientinnen ${ }^{188}$ orientieren sollten oder welche Definitionsweisen für welche $\mathrm{zu}$ beschreibenden Lemmata/Begriffe besonders geeignet seien. ${ }^{189}$

188 Zum Beispiel Muttersprachler/innen oder Lernende von Deutsch als Fremdsprache.

189 So ließen sich Körperteile besonders einfach über ihre Funktion definieren (Kolde 2001: 286). Die Diskussion, dass verschiedene Phänomene und Konzepte unterschiedliche Definitionsformen erfordern, findet man auch bei Temmerman (2000: 226). Es wird ferner in der fachsprachlichen Literatur darauf hingewiesen, dass in technischen Fächern ein stärkerer Fokus auf Definitionen und Standardisierungsprozessen im klassisch-terminologischen Sinn liege als in den 
Hierzu passt die Feststellung Wiegands, dass selbst Wörterbücher desselben Typs - z. B. „sog. Definitionswörterbücher[n]“, die „ein Sprachstadium einer historischen Einzelsprache“ untersuchen - im Detail recht verschieden sein können. In allen Wörterbüchern dieses Typs sei allerdings „eine sog. lexikographische Definition obligatorisch“ und auch in anderen Wörterbuchtypen (z. B. Autoren-, Fach-, Varietäten- und Lernerwörterbüchern) gelte „das Prinzip des semantischen Kommentars“(Wiegand 1989: 531).

Wiegand sieht die Verwendung des Begriffs `Definition ‘ für die lexikografische Arbeit in allgemeinen einsprachigen Wörterbüchern kritisch. Denn zum einen sei der Begriff der >Definition ‘ selbst ein Beispiel für eine „,abgegriffene[n] terminologische[n] Münze“, wobei es keine Verständigung darüber gebe, was unter einer lexikografischen Definition genau verstanden werde (Wiegand 1989: 532), zum anderen führe die Verwendung des Ausdrucks Definition für „Bedeutungsparaphrasenangaben“ in allgemeinen einsprachigen Wörterbüchern durch die verzweigte philosophische und wissenschaftstheoretische Prägung des Definitionsbegriffs zu „falschen“ und „irreführenden“ Auffassungen, was Einträge in allgemeinen einsprachigen Wörterbüchern leisten (sollen) (vgl. Wiegand 1989: 542). Wiegand argumentiert weiter, dass man nur dann von Definitionen in allgemeinen einsprachigen Wörterbüchern sprechen dürfe, wenn im gemeinsprachlichen Gebrauch in dialogischen Situationen auf die Frage „Was ist ein x?“ Worterklärungen folgten, „die selbst das zu erklärende Wort nicht enthalten“, und diese dann „usuell mit Definitionen“ bezeichnet würden (ebd.).

Diese Arbeit verwendet den Ausdruck Definition jedoch gerade deshalb: 1.) weil das zu erklärende Wort teilweise sogar in Frageform den darauf folgenden Erläuterungen sowohl im fachwissenschaftlichen als auch im öffentlichen Diskursstrang in vielen untersuchten schriftsprachlichen Passagen vorangestellt wird und 2.) weil man in den Texten des fachlichen, aber auch des öffentlichen Diskurses Reflexionen über den Ausdruck Definition im Ko- und Kontext zum Ausdruck Burnout findet (z. B. Enzmann/Kleiber 1989: 58, Schaufeli/Enzmann 1998: 19ff. im QV unter 8.1.5; Kaschka/Korczak/Broich 2011, Dt. Ärztebl. im QV unter 8.1.4; AU (2013) im QV unter 8.1.7; Blech 1999 in der ZEIT vom 2.12.1999 im QV unter 8.1.6, siehe auch Kap. 4.2.2). Wiegands Hinweis, dass man zwischen wissenschaftlicher und Alltagsdefinition unterscheiden müsse (vgl. Wiegand 1989: 542), wird für diese Arbeit übernommen. In diese Richtung weist auch die Arbeit von Stanaitytė aus dem Jahr 2005 zu „Alltagsdefinitionen und ihre[n] Funktionen“, auf deren Ergebnisse im Laufe dieses Kapitels noch eingegangen wird.

Geistes- und Sozialwissenschaften (vgl. Fraas 1998: 428f.; vgl. Galinski/Budin 1999: 2197-2199; vgl. Müller/Mell 2020: 202). 
Im weiteren Verlauf des Handbuchartikels beleuchtet Wiegand (1989) verschiedene fachliche Zugänge und Sichtweisen auf Bedeutungsparaphraseangaben: Er gibt einen kritischen Überblick zum Wechselverhältnis zwischen einsprachiger Lexikografie und Merkmalssemantik (Wiegand 1989: 543ff.) und führt in die handlungssemantische Deutung von Bedeutungsparaphraseangaben als „Teile von quasi-natürlichen, potentiellen Antworten auf antizipierte Fragentypen“ ein. Wiegands kritische Haltung zur merkmalssemantischen Perspektive wurde weiter oben in diesem Kapitel schon skizziert. In diesem Zusammenhang kritisiert er besonders auch das sog. Redundanzverdikt: Die ,am weitesten reichende Forderung“ von Vertretern der Merkmalssemantik (zum Beispiel Viehweger 1982) sei, „daß sog. lexikographische Definitionen nicht redundant sein sollen“ (Wiegand 1989: 550). Bei Viehweger würden Merkmale als redundant bewertet, wenn sie für die Unterscheidung einer „betreffende[n] Art (genus proximum) von anderen Arten der gleichen Gattung“ nicht relevant wären oder wenn Definitionen über die denotative Bedeutung hinaus „nichtdenotative Abbildkomponenten“ enthielten (Viehweger et al. 1977: 283f.; Wiegand 1989: 551). ${ }^{190}$ Nach Wiegand geht es bei dieser Forderung auch um das Verhältnis zwischen „sprachlichem (bes. semantischem) und enzyklopädischem Wissen“, wenn bemängelt wird „daß innerhalb von Bedeutungsparaphrasenangaben häufig im genannten Sinne ,redundante Merkmale، und damit enzyklopädische Merkmale auftreten“. Es gebe aber kein Verfahren, „wie diese von den ,nichtredundanten“ strikt getrennt werden können“, und bei bestimmten Einträgen, „z. B. bei Lemmazeichen, deren Bedeutung stark kulturspezifisch ist“, seien enzyklopädische Wissenselemente „sogar wünschenswert“ (Wiegand 1989: 551). Hinsichtlich der Frage, wie das Verhältnis zwischen sprachlichem und enzyklopädischem Wissen $\mathrm{zu}$ bestimmen ist, gibt es auch nach heutigem Forschungsstand keinen Konsens (Busse 1997: 13ff.; Felder 2006b: 26f., vgl. auch Scherner 2000: 191). Wie zu zeigen sein wird, ist bei der Analyse der definitorischen Bestimmungen von >BURNOUT< in diesem Diskurs jedoch nicht der Versuch der Abgrenzung, sondern der Verbindung von sogenanntem „Sprachwissen“ und „außersprachlichem Wissen“ und das Zusammenspiel von (implizitem) prozeduralem und deklarativem Wissen erkenntnisstiftend. ${ }^{191}$ Daran anschließend werden in dieser Arbeit auch die Ausdrücke Lexikon und Wörterbuch weitgehend synonym verwendet. ${ }^{192}$

190 Am Beispiel eines Wörterbucheintrags zu Amsel: „dessen flötender Ruf oft in der Dämmerung ertönt.“

191 Zum Verständnis von prozeduralem und deklarativem Wissen in dieser Arbeit siehe Kap. 4.1.1.

192 Zur Unterscheidung verschiedener Nachschlagewerke vgl. Schierholz (2003: 8ff.). 
Wiegand bringt das Redundanzverdikt als Beispiel dafür vor, dass die wissenschaftstheoretische Prägung des Definitionsbegriffs zu nicht praktikablen Ansprüchen in der lexikografischen Praxis führe. Aus diesem Grund bewertet er die Verwendung des Ausdrucks lexikografische Definition, wie bereits beschrieben, kritisch. Er spricht stattdessen von „Bedeutungsparaphrasenangaben“ und empfiehlt den Bezug auf „Alltagsdialoge über nennlexikalische Ausdrücke als natürliche Bezugspunkte für die einsprachige Lexikographie“ (Wiegand 1989: 553). Dies erläutert er an einem Beispielausschnitt eines Gesprächs zwischen zwei zwölfjährigen Jungen (Wiegand 1989: 554):

\begin{abstract}
„M beschreibt anhand seines Kajaks einen typischen Kajak [...], und zwar bestimmt M diesen für B dadurch näher, daß er eines der lexikalisierten Hyperonyme zu Kajak anführt, nämlich Paddelboot, so daß B ein bestimmtes Kategorienwissen als Teil des gegenstandskonstituierenden Bedeutungswissens erschließen kann. [...] Dieses Wissen wird zugleich spezifiziert durch den Prädiktor klein sowie durch die Charakterisierung „oben hat es ...“ (3).
\end{abstract}

Mit (3) äußert sich M über Kajaks, spricht damit über etwas Nichtsprachliches, und B erfährt etwas über Kajaks. Aber dadurch, daß M dies in bestimmter Weise tut, nämlich charakterisierend (also so, daß ein Kajak von ähnlichen Gegenständen als etwas Bestimmtes unterschieden werden kann), erfährt B etwas über die Bedeutung Kajak.

Bem.: M wendet natürlich nicht das klassische Definitionsverfahren nach genus proximum und differentia specifica an. Denn der zwölfjährige M kennt dieses Verfahren gar nicht, [...]. Vielmehr sieht man hier, daß allenfalls argumentiert werden kann, daß das klassische Definitionsverfahren einen Versuch darstellt, alltägliche Verfahren (wie sie z. B. bei Casagrande/Hale 1967 untersucht werden) für bestimmte Zwecke zu systematisieren, wobei aber die vorausgesetzten Zusatzannahmen (ordo universalis, prinzipielle Unterscheidung von genus- und differentia-Begriffen u.v. a.m.) sämtlich inakzeptabel sind.

(Wiegand 1989: 554f., kursive Auszeichnungen im Original)

Das Beispiel und Wiegands Analyse wurden in dieser Ausführlichkeit zitiert, da darin folgende Punkte offensichtlich werden, die für die vorliegende Arbeit von großer Bedeutung sind: Der Junge M folgt einem „Verfahrensmuster“, über das er aber nicht im Sinne von „deklarativem Wissen“ bewusst verfügt, sondern sein Verhalten basiert auf ,alltägliche[n] Verfahren“ oder anders ausgedrückt auf vorreflexivem praktischem Wissen. „Definitionen in der Interaktion“ wie in dieser beschriebenen Gesprächssequenz werden in einem aktuellen Forschungsprojekt auch am Leibniz-Institut für Deutsche Sprache untersucht. In der Projektbeschreibung werden Definitionen folgendermaßen umrissen:

Definitionen dienen Gesprächspartnern dazu, die Bedeutung von Begriffen, Ausdrücken und Konzepten gemeinsam auszuhandeln oder (etwa in Lehr-Lern-Kontexten) mittels defi- 
nierender Semantisierungspraktiken unbekannte Begriffe und Konzepte einzuführen und zu erklären. Es handelt sich dabei i.d.R. nicht um lexikonartige Definitionen, die Begriffe abstrahierend und kontextfrei definieren. Stattdessen sind Definitionen häufig an den situativen Kontext gebunden, der für die Gesprächsteilnehmer in der aktuellen [...] Gesprächssituation relevant ist [...]..$^{193}$

Menschen erlernen demnach von klein auf definierende Semantisierungspraktiken und unterscheiden dabei kontextuell und intuitiv auch zwischen relevanten und weniger relevanten Merkmalen, um den Gegenstand/Begriff zu charakterisieren oder von bedeutungsähnlichen Vertretern abzugrenzen. Henrike Helmer beschreibt mit einem konversationsanalytischen und interaktionslinguistischen Ansatz, dass Sprecher/innen in Gesprächen mit der Formulierung $x$ heißt y zum Beispiel entweder Fach- oder Fremdwörter, die ihren Gesprächspartnern nicht bekannt sind, oder indexikalische, ambige, polyseme oder problematische Ausdrücke erklären. Ihre Analysen deuten darauf hin, dass Definitionen von Fachund Fremdwörtern, obwohl diese ebenso wie die Definitionen problematischer Ausdrücke jeweils situativ verankert werden, teilweise eher allgemein formuliert werden, so dass die angegebenen Denotationen auch auf andere Situationen übertragbar sind (vgl. Helmer 2020: 278; 294).

Das wiederholte Rezipieren von Bedeutungsparaphrasen im Prozess des Spracherwerbs oder in Lehr-Lern-Situationen und die Verwendung von einsprachigen Wörterbüchern im Schulunterricht können, so ist weiterhin anzunehmen, dieses Praxiswissen zum Definieren befördern. Das Beispiel der beiden Jungen bei Wiegand zeigt, dass Definieren ein basales Bedürfnis in einer Sprachgemeinschaft darstellt. Überträgt man das zitierte Beispiel der Kinder auf die vorliegende Diskursanalyse, so lässt sich Folgendes daran veranschaulichen: Es geht für diese Arbeit ähnlich wie im Projekt „Definitionen in Interaktion“ nicht um die Frage, an welchen Stellen eins zu eins und in vollendeter Form das „klassische Definitionsverfahren“ angewendet wird, sondern welche (nicht reflektierten) Verfahrensmuster bzw. Praktiken mit definitorischer Funktion sich im Diskurs zeigen bzw. welche Ähnlichkeiten sie zu reflektierten Methoden des Definierens und der Angabe von Bedeutungsparaphrasen aufweisen. Die Erkenntnisziele und Desiderate in Bezug auf den Forschungsgegenstand DeFINIEREN aus diskurslinguistischer Sicht wurden in Kapitel 1.1 beschrieben und werden in Kapitel 4.3.4 mit Bezug auf die Heuristik des Definierens noch weiter differenziert.

193 Das Forschungsprojekt „Definitionen in der Interaktion“ wird auf folgender Internetseite beschrieben: https://www.ids-mannheim.de/definitionen/ (zuletzt eingesehen am 12.7.2021). 
Inhaltlich anknüpfend an die Ausführungen Wiegands zur lexikografischen Praxis der Bedeutungsparaphraseangaben/lexikografischen Definitionen im allgemeinen einsprachigen Wörterbuch, findet man bei Töpel (2014) eine Übersicht über den Stand der Forschung zu lexikografischen Methoden für die Erstellung von Bedeutungsparaphraseangaben und „Typen der Bedeutungsparaphrase“ in Bedeutungswörterbüchern. Töpel konstatiert, dass „bisher keine sprachwissenschaftliche Theorie eine konkrete Methode zum Verfassen von Bedeutungsparaphrasenangaben“ vorgelegt habe (Töpel 2014: 293). Man könne aber „in den konkreten semantischen Paraphrasen bestimmte theoretische Ansätze“ wiedererkennen, wie z. B. die Merkmalssemantik oder den Prototypenansatz (ebd.). Folgende zehn Typen von Bedeutungsparaphraseangaben spielen nach Töpel (2014) mit Bezug auf Schlaefer ( $\left.{ }^{2} 2009\right)$ in „monolingualen, allgemeinsprachigen Wörterbüchern der Gegenwartssprache“ eine Rolle (Töpel 2014: 302f.):

1) „Die logische Bedeutungserläuterung“ orientiert sich am „aristotelischen Vorbild“;

2) Die „paradigmatische Bedeutungserläuterung“ über „Synonyme (seltener Antonyme)“;

3) „Diemorpho-semantischeBedeutungserläuterung“-sie „paraphrasiert,das syntagmainterne Bedeutungsverhältnis der beiden unmittelbaren Konstituenten` (Schlaefer 2009, 95) und kann mit der Wortbildungsbedeutung gleichgesetzt werden, z. B.: Geburtstagsgeschenk 'Geschenk zum Geburtstag' (Duden online)“;

4) Die „Negations-/Ausschlussparaphrase“, z. B.: „locker 'nicht straff [gespannt], nicht starr; nicht fest' (Duden online)“;

5) Die „Funktionsparaphrase“, die „vorwiegend bei den synsemantischen Wortarten benutzt“ wird. „[S]ie benennt ,grammatische, semantische oder pragmatische Funktionen' (Schlaefer 2009, 96), z. B.: was 'bezeichnet in Relativsätzen dasjenige, worüber im Relativsatz etwas ausgesagt ist' (Duden online).“;

6) Die „Einwortparaphrase“ - die Bedeutungserläuterung „besteht [...] lediglich aus einem einzigen Wort“, z. B. „Zündholz 'Streichholz'“;

7) Die „Rektionsparaphrase“ - sie wird „vor allem bei Verben eingesetzt und zeigt in ihrer Struktur bereits die Rektion“;

8) Die „metalinguistische Bedeutungserläuterung,weist Relationsprädikate auf, die eine metalinguistische Aussage über die Funktion des Stichwortes enthalten' (Schlaefer 2009, 96), z. B.: Raffel '(landschaftlich salopp abwertend) großer, als hässlich empfundener Mund' (Duden online)“;

9) Die „taxonomische Bedeutungserläuterung“ nach Schlaefer ('2009: 95f.), die „stärker in Fachwörterbüchern Verwendung findet, weil sie begriffliche Taxonomien voraussetzt“.

10) Die „ostensive Bedeutungserläuterung“ nach Schlaefer (2009: 95f.), wenn eine „Abbildung die Funktion der Bedeutungsparaphrase übernimmt“.

Welche Art der Bedeutungsparaphraseangabe gewählt werde, hänge „,von einer Vielzahl von Faktoren“ ab (Töpel 2014: 304f.). „Die erste Gruppe der Aspekte“ betreffe das Wörterbuch selbst, beispielsweise die Zielgruppe und Art des Wörterbuchs (ebd.). „Die zweite Gruppe von Einflussfaktoren“ hänge „mit den speziellen Charakteristika des zu beschreibenden Lexems“ zusammen: 
Die typische logische Bedeutungserläuterung lässt sich lediglich auf Vertreter der Autosemantika anwenden, bei den synsemantischen Wortarten muss auf eine Funktionsparaphrase zurückgegriffen werden. Auch die Wortart des Lexems bzw. seine grammatischen Eigenschaften spielen eine Rolle, wenn es um die Wahl eines angemessenen Paraphrasentyps geht $[\ldots]$.

(Töpel 2014: 305)

In ähnlicher Weise argumentiert auch Kwary (2011), der eine Typologie von Definitionsformen in Wörterbüchern für spezielle Fachgebiete vorschlägt, je nachdem ob sich die Wörterbücher an Experten/Expertinnen oder Laien richten und ob sie für das Textverstehen oder die Textproduktion genutzt werden sollen.

Diese Faktoren lassen sich auf die Analyse des Burnoutdiskurses übertragen. So werden die Passagen, in denen das Phänomen oder der Begriff `BURNOUT< definiert wird, im praktischen Teil der Arbeit dahingehend analysiert, ob sie je nach Kommunikationssituation und Publikationstyp (und den damit einhergehenden Zielgruppen und Textsorten) variieren (vgl. die Kap. 6.2.2.1, 6.2.2.2 und 6.2.3.1 und 6.2.3.2). Des Weiteren ist aus diskurslinguistischer Perspektive zu hinterfragen, inwieweit der Bereich, aus dem das zu definierende Phänomen stammt (also z. B. `BURNOUT` als Phänomen des Bereichs PSYCHISCHE GESUNDHEIT UND KRANKHEIT, vgl. Kap. 3), sich auf die definitorischen Praktiken auswirkt und inwiefern die Wortart des Neologismus Burnout bzw. seine grammatischen Eigenschaften für Definitionsbemühungen bedeutsam sind (vgl. Kap. 6.1).

Mit verschiedenen Arten des Definierens im Alltag als „bedeutungsreflexive[n] Erläuterungen“ beschäftigt sich Stanaitytė in ihrer Dissertation 2005 (Stanaitytė 2005: 32) anhand von Textmaterialien aus Zeitungen, Zeitschriften und Broschüren zu unterschiedlichen Themen (Stanaitytė 2005: 13f.). Sie diskutiert zu Beginn ihrer Arbeit in Anlehnung an lexikografische Anforderungen an Definitionen zwei Kriterien für das Exzerpieren einer erläuternden Textpassage als Alltagsdefinition: erstens die „Bedingung der gegenseitigen Ersetzbarkeit [bzw. Substituierbarkeit, T.S.] von Definiendum und Definiens“, d.h., dass Definiens und Definiendum ,in jedem vorstellbaren Kontext austauschbar sein können, ohne dass dadurch eine semantische Veränderung des Satzinhaltes entsteht“ (ebd.: 33), und zweitens die „Bedingung des fremden oder unbekannten Ausdrucks“, d.h. „dass das zu Definierende vom Sprecher bzw. Schreiber beim Rezipienten als unbekannt angenommen wird“ (ebd.: 33f.). Beide Bedingungen könnten für die Beschreibung alltäglicher Definitionsverfahren jedoch „nicht hinzugezogen werden“, da im Alltag einerseits häufig nicht „,vollständig“ definiert werde. Andererseits könnten auch „semantische[n] Umdeutungen oder Interpretationen (z. B. von politischen Schlagwörtern)“, die sich nicht zwangsläufig auf unbekannte Ausdrücke beziehen, ,zu den alltäglichen Definitionsver- 
fahren gezählt“ werden (ebd. 34). Stanaitytė legt ihrer Arbeit eine eher weite Konzeption von „Alltagsdefinitionen“ zugrunde. Sie definiert Alltagsdefinitionen als

definitionsähnliche Verfahren im alltäglichen Leben [...], die der Erläuterung einer Wortbedeutung oder der Erklärung einer Sache (oder Aufklärung über eine Sache) dienen. Es sind also Bedeutungsbeschreibungen, die die Identifikation des bezeichneten Bezugsgegenstandes in einer Rede bzw. einem Text ermöglichen. Diese Erläuterungen können sowohl einzelne Wörter, Sätze als auch ganze Textsegmente umfassen. ${ }^{194}$

(Stanaitytė 2005: 30)

Wie auch schon die Argumentation Wiegands und die Erforschung von „Definitionen in Interaktion“ zeigte, hängt von der Strenge der definitorischen Kriterien ab, ob man bestimmte Strukturen in einem Diskurs oder Gespräch als Definition bezeichnet oder nicht. Stanaitytė betont des Weiteren mit Bezug auf von Polenz (2000) im Rahmen ihrer Erläuterungen zum Konzept >Alltagsdefinition`, dass „Alltagssprache“ „das spontane, direktive, kooperative sprachliche Reagieren auf natürliche und soziale Umwelt, zugunsten eines möglichst breiten, unreflektierten, auf typisierenden Interpretationen beruhenden gesellschaftlichen Konsenses" regeln würde (von Polenz 22000: 68). Die Auswirkungen dieses unreflektierten gesellschaftlichen Konsenses auf Prozesse des Definierens sind bisher jedoch nicht systematisch an einem Diskurs untersucht worden und dies soll in dieser Arbeit am Beispiel von Texten zum Burnoutsyndrom geleistet werden.

194 Stanaitytė beleuchtet im Rahmen ihrer Untersuchung zu „Alltagsdefinitionen und ihre[n] Funktionen“ mehrere Ebenen und stützt sich bei ihrer Analyse der satzsemantischen Struktur von Alltagsdefinitionen zentral auf den satzsemantischen Ansatz von Peter von Polenz (1985, im Literaturverzeichnis unter Polenz ${ }^{3} 2008$ ). Das linguistische Verständnis von >Definition ist für Stanaitytė entscheidend von lexikografischen Traditionen der Bedeutungserläuterung geprägt. Sie grenzt „Alltagsdefinitionen“ jedoch von „lexikographischen Definitionen“ dadurch ab, dass erstere nicht durch „methodisch geleitete Beschreibungssysteme“ entstünden, sondern als „Erscheinungen im semantischen Diskurs in der natürlichen Sprache“ (ebd.: 27) verstanden werden müssten. Sie untersucht darüber hinaus „Alltagsdefinitionen und ihre Funktionen im Text und in der Textillokutionsstruktur“, „Alltagsdefinitionen und ihre Positionierung in den propositionalen Strukturen des Textes" und bezieht ihre Erkenntnisse auch auf „Definitionsarten“, bei deren Differenzierung sie sich an der Wissenschaftstheorie und wissenschaftlichen Lexikografie orientiert (vgl. Stanaityte 2005: 172). Stanaitytės Analyseergebnisse werden bei der Formulierung der Forschungsdesiderate dieser Arbeit und der Konzeption der Arbeitsdefinition einer diskursiven Praxis des Definierens berücksichtigt. Es wird dabei dargelegt, in welcher Weise der vorliegende Begriff einer >diskursiven Praxis des Definierens « eine andere Analyseperspektive einnimmt, zum Beispiel dadurch, dass auch „funktionsähnliche[n] sprachliche[n] Mittel“, die Aufgaben des Definierens in der „Fläche“ der Diskursstränge erfüllen, mit einbezogen werden (Kap. 4.3.4). Stanaitytė konzentriert sich auf schriftsprachliche Texte öffentlicher Kommunikation (Medientexte, politische Texte, Broschüren, etc.) (siehe Stanaitytė 2005: 13f.). 
Zum Schluss dieses Überblicks sei noch die korpuslinguistische Erforschung von Fachwortschätzen, Definitionen und kommunikativ-wissenschaftlichen Praktiken angesprochen. Müller/Mell (2020: 198) führen aus, dass der korpuslinguistische Zugang in Arbeiten „zum akademischen Diskurs im Spannungsfeld von Wissen, Sprache und institutionellem Kontext“ aus dem Umfeld der „Didaktik der englischen Wissenschaftssprache“ eine große Rolle spielt:

In diesem Rahmen werden z. B. Termini über Kollokationsprofile bestimmt (Gledhill 2000).
Termini werden gleichsam profanisiert und in eine Reihe etwa mit Routineformeln in aka-
demischen Texten gestellt (Hyland 2008). Erhöhte Aufmerksamkeit erhält auch die Frage,
welche Rolle Metaphorizität bei der Bildung und beim Gebrauch von Termini spielt. Es ist
eher die Regel als die Ausnahme, dass Termini aus anderen Wissensdomänen in Fachdis-
kurse importiert werden.
(Müller/Mell 2020: 198)

Des Weiteren geht es in korpuslinguistischen Arbeiten um die Frage der Annotation von Definitionen in den zu untersuchenden Textkorpora. Die Dissertation aus der Computerlinguistik von Irene M. Cramer verfolgt das Ziel, „,Voraussetzungen und Methoden für die automatische Extraktion definitorischer Textsegmente aus Korpora zu untersuchen“ (Cramer 2011: 3). Sie fokussiert ähnlich wie Stanaitytè (2005) Alltagsdefinitionen (Cramer 2011: 3) und formuliert für ihre Annotationsarbeit folgende Definition der Definition:

Eine Definition im Sinn der vorliegenden Arbeit ist eine kurze [hier ergänzt die Autorin per Fußnote: „[i]n der Regel nicht länger als ein Satz“, T.S.] Beschreibung der Bedeutung oder Verwendung einer sprachlichen Einheit. Sie nennt zentrale Bedeutungs- bzw. Verwendungsaspekte dieser Einheit und sollte in Bezug auf Kontexteinbettung, Formulierung und Rezipient informativ und angemessen sein. Für einen Rezipienten ist sie damit ein Hilfsmittel zur Verortung der definierten Einheit in seinem Wortschatz. (Cramer 2011: 6)

Sie greift auf Vorarbeiten zur (halb)automatischen Extraktion von Definitionen zurück und erläutert deren Untersuchungsmethoden und Ausgangsbedingungen, beispielsweise von welchen Definitionsverben, -konstruktionen und Definitionsformen diese ausgehen (z. B. terminologische Definitionen in Fachtexten), wobei „hier häufig eine Beschränkung auf die aristotelische Definition zu beobachten“ sei (Cramer 2011: 97). Die dort genannten „Definitorverben“ (z. B. bedeuten, benennen, definieren, ...) und Definitorkonstruktionen (vgl. Cramer 2011: 62; Westerhout/Monachesi (2007) $)^{195}$ werden mit den in den analysierten Texten

195 Cramer nennt mit Rückgriff auf Westerhout/Monachesi (2007) erstens „Definitionen mit dem Definitor sein“, zweitens mit „metasprachlichen Definitorien“ wie „etwa bedeuten, genannt 
des Burnout-Diskurses aufgefundenen Definitorverben und -konstruktionen verglichen und gehen dadurch auch in die Übersichtstabellen zu sprachlichen Mitteln des Definierens (siehe Kap. 6.2.2.4 und 6.2.3.3) und in das Modell einer diskursiven Praxis des Definierens ein (vgl. Kap. 7). Darüber hinaus lässt sich die von Cramer durchgeführte Fragebogenstudie mit den in Kapitel 4.2.2 herausgearbeiteten „Erwartungen an die Tätigkeit des Definierens im Burnout-Diskurs“ vergleichen. In dieser Umfrage sollten 96 Versuchspersonen intuitiv für verschiedene Textsegmente bewerten, ob es sich ihrer Meinung nach „sicher um eine Definition“, „evtl. um eine Definition“ oder „sicher um keine Definition“ handle. Cramer, die vier Definitionstypen ${ }^{196}$ in ihren weiterführenden Annotationsexperimenten berücksichtigt, kommt auf der Basis ihrer aus der Umfrage abgeleiteten Beobachtungen zu dem Schluss:

Die verschiedenen Experimente des Dissertationsprojekts zeigen allerdings, dass es sich bei Definitionen häufig um syntaktisch, semantisch und pragmatisch äußerst komplexe Textsegmente handelt, die nicht nur schwer zu extrahieren, sondern vor allem schwer zu annotieren sind. Ob also ein Textsegment von einem bestimmten Rezipienten als Definition interpretiert und genutzt wird, hängt teilweise stark von individuellen Faktoren ab.

(Cramer 2011: iv)

Auch Bender/Müller (2020), die Definitionen in einem Forschungsprojekt als eine heuristische Textpraktik unter anderen in verschiedenen wissenschaftlichen Disziplinen untersuchen, diskutieren die verschiedenen Schritte ihres komplexen kollaborativen Annotationsschemas, das sie in ihrer Studie zur Identifikation verschiedener Typen und Varianten heuristischer Textpraktiken anwenden (vgl. Bender/Müller 2020: 15-22): Zum Beispiel ergebe sich bei einer Annotation einer textpragmatischen Kategorie wie der Definition die Frage, „wo ein zu annotierendes Segment beginnt und wo es aufhört“ (Bender/Müller 2020: 20) und wie man gewährleisten könne, dass annotierte Kategorien miteinander vergleichbar

werden“, drittens mit „Satzzeichen als Definitor“ (zum Beispiel Doppelpunkt, vgl. Kap. 6.2.2.1), viertens „Definitionen mit typographischen Merkmalen“ (vgl. Kap. 6.2.2.1 und 6.2.2.2) und fünftens „Definitionen, die Relativ- bzw. Possessivpronomen [sic! Westerhout/Monachesi sprechen nicht von Possessivpronomen, sondern von „demonstrative pronouns“, T.S.] enthalten, mit denen auf ein Definiens in einem vorangegangenen Satz verwiesen wird“ (Cramer (2011: 99) mit Bezug auf Westerhout/Monachesi (2007: 4ff.), online abrufbar unter: https://www.semanticscholar.org/paper/Extraction-of-Dutch-definitory-contexts-for-Westerhout-Monachesi/ fc8431ac49d63179ab80817e05a8f3de461ce31f?p2df (zuletzt eingesehen am 21.2.2021)).

196 Sie bezieht sich dabei auf „die aristotelische Definition, die operationale Definition, die wortassoziative Definition und die einfache Synonymendefinition bzw. exemplarische Definition“ (Cramer 2011: 166ff.). 
seien (vgl. ebd.). Aus diesem Grund entscheiden sie sich dafür, „grundsätzlich nur syntaktische Sätze“ zu taggen (ebd.). Bender/Müller verweisen zudem auf die Problematik von Überschneidungen zwischen den zu annotierenden Kategorien und kommen zu dem Schluss, dass es im Hinblick auf die Auswertung besser sei, Mehrfachannotationen zu vermeiden und stattdessen das Kategorienschema so weit zu entwickeln, bis es ,eine trennscharfe Annotation mit exklusiven Kategorien“ erlaube (ebd.: 21). Schließlich sei die „Interpretationstiefe im Kategorisierungsprozess“ bei komplexen Annotationen zu bedenken, da es zwischen „sprachpragmatischen und sprachstrukturellen Kategorien probabilistische, nicht aber feste Verbindungen“ gebe (ebd.). Dadurch seien ,indirekte Performances heuristischer Textpraktiken“ gegebenenfalls nicht eindeutig erkennbar und würden eine Tiefeninterpretation erfordern. Dies führe jedoch wiederum dazu, dass „Tags auf unterschiedliche Interpretationstiefen“ zugriffen, was die Vergleichbarkeit beeinträchtige, „[s]elbst, wenn im Einzelfall im Sinne eines kollaborativen Annotator-Agreements Übereinstimmung über eine tiefe Interpretation erzielt" worden sei (ebd.).

Der in diesen Beispielen deutlich gewordenen Komplexität der „Textsegmente“ bei Definitionen soll durch die in dieser Arbeit vorgelegte Heuristik, die induktive und deduktive Analysezugänge kombiniert und die Praxis des Definierens auch über Textgrenzen hinweg diskurslinguistisch in den Blick nimmt, nachgegangen werden. Die in diesem Kapitel dargelegten linguistischen Ansichten zum Forschungsgegenstand >Definition` und die damit zusammenhängenden Praktiken lexikografischer Definition dienen als wichtige Ausgangs- und Orientierungspunkte für die Analyse sprachlicher Mittel des Definierens im Burnout-Diskurs (punktuelle Perspektive, siehe die Kap. 6.2.2-6.2.3). Sie sind Teil der Untersuchungsheuristik, die in Kapitel 4.2. und seinen Unterkapiteln (4.2.14.2.4) entfaltet wurde.

\subsection{Zusammenfassung: Das Untersuchungsmodell im Überblick}

\subsubsection{Vorbemerkung}

Die folgenden Kapitel bieten eine Zusammenführung der theoretischen und methodischen Grundlagen, die der folgenden diskurslinguistischen Analyse $\mathrm{zu}$ wiederkehrenden Zeichenkonstellationen mit definitorischem Potenzial zugrunde liegen. In Kap. 4.3.1 werden demnach in einem kurzen Abriss die Verbindungslinien zwischen den in den letzten Kapiteln dargelegten semiotischen, diskurslinguistischen und praxeologischen Theorien mit Bezug auf den Analysegegenstand aufgezeigt. Daraus ergeben sich zwei Blickwinkel auf das Diskurs- 
phänomen „Definieren“: ein sprachhandlungsorientierter (Kap. 4.3.2) und ein praxeologischer (Kap. 4.3.3). Auf der Zusammenführung dieser Perspektiven fußt die Arbeitsdefinition einer diskursiven Praxis des Definierens, die zusammen mit den Desiderata in Bezug auf den Untersuchungsgegenstand des Definierens im Diskurs in Kap. 4.3.4 dargelegt wird. Die genaue Beschreibung des Analysevorgehens, die eng an diese Kapitel anschließt, erfolgt schließlich in Kap. 6.2.1 im Rahmen des Großkapitels zur Analyse der fachinternen und fachexternen Diskursstränge.

\subsubsection{Zusammenfassung theoretischer und methodischer Grundlagen}

In Kapitel 2, 3 und 4 wurden Grundannahmen einer zeichengebunden diskursiven Wissenskonstituierung mit Bezug auf die Semiotik von Peirce, die Diskurslinguistik im Anschluss an Foucault und die Analysekategorie diskurslinguistischer Praktik bzw. Praxis entfaltet. Diese Theorien wurden für die Arbeit miteinander verbunden, weil sie alle von den (sprachlichen) Zeichen selbst ausgehen und ihnen praktische Effekte und damit eine konstitutive Rolle bei der Entstehung von Wissen zusprechen. Des Weiteren eint diese Ansätze zum einen, dass sie sowohl sprach- bzw. diskursintern-systematische als auch sprach-/diskursexternpragmatische Faktoren in den Sinnbildungsprozess mit einbeziehen und zum anderen, dass sie sich mit dem intrikaten Wechselverhältnis zwischen (vorreflexivem) prozeduralem und (bewusstem) deklarativem (Regel-)Wissen auseinandersetzen (vgl. die Kap. 2.2 und 4.1). Insbesondere die Analysekategorie der Praktik/ Praxis, die in dieser Arbeit für die Diskursanalyse stark gemacht wird, eignet sich gut, um die „im Sozialen gelagerten kognitiven, volitiven, emotionalen und physischen Verhaltensroutinen“ (Müller 2015: 18), die intentionale Handlungen begleiten, differenziert zu beschreiben und in der Analyse mit intentionalen Kriterien zusammenzuführen.

Auf den Untersuchungsgegenstand einer diskursiven Praxis des Definierens bezogen heißt dies, dass Definieren aus sprachhandlungsorientierter und praxeologischer Perspektive untersucht wird. Im Kapitel 4.2, der Heuristik des Definierens, wurden schon einige Funktionen, die Definitionen erfüllen sollen, aus metasprachlichen Äußerungen von Diskursakteurinnen und -akteuren extrahiert, und in den Kapiteln danach wurden wissenschaftstheoretische und linguistische Definitionskriterien dargelegt. Die folgenden Kapitel reflektieren nun den sprachhandlungsorientierten und praxeologischen Blickwinkel genauer und leiten über zum letzten Unterkapitel von Kapitel 4, in dem eine Arbeitsdefinition für die weitere Analyse der diskursiven Praxis des Definierens gegeben wird. 


\subsubsection{DDefinieren aus sprachhandlungsorientierter Perspektive - repräsentative und deklarative Aspekte}

Das Paradigma einer Definitionshandlung mit Mitteln der Sprache ist ein Sprechakt, dem sowohl repräsentative als auch deklarative Merkmale zukommen. Repräsentative, da, wie die Beispiele aus dem Burnout-Metadiskurs zum Definieren gezeigt haben (vgl. Kap. 4.2.2), die Propositionen des Definierenden zumindest bei Realdefinitionen danach beurteilt werden, ob sie „der Welt entsprechen“ (Searle 1980: 84). Dieser Anspruch nach sachgemäßem Realitätsbezug führt direkt in die sprachphilosophische Debatte um die Frage, worauf sprachliche Zeichen verweisen, auf „reale Gegenstände und Sachverhalte, [...] mentale Konzepte oder [...] sprachliche Zeichen“ (Bär 2015: 25) ${ }^{197}$ Auch wenn man annimmt, dass es eine außersprachliche Realität gibt, so heißt das nicht, dass diese „mit ihren materiellen und geistigen Gegenständen und Sachverhalten in unserer Erkenntnis objektiv gegeben ist" und dass die Wörter nur „der Bezeichnung dieser Gegenstände“ dienen (Gardt 2002: 111; vgl. Bär 2015: 25). In Definitionen mit sprachlichen Mitteln verweisen Zeichen auf Zeichen und der kommunikative Zweck einer Definitionshandlung besteht darin, dass der Definierende im propositionalen Akt das in Frage stehende Bezugs- oder Redeobjekt prädikativ durch bereits bekannte Zeichen ${ }^{198}$ für sich selbst und etwaige Rezipienten (hinreichend genau, wesentlich und systematisch) feststellt oder festsetz ${ }^{199}$, von anderen Sachverhalten/Begriffen differenziert, in bestehendes Wissen einordnet und es dadurch mehr oder weniger genau identifiziert. Metaphern sind dabei möglicherweise aufgrund ihrer ikonischen Kraft zwar ein beliebtes Mittel, aber sie sind vor dem Hintergrund ihres Bezugs zur außersprachlichen Realität auch Gegenstand von Definitionskritik, wie das Beispiel unter Abschnitt D in Kap. 4.2.2 gezeigt hat. Doch könnte diese

197 Einen differenzierten Überblick zum Repräsentationsproblem (sprachlicher) Zeichen findet man bei Köller (2004: 219ff.) sowie bei Bär (2015: 25ff.); Spitzmüller/Warnke behandeln das Problem der Referenz für die Diskurslinguistik (Spitzmüller/Warnke 2011: 48ff.).

198 Dabei kann die Gruppe, in der die Zeichen bekannt sind, differieren, beispielsweise Fachgruppen, Berufsgruppen oder die Sprecher/innen der Standardvarietät des Deutschen.

199 Pawłowski verdeutlicht am Verbenpaar a) feststellen und b) festsetzen die Unterscheidung zwischen einer Definition, die a) ,den Sinn, den dieser Ausdruck in Sprache S besitzt, getreu wiederzugeben“ versucht und b) ,wenn der Ausdruck A in der Sprache S vor der Einführung der Definition ungebräuchlich war, oder wenn sie für den Ausdruck A einen neuen Sinn festsetzt, ohne sich um den bereits festgestellten Sinn dieses Ausdrucks zu kümmern“. Für Pawłowski gibt es noch eine dritte „regulierende Definition“, die „zwischen diesen beiden Extremen“ vermittelt (Pawłowski 1980: 18/19). Die Definitionsart b) wird in der Literatur auch als „stipulative Definition“ bezeichnet (Prechtl 52016: 131). 
Kritik, dass der metaphorische Ausdruck Burnout nicht sachadäquat sei, auch ohne realsemantische Rückgriffe aus gebrauchssemantischer Sicht gedeutet werden? Im Beispiel von Burisch ( ${ }^{5} 2014: 9 \mathrm{f}$. im QV unter 8.1.5) zeigt sich ein Konflikt zwischen seiner aktuellen zeichengebundenen Perspektivierungsanstrengung und anderen regelhaften Verweisen bzw. früheren kulturellen Perspektivierungen (vgl. Köller 2004: 219): Burisch versucht, den Zeichenausdruck Burnout als „regelhafte[n] Verweis“ (vgl. Bär 2015: 34) für den Verwendungszusammenhang >Erschöpfung durch anhaltende negative Energiebilanz` festzusetzen. Dem steht, wie Burisch behauptet, jedoch ein sich im Zeichen Burnout manifestierender regelhafter Verweis auf 'plötzliches Durchbrennen von etwas' und dadurch das Konzept splötzlicher, gänzlicher Leistungsverlust` gegenüber. Wenn von Definitionsakten eine repräsentative Kraft im Searle'schen Sinne verlangt wird, so hieße dies aus pragmasemiotischer Sicht, dass die definitorischen Propositionen danach beurteilt werden, ob sie anderen zeichengebundenen kollektiven Erfahrungen und dem sich in Zeichen manifestierenden „Willen zum Wissen“ (Foucault [1970] 1993: 14f.) entsprechen bzw. daran anschließbar sind. Die definierende Person müsste schließlich - wieder analog zur Argumentation Searles - glauben, dass diese Anschließbarkeit an bestehendes Wissen und damit kollektive Akzeptanz möglich ist. Der ontologische Status des Definiendums, sprich des in Frage stehenden Bezugsobjekts, wäre vor diesem Analysehintergrund eigentlich gleichgültig, da in der Definitionshandlung nur Zeichen auf Zeichen verweisen. Dass der Realitätsbezug dennoch für die Beschreibung definitorischer Praxis im Diskurs Relevanz besitzt, resultiert daraus, dass viele der Definitionen im Diskurs von einem solchen Denkhorizont aus formuliert und in dieser Weise auch sprachlich modalisiert werden (vgl. Köller 1995: 39f; Felder 2006a: 167ff.). Sprachliche Praktiken, welche den Geltungsanspruch einer Definition qualifizieren, sind damit genuiner Bestandteil definitorischer Praxis und daher Gegenstand der vorliegenden Analyse. Des Weiteren würde eine rigorose Absage an den Realitätsbezug in sprachlichen Definitionen dazu führen, dass auch Symptome wie ein stark erhöhter Puls oder Einschlafprobleme, die wir als unmittelbar erfahrbare Reize erleben bzw. die mit den Worten von Peirce Indices darstellen (vgl. Kap. 2.2.2), in den Definitionen gewissermaßen nur als rein sprachliche Produkte erschienen.

Dass Definitionen deklarative Kräfte entfalten können ${ }^{200}$, wird deutlich, wenn man sich im Bereich von Gesundheit und Krankheit die Rolle der interna-

200 Vgl. auch Felder 2003, der in Anlehnung an Searle definieren den „Deklarativa“ zuordnet (Felder 2003: 70). 
tionalen Klassifikationssysteme (ICD, DSM) ansieht. Denn diese Institutionen bewirken, wenn sie ein Beschwerdebild in ihr Klassifikationssystem aufnehmen, dass der noch mögliche „Streit über die Wahrheit einer Behauptung [hier der inhaltlichen Bestimmung eines psychosomatischen Phänomens und der Klassifizierung als Krankheit, T.S.] zu einem Ende kommen kann“ (Searle 1980: 99). ${ }^{201}$ Durch die deklarative Kraft wird „eine endgültige Meinung“ durchgesetzt, die für Peirce ein regulatives Ideal im eigentlich unabschließbaren Sinnbildungsprozess darstellt (vgl. CP 8.148 und Kap. 2.2.2). Die deklarierenden Institutionen bringen den propositionalen Gehalt der jeweiligen Definition mit der Wirklichkeit/dem bestehenden Wissen dahingehend zur Deckung, dass jemand nur dann als >depressiv ' gilt und Leistungen der Krankenkasse in Anspruch nehmen kann, wenn er die dort definierten Symptome über einen bestimmten Zeitraum hinweg aufweist (vgl. Searle 1980: 98; Saß/Saß-Houben 2005: 137ff.). Für die in Kapitel 6 erfolgende Analyse ergibt sich daraus die Untersuchungsfrage, an welchen Stellen im Diskurs Definitionshandlungen stattfinden und mit welchen sprachlichen Mitteln diese markiert werden. Einige Funktionen des Definierens (Differenzierung des in Frage stehenden Sachverhalts von sachverwandten Gegenständen etc.) können allerdings auch über ein Zusammenspiel verschiedener im Diskurs verteilter Praktiken ,erfüllt` werden. Das folgende Kapitel widmet sich Phänomenen dieser Art aus einer praxeologischen Perspektive.

\subsubsection{Definieren` im Diskurs aus einer praxeologisch-phänomenorientierten Perspektive}

Dem deklarativen Akt der Definition eines Krankheitsbildes in einem Klassifikationssystem geht ein „diskursiv-symbolischer“ Interaktionsprozess (Konerding 2009: 90) der Aushandlung und Einigung voraus. Die Deklaration ist das Ergebnis eines Definitionsprozesses innerhalb eines (fach-)kulturellen, sozialen Bedingungsgefüges. Durch die geforderten Kriterien der Allgemeingültigkeit, Exaktheit, Adäquatheit etc., die sich in verschiedenen sprachlichen Modalitätsspielformen widerspiegeln, scheint expliziten Definitionsakten der Stellenwert eines Anhaltsoder Kontrollpunkts für den „diskursiven Regress“(Konerding 2009: 81) innerhalb

201 Searle bezeichnet solche Fälle, in denen Behauptungen deklarative Unterstützung erhalten, auch als „Repräsentativdeklarationen“ (Searle 1980: 99). Des Weiteren führt Searle unter anderem lexikalische Definitionen als Ausnahmebeispiel für Deklarationen an, die keine ,außersprachliche Institution“ erfordern, um die Deklaration erfolgreich zu vollziehen (Searle 1980: 98). 
einer legitimierenden Argumentation oder eines Diskurses zur Herausbildung deklarativen Wissens zuzukommen. Das Ziel der Aushandlung ist, zumindest im Kontext medizinischer Klassifizierungsbemühungen und Verschreibungspraktiken, ein gemeinsamer Nenner, sprich Konsens. Das heißt jedoch nicht, dass die Gültigkeit von Definitionen und die sich darin zeigenden interessengeleiteten, semiotisch perspektivierten Sachverhalts- und Bedeutungsfestsetzungen bei Themen aus dem Bereich Gesundheit und Krankheit nicht diskursiv ausgehandelt werden (vgl. Felder 2006b; Busch 2006; Felder 2013; Schnedermann 2016 und Kap. 7.3). Wenn in einem Diskurs jedoch Stimmen eine einheitliche Definition fordern bzw. deren Vorhandensein immer wieder negieren, so lässt dies vermuten, dass ein Bedürfnis nach einer gemeinsamen Verständigungsbasis bzw. Identifizierung eines als problematisch wahrgenommenen Phänomens besteht, um für dieses einen gesellschaftlich praktikablen und kontrollierten Umgang zu erzielen. Die Tätigkeit des Definierens erscheint vor diesem Hintergrund als kollektiv-gesellschaftliche „problemlösungsbestimmte Verfahrensweise[n], [...] -routine[n]“ (vgl. Konerding 2009: 85 und Kap. 4.1 dieser Arbeit) zur kontrollierten Identifizierung eines Phänomens. ${ }^{202}$ Wenn sich in einem Diskurs zudem der Eindruck einstellt, dass sich eine definitorische Konzeptualisierung durchzusetzen scheint, dann ist danach zu fragen und diskursanalytisch transparent $\mathrm{zu}$ machen, wodurch dieser Eindruck entsteht (z.B. durch diskursive Praktiken der Verknappung, Gewichtung und Geltungsvalidierung, siehe Kap. 6.2.4.2), von welcher Qualität dieser vermeintliche definitorische Konsens ist (vgl. Felder 2013: 20 und die zusammenfassenden Kapitel in Kap. 6) und welche meist nicht bewusst verfügbaren sozialen Praktiken und Commonsense-Überzeugungen ${ }^{203}$ sich in den Definitionsbemühungen manifestieren bzw. zur Abgrenzung des Definiendums von benachbarten Phänomenen oder Konzepten beitragen (siehe besonders Kap. 6.2.4.1).

Interessant aus dem Blickwinkel einer praxeologisch-phänomenorientierten Perspektive ist folglich, welche Spuren (unwillkürlicher) sozio-kultureller, dis-

202 Dass Definitionen auf ein Bedürfnis nach Orientierung reagieren, wird auch durch die Forschung zu Benutzervoraussetzungen von Wörterbüchern unterstrichen. Wörterbücher seien „Gebrauchsgegenstände“, die „vor allem (aber nicht nur) benutzt werden, wenn sprachbedingte aktuelle Kommunikationsstörungen (Textproduktions- und Textrezeptionsstörungen) oder Unsicherheiten auftreten“ (Wiegand 1989: 552).

203 Mit `Common Sense`/>Gemeinsinn` wird hier z. B. auf gewohnheitsmäßige Verhaltens- und Handlungsweisen des Umgangs mit Phänomenen aus dem Bereich zwischen `Gesundheit $\triangleleft$ und `Krankheit`, gesellschaftliche Toleranzgrenzen, Skalen, Normen und (Berufs-)Rollenvorstellungen, aber auch fachkulturelle und praktizierte Methoden, Paradigmen etc. referiert. 
kursiver Praktiken bzw. Stimuli der Diskurs aufweist, die auf den Prozess des Definierens einwirken bzw. in ihrer Gesamtheit eine diskursive Praxis des Definierens bilden. Mit anderen Worten und auf das Diskursthema bezogen: Welche diskursiven sprachlichen Strukturen korrelieren mit gewohnheitsmäßigen Verhaltens- und Handlungsweisen, um einen Gegenstand wie BuRNout zwischen den Polen `Gesundheit ` und `Krankheit ` definitorisch zu verorten?

Im folgenden Kapitel werden die in den letzten Kapiteln aufgeworfenen Fragen und herausgearbeiteten definitorischen Kriterien in einer Arbeitsdefinition und einer diskursiven Praxis des Definierens gebündelt und prospektiv in ein Analyse-Modell überführt.

\subsubsection{Arbeitsdefinition einer diskursiven Praxis des Definierens und Forschungsdesiderate}

Die Beschreibungsmethode der folgenden Analyse orientiert sich, wie in den letzten Kapiteln dargelegt, an der Analysekategorie der Praktik/Praxis, da diese die Aufmerksamkeit auf die dynamische Verbindung von musterhafter Routine und subjektiver performativer Gestaltung bei der diskursiven Konstituierung von Wissen lenkt. Dem Arbeitsbegriff diskursiver Praxis des Definierens sei daher noch einmal vorausgeschickt, was in der vorliegenden Arbeit mit Rückgriff auf Foucault und soziologische und linguistische Theorien unter einer diskursiven Praktik verstanden wird (vgl. Kap. 4.1 dieser Arbeit):

Diskursive Praktiken sind gewohnheitsmäßige, habituelle ${ }^{204}$ Verhaltens- und Handlungsweisen ${ }^{205}$ im Umgang mit Aufgaben, Problemen, Gegenständen ${ }^{206}$ und semiotischen Ressourcen, die an der Textoberfläche sichtbar werden.

Daran schließt sich folgende Arbeitsdefinition diskursiver definitorischer Praktiken/Praxis an:

204 Vgl. die Bedeutungsangabe zu habituell auf Duden.online https://www.duden.de/rechtschreibung/habituell (zuletzt eingesehen am 8.9.2019).

205 Die Doppelform „Verhaltens- und Handlungsweisen“ verwendet auch Konerding (2009: 86). Zum Begriff des sprachlichen Verhaltens siehe ausführlich Müller (2015: 16ff., zusammenfassend ebd.: 19).

206 vgl. Feilke (2016: 265). 
Diskursive definitorische Praktiken werden als Praktiken bestimmt, die einzelne Zwecke oder Aufgaben, die aus den Funktionsansprüchen (eines Fachbereichs) an die Tätigkeit des Definierens erwachsen, mit verfügbaren (sprachlichen) Ressourcen verbinden und in ihrer Gesamtheit dadurch definitorische Wirkung entfalten, $d$. h. eine diskursive Praxis des Definierens bilden.

In dieser Arbeitsdefinition einer diskursiven Praxis des Definierens werden intentionale und nicht bewusst intendierte Sprachverwendungsregularitäten gleich gewichtet. Das heißt, einerseits werden aus handlungsorientierter Perspektive folgende Anforderungen an eine Definierenshandlung gestellt (vgl. Kap. 4.2.2 und 4.3.2):

Der kommunikative Zweck einer Definierens-Handlung besteht im strengen Sinn und insbesondere in Fachtexten darin, dass der Definierende das in Frage stehende Zeichen benennt (= Definiendum ${ }^{207}$ und in eine Entsprechungs-, bzw. Äquivalenzbeziehung (= Definitor) zu anderen bereits bekannten Zeichen(ketten) stellt (= Definiens), ${ }^{208}$ wodurch er das Definiendum für sich selbst und etwaige Rezipienten hinreichend genau, wesentlich bzw. in seiner Typik erfassend und mit dem Anspruch der Adäquatheit und intersubjektiver/allgemein konsentierter Gültigkeit feststellt oder festsetzt, von anderen Sachverhalten/Begriffen/Termini differenziert und in bestehendes Wissen einordnet.

Andererseits, wie an Beispielen in den letzten Kapiteln schon angedeutet wurde und wie in der folgenden Analyse gezeigt werden soll, ist Definieren in diesem Diskurs weit mehr als ein Satz oder Textabschnitt, der eingeführt von einer sprachlichen Formel wie $x$ ist/bedeutet/bezeichnet $y$ punktuell, intentional und

207 Nach Peirce könnte man sagen, es wird ein (neuer) Zeichenträger (sign), der im Akt der Interpretation mit einem „Zeichenobjekt“ $\mathrm{x}$ symbolisch verbunden werden soll, eingeführt; in der satzsemantischen Terminologie von P. von Polenz könnte man sagen, dass ein (neuer) „Bezugname“ genannt wird, der mit einem „Bezugobjekt“ $\mathrm{x}$ verbunden werden soll (von Polenz 32008: 138).

208 Stanaitytė (2005) spricht in diesem Zusammenhang mit Bezug auf die satzsemantische Terminologie nach P. von Polenz (1985) davon, dass „das Explizieren einer Bedeutung ein Akt des doppelten Referierens ist: zunächst wird ein Bezug zu einer Referenzstelle hergestellt, worauf dann der zweite Akt des Referierens folgt, indem auf die gleiche Referenzstelle ein weiterer Bezug genommen wird, der sich von dem ersten dadurch unterscheidet, dass er andere Referenzausdrücke zur gleichen Bezugsstelle verwendet“ (Stanaitytė 2005: 97). Beim Definieren werden zwei Zeichen direkt aufeinander bezogen. Da Zeichen, wie Bär (2015: 6) mit Bezug auf die Etymologie des Ausdrucks Zeichen ausführt, „nichts anderes als zeigend bzw. zeichenhaft handeln“ heißt, könnte man beim Akt des Definierens davon sprechen, dass das Definiendum-Zeichen und das Definiens-Zeichen in dieselbe Richtung zeigen. (ebd.). 
explizit in klassisch-terminologischen bzw. genau gefassten fachsprachlichen Kontexten geäußert wird. Es ist folglich darüber hinaus aus praxeologischer Perspektive zu fragen, welche sprachlichen Formen in der Zusammenschau im transtextuellen Diskursgeflecht definitorische Funktionen übernehmen, auch wenn sie für sich allein genommen keine Definitionshandlungen darstellen. Es wird also des Weiteren gefragt, welche Spuren (unwillkürlicher) sprachlicher und sozio-kultureller Praktiken der Diskurs aufweist, die auf den Prozess des Definierens einwirken bzw. in ihrer Gesamtheit über einen gewissen Zeitraum hinweg definitionsähnliche Effekte stimulieren können.

In der Arbeitsdefinition wurde bewusst nicht zwischen wissenschaftlicher und alltäglicher Definitionstätigkeit unterschieden. Die Arbeit schließt hierbei an empirische Arbeiten der Fachsprachenforschung an, die zwischen Fach- und Alltagswortschatz Verbindungen auch in fachlich geprägten Kontexten gefunden haben (vgl. Kap. 4.2.1 und 4.2.4). Dadurch, dass die definitorischen Praktiken in dieser Arbeit aber kontrastierend in fachlichen und fachexternen Kontexten analysiert werden, können Unterschiede sichtbar gemacht werden, die sich in den dominierenden Typen diskursiver Praxis des Definierens widerspiegeln (vgl. Kap. 7.2). Die Unterscheidung zwischen wissenschaftlicher und alltäglicher Definition ist einerseits wichtig, um bestimmte Kriterien wissenschaftlicher Begriffsbildung herauszustellen und zu schärfen. Sie kann andererseits aber dazu führen, dass die Praxis des Definierens zum einen nur in fachwissenschaftlichen Kommunikationsbereichen untersucht wird und zum anderen, dass mögliche Ähnlichkeiten oder Unterschiede sowie Bedingungsverhältnisse zwischen fachwissenschaftlichen und im Alltag entstehenden Definierenspraktiken, beispielsweise der Bezug auf gemeinsame implizite gesellschaftliche Normvorstellungen, nicht berücksichtigt werden. Dennoch ist mit Rückgriff auf die Untersuchung von Stanaitytè darauf hinzuweisen, dass Alltagsdefinitionen, in einigen Fällen aber auch fachliche Definitionen, gemessen an den oben formulierten strengen Ansprüchen (auf Adäquatheit, Wesentlichkeit etc.) und insbesondere gemessen an Kriterien „korrekte[r] Definitionen“ der traditionellen Logik (Kutschera/Breitkopf ${ }^{4} 1979$ : 140; vgl. Kap. 4.2.3) und der klassischen Terminologieforschung (vgl. Wüster ${ }^{3} 1991$ und Kap. 4.2.4), eher „definitionsähnliche Verfahren im alltäglichen Leben“ darstellen, „die der Erläuterung einer Wortbedeutung oder der Erklärung einer Sache (oder Aufklärung über eine Sache) dienen“ (Stanaitytė 2005: 30). Die vorliegende Arbeit schließt damit auch an Erkenntnisse empirisch-deskriptiver Analysen zum Gebrauch und zur Definition von Fachwörtern an, die Gütekriterien der strengen klassischen terminologischen Normung in Frage stellen (siehe die Zusammenfassung dieser Kritikpunkte in Kap. 4.2.4). Doch auch wenn die in Kapitel 6 im Folgenden zu untersuchenden definitorischen Textstellen punktuell, das heißt im Rahmen eines Abschnitts, nicht alle 
strengen Kriterien erfüllen, so ist die These dieser Arbeit, dass diese Ansprüche (z. B. nach 'intersubjektiver Gültigkeit' oder 'hinreichender genauer Abgrenzung') im weiteren (trans)textuellen Umfeld über einen Zeitraum hinweg dennoch zum Ausdruck gebracht werden können. Schon Wiegand hatte darauf hingewiesen, dass „definitionsähnliche Verfahren“ in „der alltäglichen Rede“ sich auf „verschiedene Gesprächsschritte verschiedener Gesprächspartner“ verteilen können (Wiegand 1989: 542). Diese Beobachtung wird auf den Diskurs sowohl räumlich als auch zeitlich übertragen.

Vor dem Hintergrund der bisher referierten wissenschaftstheoretischen und linguistischen Perspektiven auf die Tätigkeit des Definierens werden die Erkenntnisziele dieser Forschungsarbeit und Forschungsdesiderate im Folgenden nochmals zusammengefasst:

- Definieren wurde bisher überwiegend als reflektiert-bewusste, zeitlich begrenzte, ${ }^{209}$ punktuelle Sprachhandlung eines Textautors/einer Textautorin untersucht, in der symbolische Zeichen auf symbolische Zeichen bezogen werden (= symbolischer Fokus). Damit zusammenhängend wurde der Fokus in (korpus)linguistischen Untersuchungen zum Gegenstand >Definition` in schriftlichen Texten überwiegend auf Mehrwort-Cluster und die Satz- oder maximal Textabschnittsebene gerichtet (vgl. Stanaitytė 2005; Cramer 2011; Bender/Müller $2020^{210}$ und Kap. 4.2.4). Wie ist aber die Beobachtung zu deuten, dass sich bestimmte definitorische Konzeptualisierungen über einen gewissen Zeitraum hinweg in einem Diskurs durchzusetzen scheinen, obwohl es zur gleichen Zeit auch Marker des Dissenses bezüglich der Allgemeingültigkeit dieser Definitionen gibt? Kann man Definieren vor dem Hintergrund dieser Beobachtung zusätzlich zur bewussten Definitionshandlung auch als überindividuellen, transtextuellen chronologischen Prozess begreifen und beschreiben? Welche sozialen und (fach)kulturellen Praktiken und Normen beeinflussen einen solchen sich im Diskurs vollziehenden Definitionsprozess (= indexikalischer Fokus, vgl. Müller 2015: 48ff.)? In welcher Weise ist die intentionale Definitionshandlung „umspielt [...] von im Sozialen gelagerten kognitiven, volitiven, emotionalen und physischen Verhaltensrouti-

209 Müller/Mell (2020: 203) sehen darin ein noch „weitgehend unbeackertes Forschungsfeld“, dass Methoden der sprachhistorischen Forschung zur Fachlexik, die die „historische Dynamik von Fachwortschätzen“ beschreibe, auch auf kürzere Zeiträume von etwa 10 Jahren angewendet werden. Zur diachronen Analyse im Rahmen der deskriptiven Terminologieforschung siehe auch Temmerman (2000: 230).

210 Bender/Müller taggen syntaktische Sätze, um die quantitative Vergleichbarkeit ihrer annotierten Kategorien zu gewährleisten. Sie merken aber an, dass es komplexe definitorische Passagen gebe, die in „Koreferenzketten organisiert“ seien (Bender/Müller 2020: 20). 
nen“ (Müller 2015: 18, vgl. Kap. 4.1.2)? Vor diesem Hintergrund untersucht die vorliegende Arbeit Praktiken des Definierens im Burnout-Diskurs in ihren fachkulturellen, sozial-gesellschaftlichen und diskursiven Bedingungen, um daraus Impulse für eine empirisch begründete „Diskurstheorie des Definierens“211 zu entwickeln (vgl. Schmidt-Hertha/Tippelt 2011: 23).

- Die verzweigte philosophische, wissenschaftstheoretische und linguistische Literatur zum Definitionsbegriff und die aus der klassischen Terminologielehre, Merkmalssemantik und traditionellen Logik stammenden strengen Gütekriterien von Definitionen (z. B. notwendige und hinreichende Merkmale oder die Bedingung der gegenseitigen Ersetzbarkeit von Definiens und Definiendum (vgl. Stanaitytė 2005: 33), im Überblick Cramer (2011: 84) und Kutschera/Breitkopf ( ${ }^{4} 1979:$ 139ff.) vgl. Kap. 4.2.2-4.2.4) haben dazu geführt, dass diese Kriterien in linguistischen Arbeiten insbesondere für Alltagsdefinitionen, aber auch für lexikografische Bedeutungsparaphraseangaben in allgemeinsprachlichen Wörterbüchern und teilweise auch für terminologische Begriffssysteme in überzeugender Weise als zu einschränkend und zu starr zurückgewiesen wurden (vgl. Temmerman 2000: 4-15; Felder 2009a: 43; im Überblick Roelcke 42020: 92-105). Dadurch wurden manche dieser Kriterien für die Praxis des Definierens möglicherweise jedoch zu radikal aussortiert. In der vorliegenden Arbeit wird die These vertreten, dass an Definitionen nicht nur in fachsprachlichen, sondern auch in alltäglichen Kontexten je nach Fachbereich, Kontext und Situation bestimmte funktionale Ansprüche gestellt werden, die über das kontextsensitive „Verständnis sichern“ (vgl. Cramer 2011: 47) bzw. „optimal understanding“ (Temmerman 2000: 121) hinausgehen: Damit sei nicht gesagt, dass eine einzelne fachliche oder fachexterne Definition punktuell betrachtet alle definitorischen Ansprüche erfüllt (vgl. Kap. 4.2.2). Doch diese Kriterien, z. B. der „Anspruch auf angemessene Umgrenztheit und Konzentration auf wesentliche Faktoren“ oder auf ,allgemeine Gültigkeit, Validität und Intersubjektivität“, können sich durch Definitionskritik und intertextuelle Bezugnahmepraktiken in einem Diskurs nach und nach durchsetzen. Es scheint nicht nur fachintern, sondern auch fachextern ein prozedurales Wissen vorhanden zu sein, wie man die Aufgabe erfüllt, etwas zu definieren (vgl. Wiegand 1989; Helmer 2020, siehe Kap. 4.2.4). Aus diesem Grund werden in die vorliegende Heuristik einer Praxis des Definierens im Bereich psychischer Gesundheit und Krankheit die Ansprüche an die Tätigkeit des Definierens, wie sie von Stimmen im Burnout-Diskurs in fach- 
lichen und fachexternen Texten formuliert werden (= Metadiskurs zum Definieren im Burnout-Diskurs, siehe Kap. 4.2.2), mit einbezogen.

- Die im Burnout-Diskurs aufgefunden definitionsreflexiven Ansprüche sind induktiver Baustein einer Heuristik, die es sich zur Aufgabe macht, für den Fach- und Alltagsbereich psychischer Gesundheit bzw. Krankheit ein 11-Punkte-Modell einer diskursiven Praxis des Definierens $\mathrm{zu}$ entwerfen (siehe Kap. 7.2) und aus den Ergebnissen - den dominierenden Typen diskursiver Praxis des Definierens - eine Typologie abzuleiten, die für Anschlussstudien fruchtbar gemacht werden kann. Nach Töpel (2014: 304f.) hängt die Entscheidung, welche Art der Bedeutungsparaphrase gewählt wird, immer auch „mit den speziellen Charakteristika des zu beschreibenden Lexems“ zusammen und nach Kwary (2011) unterscheiden sich Definitionsformen in Wörterbüchern je nach Fachgebiet (vgl. dazu in Bezug auf die deskriptive Terminologieforschung auch Temmerman 2000: 226). Auf die diskursive Praxis des Definierens übertragen heißt das, dass in verschiedenen Fachgebieten und textuellen Erscheinungsweisen unterschiedliche Funktions-Ansprüche an Definitionen gestellt werden können. Das Desiderat dieser Arbeit ist es, ein Analysemodell einer diskursiven Praxis des Definierens zu entwerfen, das an einem thematisch gebundenen Diskurs des Bereichs psychischer Gesundheit und Krankheit und dabei anhand fachlicher als auch fachexterner Texte erprobt wird. Durch die komparative Analyse einerseits von sprachlichen Mitteln und Praktiken mit definitorischer Funktion, die sich punktuell in einzelnen fachlichen und fachexternen Textpassagen zeigen, und andererseits von sprachlichen Stimuli definitorischer Praktiken im weiteren transtextuellen Textgeflecht wird eine mehrdimensionale Typologie diskursiver Praxis des Definierens erarbeitet (siehe Kap. 7.2), die auf andere thematische Diskurse übertragen werden kann.

- Durch Anschluss-Analysen zu Definierenspraktiken in Diskursen mit einer anderen thematischen Ausrichtung (z.B. Fach- und Vermittlungsdiskurse der Physik, Chemie oder Kunst und Musik) könnte schließlich pro Diskurs herausgearbeitet werden, welche Praktiken spezifisch für das Definieren des jeweiligen Bereichs, hier von Phänomenen aus dem Bereich zwischen psychischer Gesundheit und Krankheit, sind und welche Praktiken themenunabhängig definierende Funktionen erfüllen.

Die bisherige Heuristik sei an folgendem Schaubild zusammengefasst (siehe Abbildung 4). Die ausgefüllten Rechtecke stellen die bisher in dieser Arbeit ausgeführten Schritte der Kapitel 1-4 dar. Die nur umrandeten Rechtecke geben einen Ausblick auf die Analyseschritte der folgenden Kapitel, in denen die Korpora der einzelnen Diskursstränge und die Erscheinungsformen der Texte des Burnout-Diskurses 
beschrieben werden (Kap. 5), um im Anschluss daran das diskurslinguistische Analyseverfahren zu erläutern (Kap. 6.2.1) und jeweils auf den fachinternen und fachexternen Diskursstrang anzuwenden (Kap. 6.2.2-6.2.4):

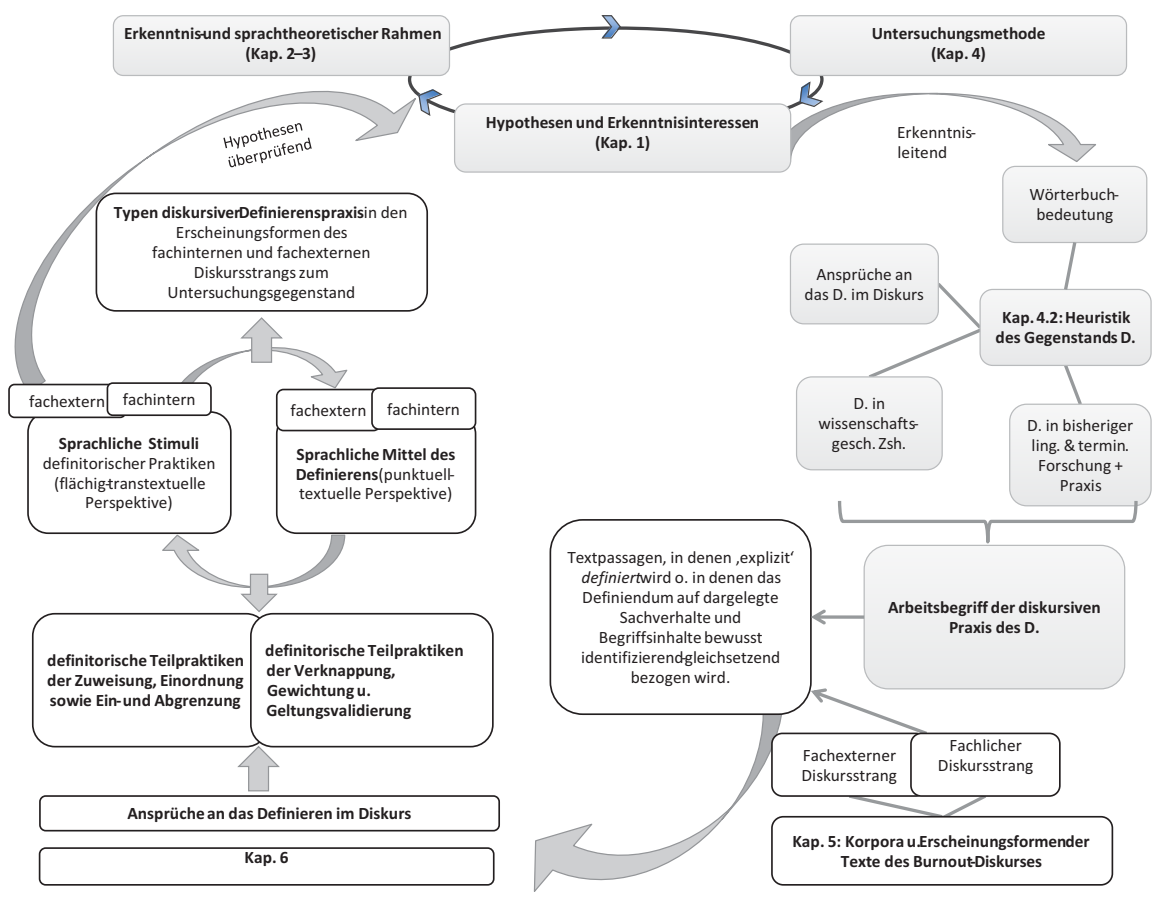

Abb. 4: Heuristik einer diskursiven Praxis des Definierens und Ausblick auf die weitere Analyse in Kap. 5 und 6 dieser Arbeit; (die Abkürzung „D.“ steht für „Definieren“). 